\title{
WestVirginiaUniversity
}

THE RESEARCH REPOSITORY @ WVU

Graduate Theses, Dissertations, and Problem Reports

2012

\section{A UK Market Town Maintaining Identity Amidst Urbanizing Sprawl: A Learning History}

Jennifer Rachelle Parsons

West Virginia University

Follow this and additional works at: https://researchrepository.wvu.edu/etd

\section{Recommended Citation}

Parsons, Jennifer Rachelle, "A UK Market Town Maintaining Identity Amidst Urbanizing Sprawl: A Learning History" (2012). Graduate Theses, Dissertations, and Problem Reports. 518.

https://researchrepository.wvu.edu/etd/518

This Dissertation is protected by copyright and/or related rights. It has been brought to you by the The Research Repository @ WVU with permission from the rights-holder(s). You are free to use this Dissertation in any way that is permitted by the copyright and related rights legislation that applies to your use. For other uses you must obtain permission from the rights-holder(s) directly, unless additional rights are indicated by a Creative Commons license in the record and/ or on the work itself. This Dissertation has been accepted for inclusion in WVU Graduate Theses, Dissertations, and Problem Reports collection by an authorized administrator of The Research Repository @ WVU.

For more information, please contact researchrepository@mail.wvu.edu. 


\title{
A UK Market Town Maintaining Identity Amidst Urbanizing Sprawl: A Learning History
}

\author{
Jennifer Rachelle Parsons
}

Dissertation submitted to the

Davis College of Agriculture, Natural Resources and Design

at West Virginia University

in partial fulfillment of the requirements

for the degree of

Doctor of Philosophy

in

Human and Community Development

Barbara McFall, Ph.D., Chair

Kathryn Burton, Ph.D.

Michael Dougherty, Ph.D.

Ronald E. Dulaney, Jr., M. Arch.

Jennifer Selin, J.D.

Division of Design and Merchandising

Division of Resource Management

Morgantown, West Virginia

2012

Keywords: Learning History, English Market Town, Revitalization, Growth, Downtown

Copyright 2012 Jennifer R. Parsons 


\author{
ABSTRACT \\ A UK Market Town Maintaining Identity Amidst \\ Urbanizing Sprawl: A Learning History \\ Jennifer R. Parsons
}

English market towns greatly reflect British culture through unique traditions, architecture, and other characteristics. Market towns are often secluded from the outside world, located in rural areas of England with less significant roadways and very few railways leading into the towns. Despite the charming façade of market towns, challenges in contemporary society and the expansion of cities throughout the $20^{\text {th }}$ century have swamped these rural communities, threatening their historical character and initiating problems such as forced growth, increased housing, and urbanization.

This study seeks to better understand the experiences and perspectives of the individuals and organizations dealing with change in an English market town. Employing the Learning History methodology developed at MIT, community involvement in planning and change efforts in Buckingham, England, from 19672011 are examined through the narrative of key stakeholders, with specific emphasis on issues of growth, urban sprawl, and the decline of the historic downtown area. The resulting narrative has the potential to inform new stakeholders participating in current and future market town processes. Ideally, this transfer of knowledge will serve locally to smooth transitions and sustain a productive change process in Buckingham. 
Findings from the research study are presented in a SWOT Analysis (Strengths, Weaknesses, Opportunities, and Threats). Strengths and opportunities from the Buckingham community include a deep sense of community, dedicated Town Council, Proactive Traders’ Association, a Localism bill, and a strong town and gown relationship. Weaknesses and threats from the Buckingham community include a repeat of the same problems, conflicts relating to shared governance, distrust of local government systems, uncontrollable development, and mandates for growth.

The goal of this research is to provide credible and useful information about Buckingham's experience with change and planning processes over time in a format that might inform this and similar communities seeking to retain or reenvision their identities in the future. Use of the Learning History methodology contributes to the existing body of knowledge regarding planning processes, strategies for community development and revitalization efforts, and the experiences of the individuals involved with these planning procedures. 


\section{DEDICATION}

I dedicate my dissertation to my loving parents, Rich and Terry, who have supported me in every step of the way throughout my education, and to my understanding and patient fiancé, Nathan. You all have been an incredible inspiration and an endless source of support throughout this process. 


\section{ACKNOWLEDGEMENTS}

This project could not have been completed without the help of others. I owe many thanks and gratitude to those individuals that have shown continued support and guidance throughout the completion of this document.

I would like to acknowledge my committee chair, Dr. Barbara McFall, for her encouragement and guidance during this research process. Throughout my graduate studies, Dr. McFall has been an incredible mentor and I would like to send my sincere appreciation. I would also like to thank my graduate committee members: Dr. Kathryn Burton, Dr. Michael Dougherty, Ron Dulaney, and Jenny Selin. Each of you has provided me with endless support, direction, and inspiration during this research process.

To my friends and colleagues, thank you for support and for being an escape when needed.

Lastly, I would like to extend a huge thank you to the residents, leaders, and members of the Buckingham community for welcoming me into your idyllic market town. Your compassion and determination to protect and preserve the Buckingham community is overwhelming and I wish you all the best in the future. 


\section{TABLE OF CONTENTS}

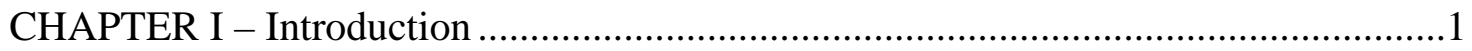

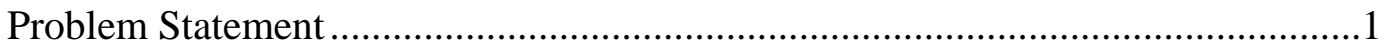

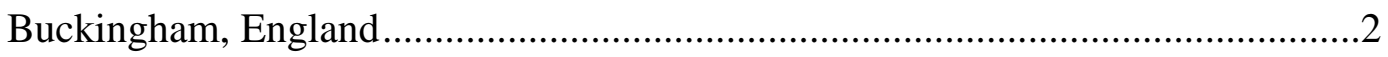

The Growth Challenge .....................................................................6

Reasons to Promote Growth. .............................................................10

Targeting a Viable and Sustainable Balance. ........................................10

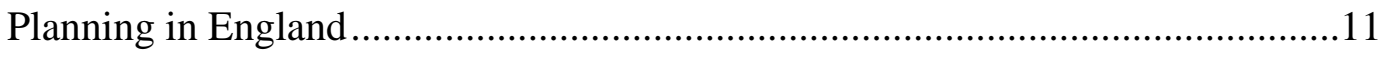

The South East Plan .............................................................................11

The Buckingham Plan........................................................................11

Purpose of the Study ................................................................................... 12

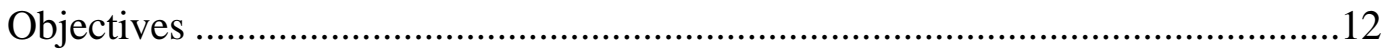

Delimitations and Limitations...............................................................13

Delimitations................................................................................13

Limitations. ............................................................................13

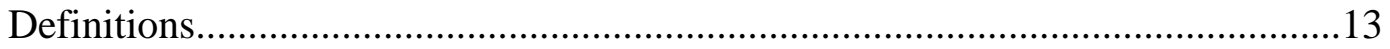

CHAPTER II - Review of Literature .................................................................16

Urban and Regional Planning .................................................................. 17

Urban and Regional Planning Initiatives in England.............................18

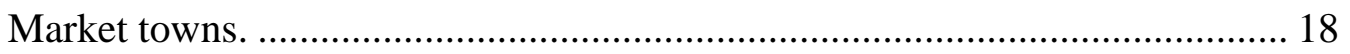

Garden City Movement....................................................................... 20 
Sustainable Principles, New Urbanism, and Revitalization............................ 22

Urban and Regional Planning in England.....................................................24

Regional Planning: The South East Plan. ..............................................25

Local Government Planning .....................................................................28

Local Planning in Buckingham.................................................................29

The Buckingham Plan..................................................................29

Buckingham Vision and Design Statement. .........................................32

Development of Buckingham, England ......................................................34

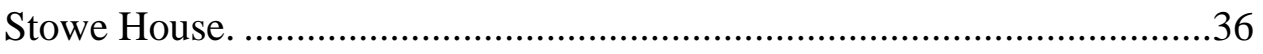

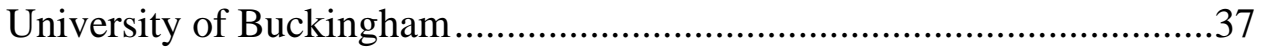

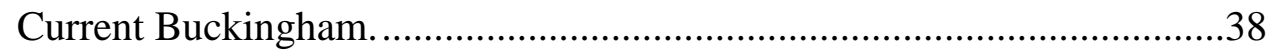

Community Identity and Sense of Place ....................................................40

Branding in Buckingham. .............................................................44

The English Market Town: Traditional and Modern..............................42

Market Towns in Contemporary England...................................................... 43

Influences Shaping Contemporary Market Towns. ...................................... 44

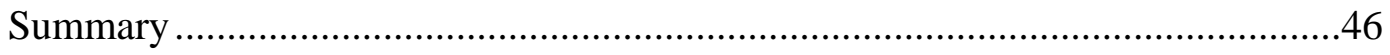

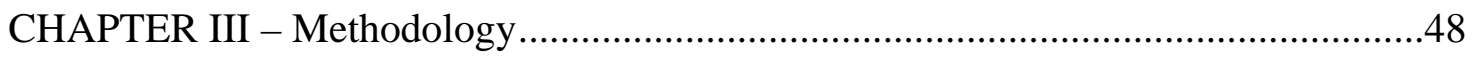

Purpose of the Study …............................................................................48

Specific Objectives ..........................................................................48

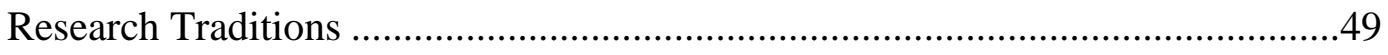


Methodology: The Learning History

A New Format of Story-Telling.........................................................54

Potential Benefits of a Learning History. ...............................................57

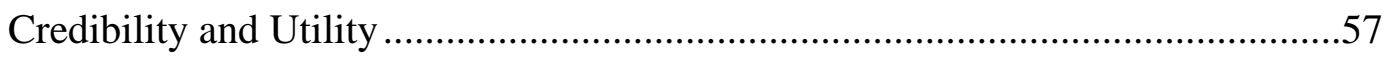

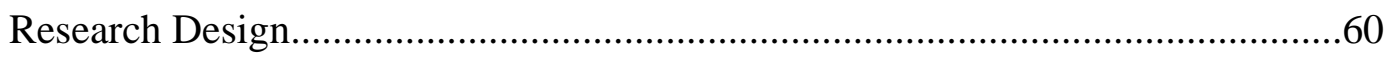

Selecting a Potential Project ...........................................................60

Designing the method .................................................................61

Selecting the interviewees...........................................................64

IRB Protocol ...............................................................................64

Executing the Research Design ...............................................................66

Data Collection .........................................................................66

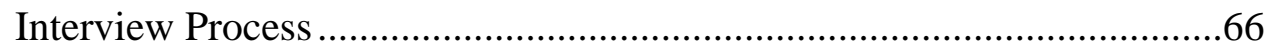

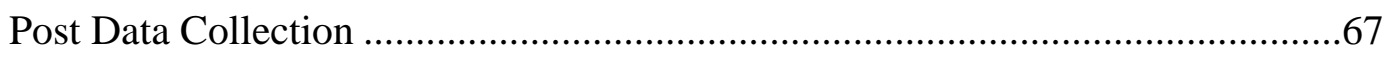

Transcribing the data...............................................................67

Credibility of the data .................................................................68

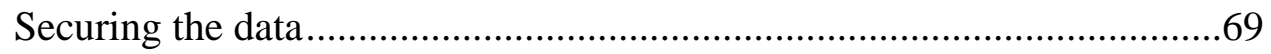

Learning History narrative .............................................................69

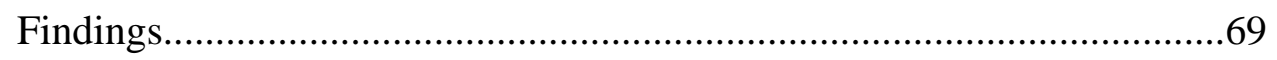

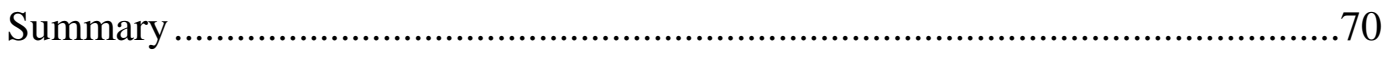

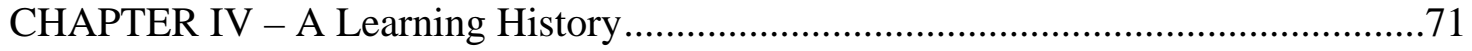


Overview of the Participants

Searching for the Identity of a Market Town......................................................77

Trading in Buckingham ..................................................................................91

Changes in Buckingham: 1967-2011 ...........................................................97

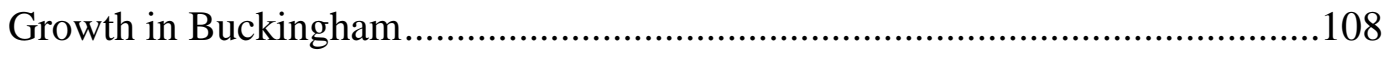

Local Government, District Council, and County Council...............................118

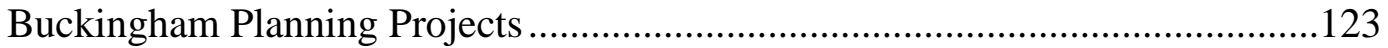

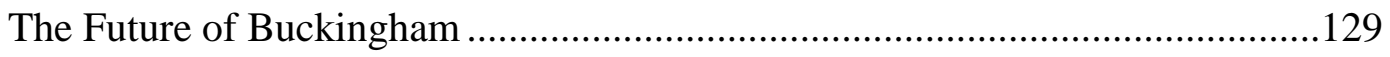

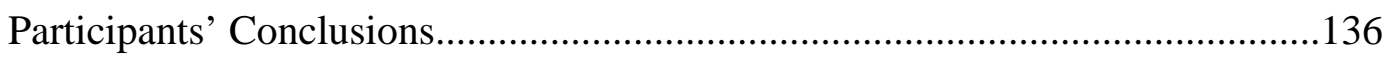

CHAPTER V - Discussion .........................................................................139

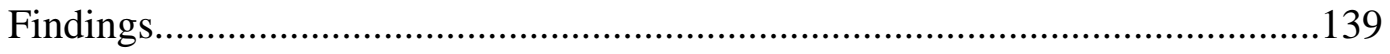

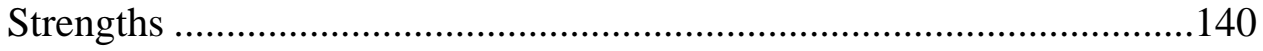

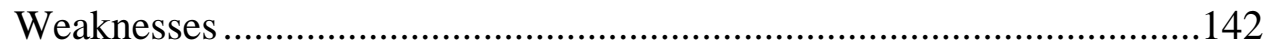

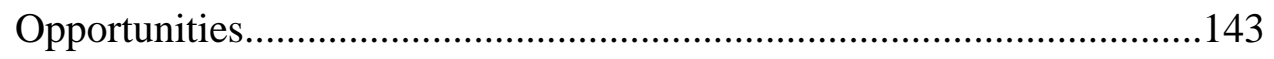

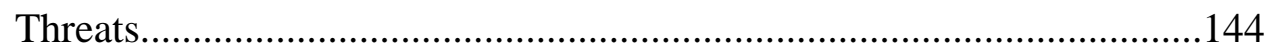

Assessing the Methodology .............................................................145

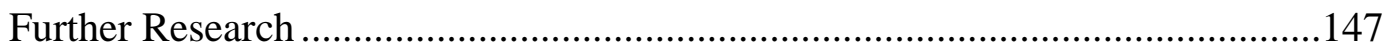

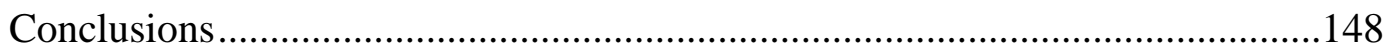

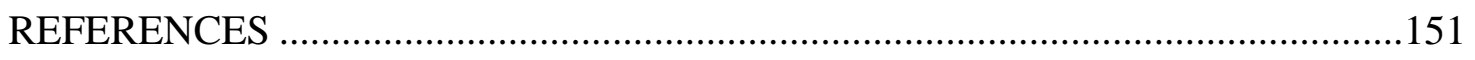

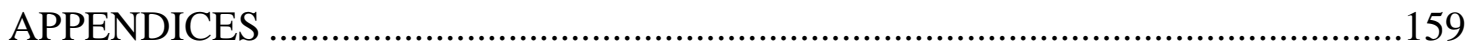

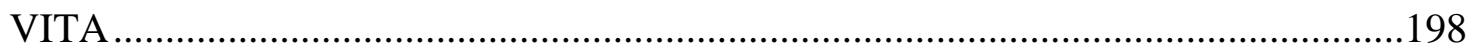




\section{LIST OF FIGURES}

Figure 1: England, Buckinghamshire County, and Buckingham ...................................

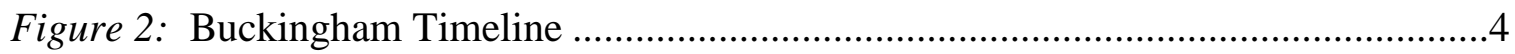

Figure 3: Citizens Engaging in Buckingham's Weekly Market .....................................5

Figure 4: The Historic City Center of Buckingham ...................................................

Figure 5: New Build Completions as a Proportion of England Total by Region,

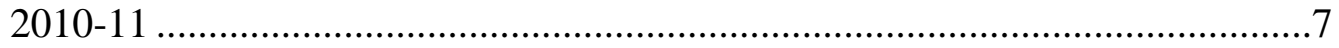

Figure 6: Index of Population Change in England, 2001-2010 ..................................8

Figure 7: Net Housing per 1000 Dwellings for each Local Authority, 2011...................9

Figure 8: The Exploration of Planning in England, regarding Buckingham ..................16

Figure 9: Principles of the Garden City Movement .................................................21

Figure 10: Map of the South East Region of England ..............................................25

Figure 11: Ten Areas Targeted for Growth and Regeneration in the South East ...........27

Figure 12: Buckingham Then and Now, 1886-1999................................................31

Figure 13: Historic Georgian Architecture in Buckingham’s Town Center. ...................34

Figure 14: Buckingham’s River Walk ..................................................................35

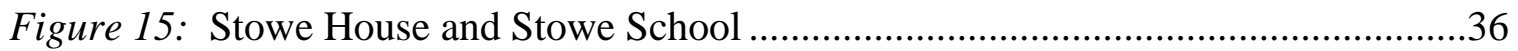

Figure 16: University of Buckingham Campus.......................................................37

Figure 17: Population Increase in Buckingham ......................................................39

Figure 18: Buckingham’s Branding Logo...........................................................42

Figure 19: Buckingham’s Vintage Market.............................................................45 


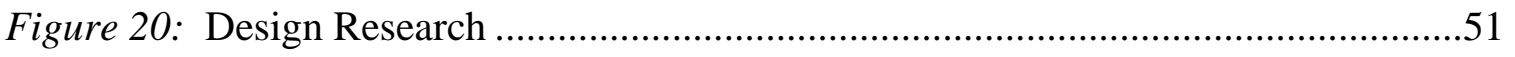

Figure 21: Example of a Learning History Format .......................................................56 


\section{LIST OF TABLES}

Table 1: Comparing Scientific, Humanities, and Design Research................................50

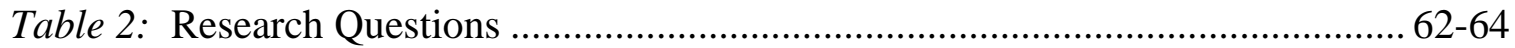

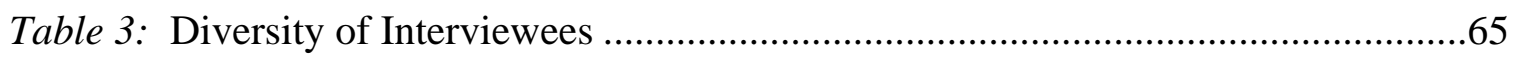

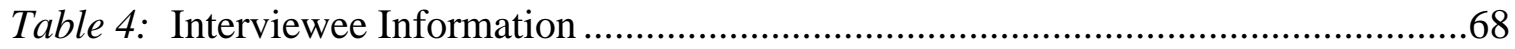

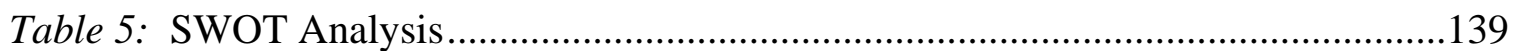


We can make a much bigger and better town, providing that people aren't just sleeping here and working and shopping somewhere else. People are actually a part of the town. That's what we've got to do. We've got to make people think, "I am a Buckingham person."

-Buckingham Resident 


\section{CHAPTER I}

\section{Introduction}

"Market towns are viewed as very British in their character and traditions and offer a close fit with the culture of the nation and its way of life” (New Market Towns, 2011, p. 1). English market towns are often secluded from the outside world, located in rural areas of England with less significant roadways and very few railways leading into the town. Most market towns still hold a regular market once a week where fresh produce, flowers, gifts, and vintage items can be found. However, despite the charming façade of market towns, challenges in contemporary society and the expansion of cities throughout the $20^{\text {th }}$ century have swamped these rural communities, threatening their historical character and initiating problems such as forced growth, increased housing, and urbanization.

\section{Problem Statement}

How can a town maintain its identity amongst urbanizing sprawl that occurs around it? The Learning History presented in this study explores the lived experience of change in the small market town of Buckingham, England, with specific emphasis on issues of growth, urban sprawl, and the decline of the historic downtown area. Using the Learning History methodology developed at MIT (Kleiner \& Roth, 1997), community involvement in planning and change efforts from 1967-2011 will be examined through the narrative of key stakeholders. Their stories will be supplemented by researcher observations and analysis. The goal of this research is to provide credible and useful information about Buckingham's experience with change and the design process over 
time in a format that might inform this and other similar communities seeking to retain or re-envision their identities in the future.

\section{Buckingham, England}

Buckingham, England, is a quaint English market town nestled along the river Great Ouse, just 70 miles outside of greater London. Located in the county of Buckinghamshire, it is the largest town in the northern section of the county with a population of approximately 12,000 residents (Buckingham Town Council, 2008). Buckingham functions as a hub for the surrounding communities and villages, as thousands of local residents travel to the town for their daily shopping and use of public transportation and facilities. The Buckingham Traders’ Association, a group of shop owners, actively supports Buckingham's historic town center and the vibrancy of the town. Buckingham holds a regular market twice a week, on Tuesdays and Saturdays, where local produce, crafts, flowers, and vintage items are for sale. The University of Buckingham, established in 1971, is located in the heart of the town and is the only private university in England (Clarke, 1984). Milton Keynes, approximately ten miles from Buckingham, is a larger modern city that has been impacting Buckingham with increased growth since it was established in the late 1960s.

Residents of Buckingham are coming together with an understanding that they must plan wisely for the growth that is occurring in the town. As they understand the implication of forced growth, they are empowered to make a difference in their community and improve the quality of life for all. Stakeholders, involved citizens, and lifelong residents are trying to hold on to what is left of the historic city center. 


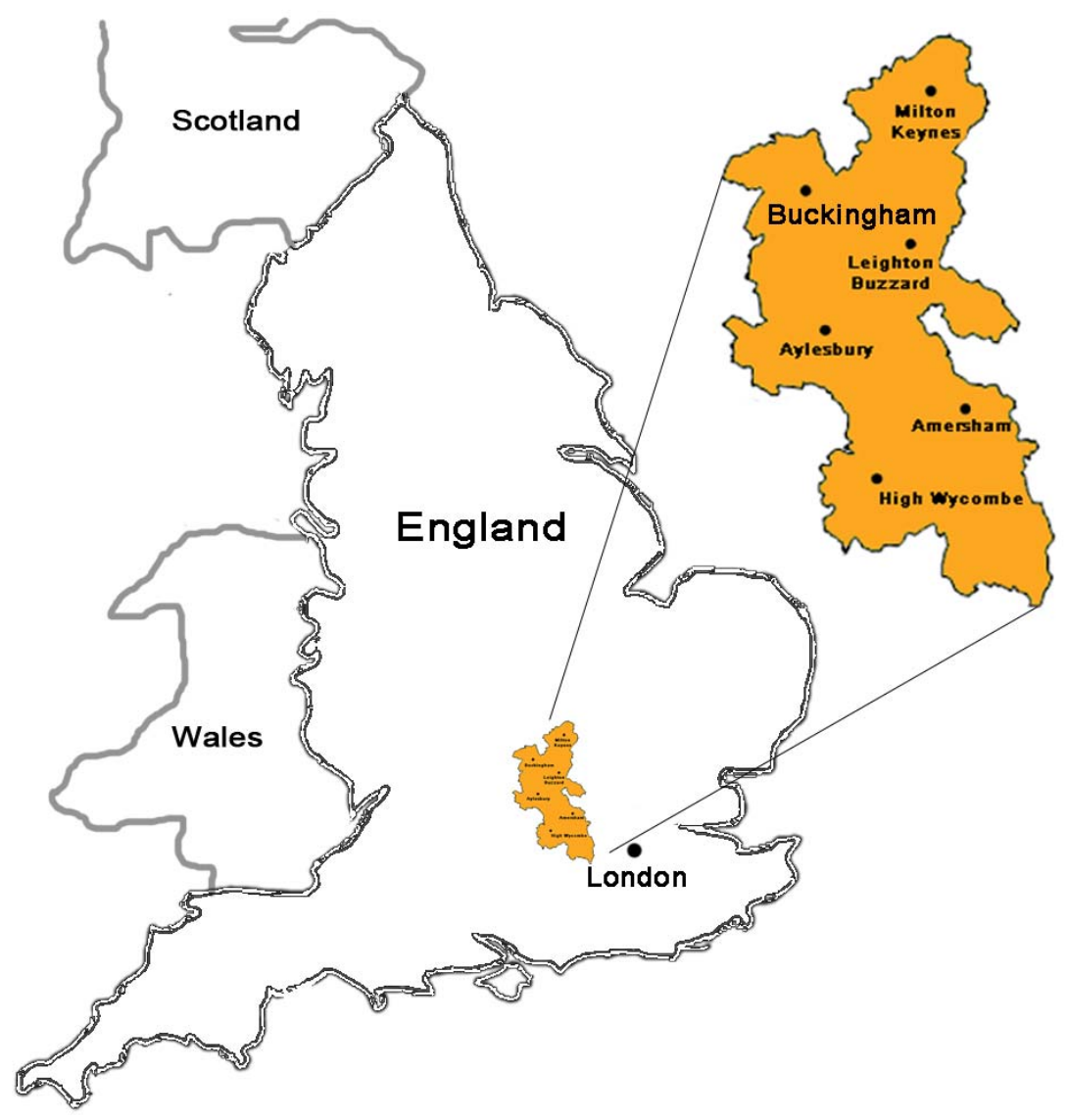

Figure 1. England, Buckinghamshire County, and Buckingham.

A shopkeeper anecdotally communicated problems and opportunities in Buckingham when she described how a particular resident had lived in Buckingham for almost seven years and had never visited Buckingham’s historical town center. When the resident finally ventured downtown, she commented on how lovely and unique Buckingham was. The issue of not supporting local businesses and downtown activities is becoming a major problem for small towns that are experiencing growth. Downtowns are decaying and storefronts are becoming vacant as convenience becomes a priority; residents are shopping in larger city centers where various stores and shops are available. 


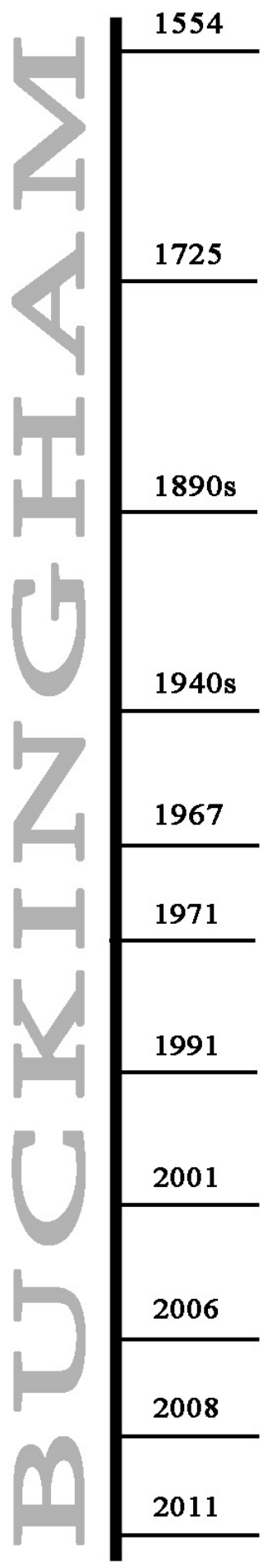

Buckingham was granted permission from the Royal Charter to hold a regular market.

Great fire of Buckingham nearly destroys two thirds of the town. Buckingham is rebuilt with buildings reflecting the Georgian style architecture.

Buckingham experiences changes and a shift from agriculture to manufacturing during the industrial revolution.

Buckingham begins to experience population increases as people leave London for the countryside after World War II (population 4,000).

Milton Keynes, a New Town, was constructed 15 miles from Buckingham.

University of Buckingham was established in Buckingham.

Big Box Era hits Buckingham as Tesco is established outside of town.

Buckingham Vision and Design Statement, produced by the Buckingham Design Group, generated guidelines for new construction in Buckingham.

South East Plan was established by Parliament to increase housing in areas around London.

The Buckingham Plan, created by the Buckingham Town Council, was created as a strategic plan for Buckingham's future.

Buckingham (population of 12,000 residents) continues to adjust to changing conditions and events occurring both inside and outside the community.

Figure 2. Buckingham Timeline (Jennifer Parsons, 2012). 


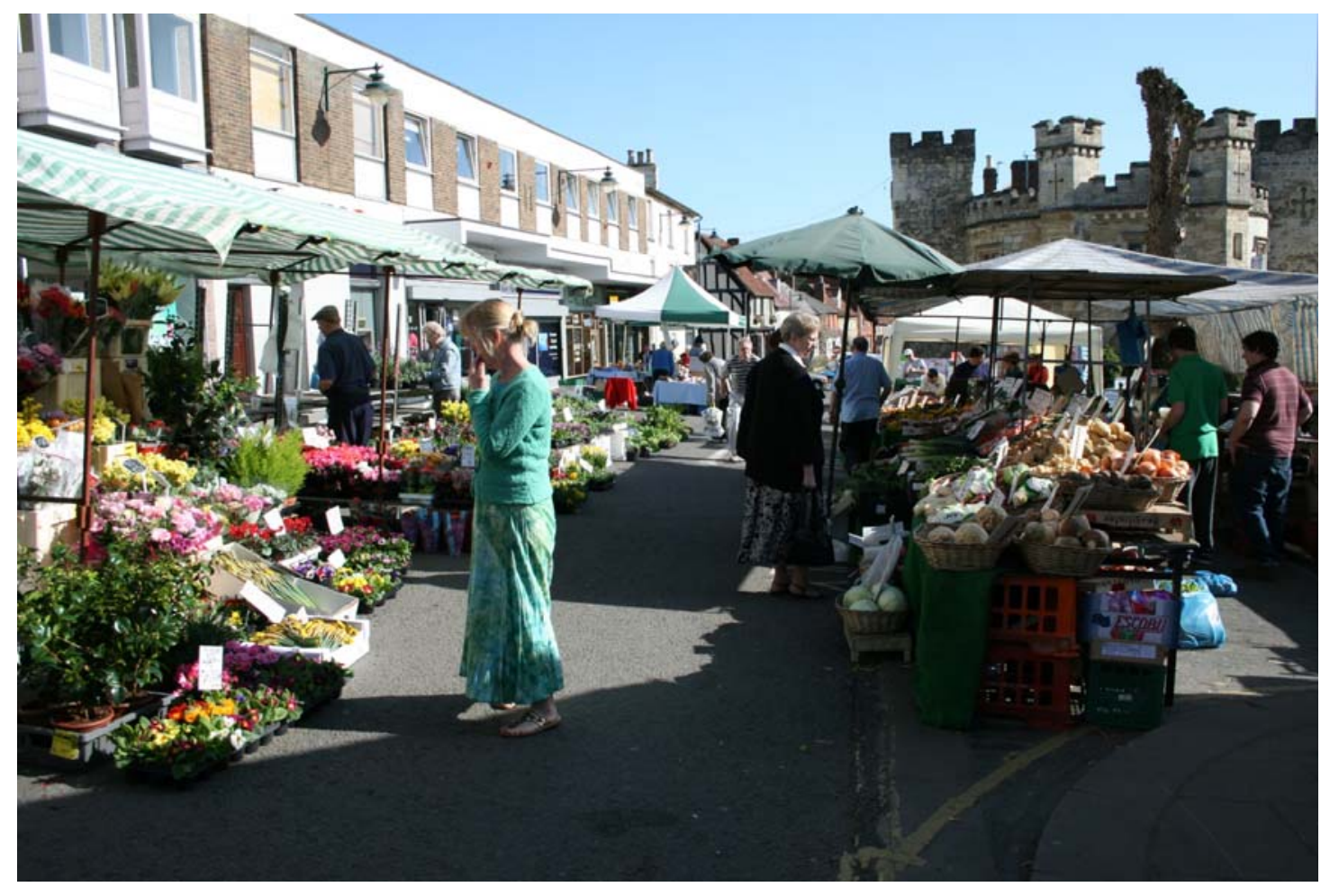

Figure 3. Citizens engaging in Buckingham's weekly market.

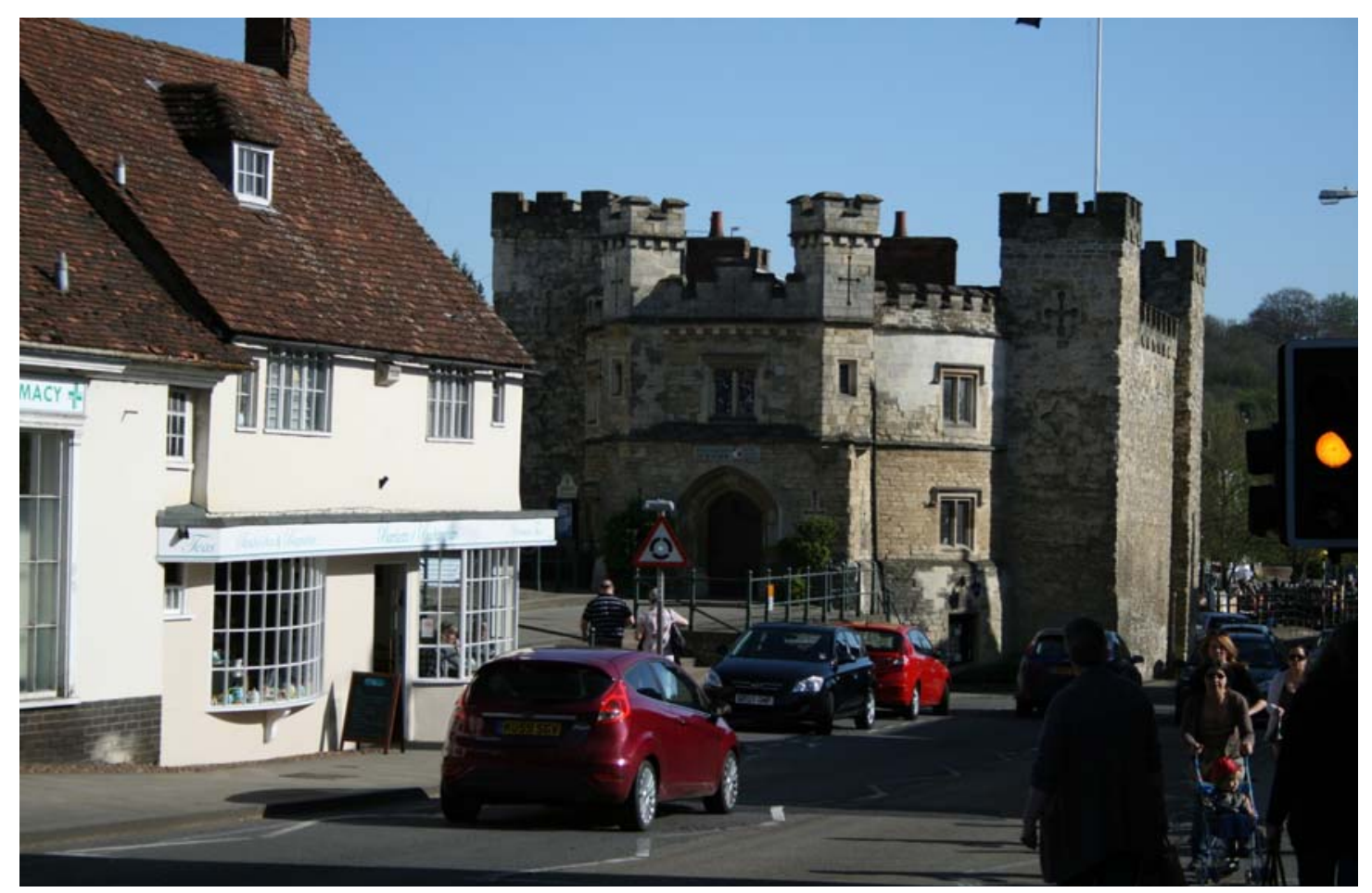

Figure 4. The historic city center of Buckingham. 
The Growth Challenge. Continuous growth and development is occurring throughout the world (Sustainable Development Commission, 2011). Thousands of new homes, business, and retail spaces are being constructed throughout our communities each day. In England, it is estimated that 60 percent of the total new retail space constructed in the next ten years will be outside of town centers (Dixon, 2009, p. S47). In order to promote growth in our communities, we must understand how to manage it (Centre for Cities, 2011b). If growth is not carefully considered both critically and creatively, it will promote unsustainable practices such as longer commutes for residents, unfriendly pedestrian streets, less walkability, urban sprawl, strip malls, and low density housing (Sustainable Development Commission, 2011). Excessive and rapid unmanaged growth has major impacts on infrastructure, including transportation, education, leisure, and employment, which must be managed and, at times, mediated. All of these impacts are the result of unmanaged growth patterns in a community.

In particular, England has been experiencing growth as the population of the country continues to rise. More recently, the government has been focusing policies toward the need to increase the level of homebuilding, especially in the South East region of the country (Dixon, 2009). Dixon states, "Demographic change is likely to play an important role in housing markets. The UK population is projected to increase by 4.4 million to reach approximately 71 million by 2016 . There is a projected need for three million new homes by 2020” (2009, p. S51). The Communities and Local Government housing report illustrates that approximately 117,700 new homes were constructed in England in 2010-11 (Communities and Local Government, 2011). The South East region of England has the largest proportion of new homes (18\%), with a total of 20,980 homes 
constructed in 2011 (Communities and Local Government, 2011, p. 8). Buckingham is located in the South East region of England.

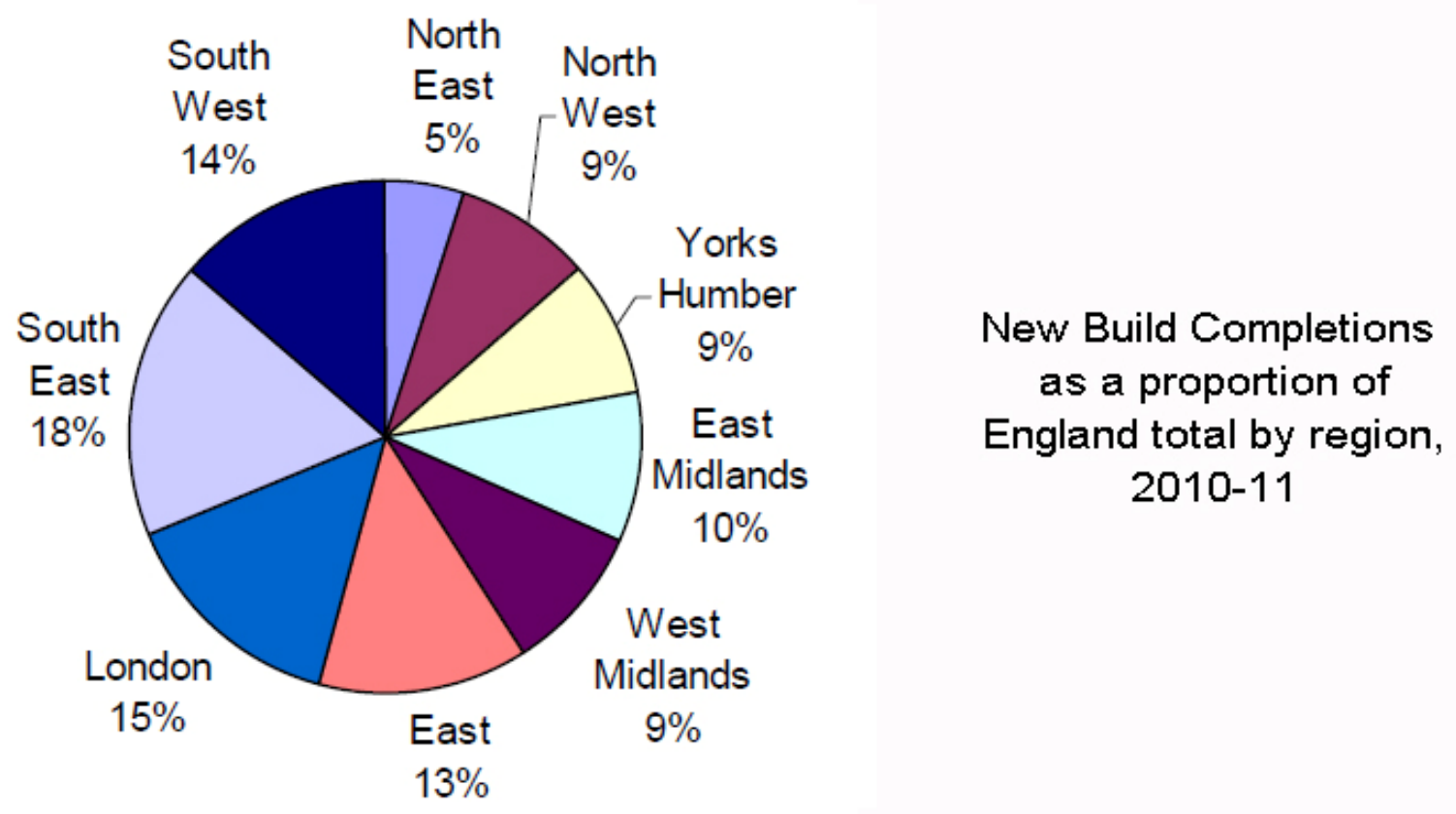

Figure 5. New Build Completions as a Proportion of England Total by Region, 2010-11. Adapted from “Net supply of housing: 2010 -11,” by Communities and Local Government, 2011, p. 8, England. Crown Copyright 2010.

Population changes have also indicated a migration shift as more individuals in England are moving to rural communities in different parts of the country (Department for Environment Food and Rural Affairs, 2011); (See figure 6). Between 2001 and 2010, the greatest population change has occurred in less sparse villages and dispersed areas; the population has grown 6.7 percent in this area (Department for Environment Food and Rural Affairs, 2011). In contrast, the sparse urban areas had the least amount of population change with only 3.3 percent of migration (Department for Environment Food and Rural Affairs, 2011). 


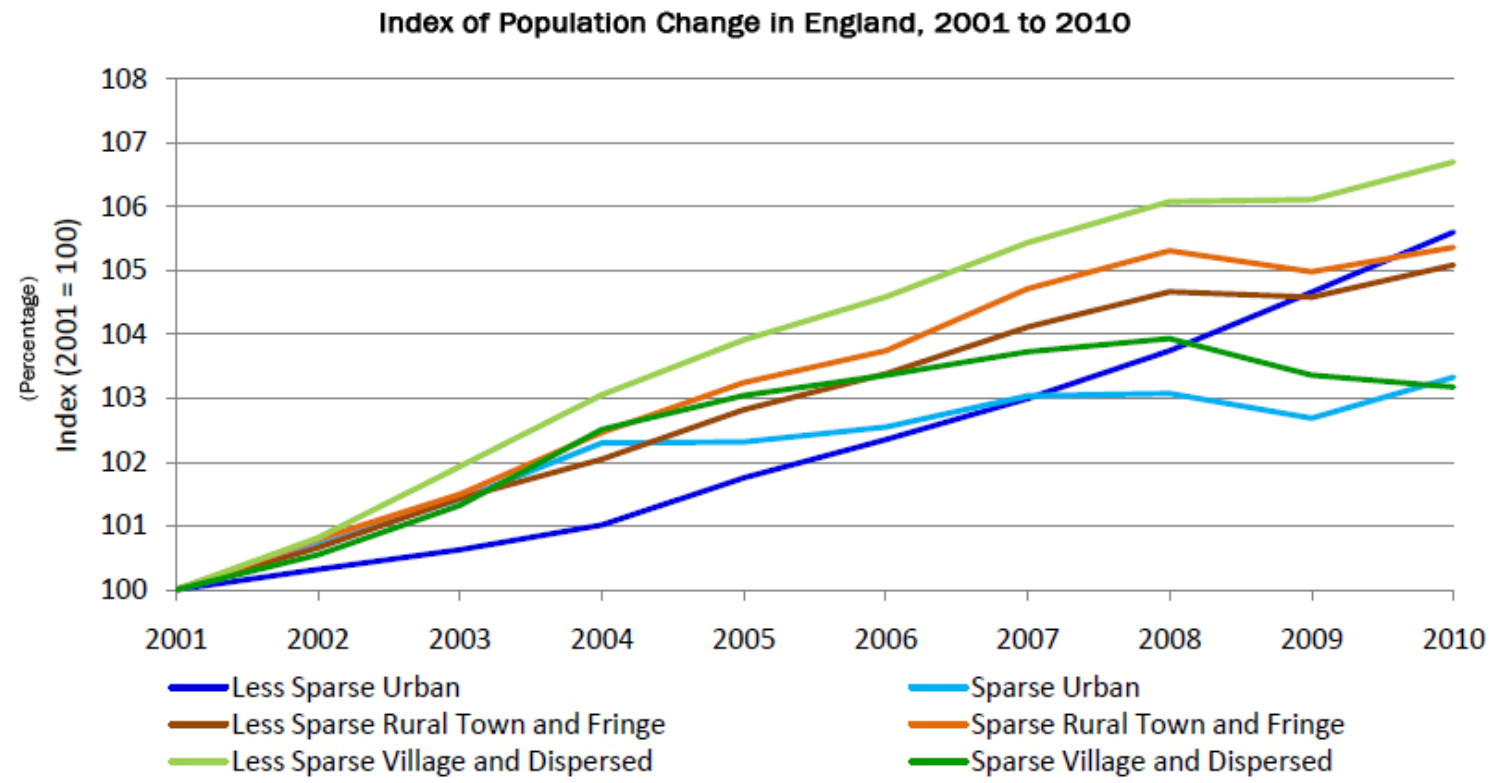

Figure 6. Index of Population Change in England, 2001-2010. Adapted from "Mid-2010 population estimates for lower layer super output areas," by Department for Environment Food and Rural Affairs, 2011, p. 3. Crown Copyright 2010.

A pattern of new home construction is occurring in various regions throughout England (Department for Environment Food and Rural Affairs, 2011). Figure 7 illustrates the 326 local authority districts in England and the number of new dwellings constructed in 2011 (Communities and Local Government, 2011). Buckingham is located in one of those districts with the highest growth and new housing construction. 


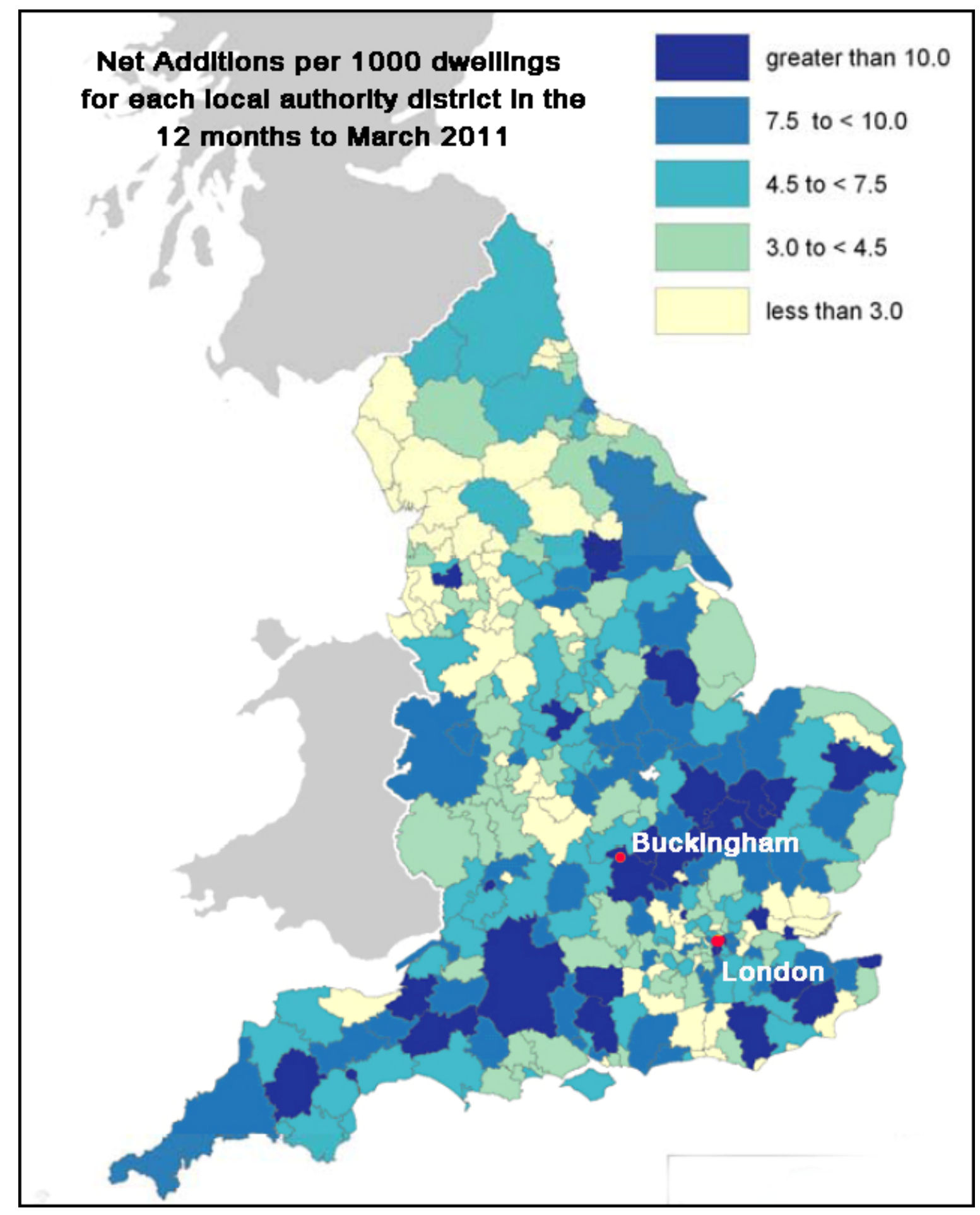

Figure 7. Net housing per 1,000 Dwellings for each Local Authority, 2011. Adapted from "Net supply of housing: 2010 -11," by Communities and Local Government, 2011, p. 10, England. Crown Copyright 2010. 
Reasons to Promote Growth. Encouraging growth in communities promotes several positive benefits (Sustainable Development Commission, 2011). Managed urban growth increases employment rates in communities and promotes healthy, viable downtown city centers (Centre for Cities, 2011a). Historically, growth has been actively promoted in English suburban towns to decrease population pressures on London (Walker, 1994). This initiative to relieve overcrowding in London continues today. Urban growth also promotes greater funding opportunities for various projects in towns and communities, including new facilities, infrastructure, and additional means of transportation (Sustainable Development Commission, 2011).

Targeting a Viable and Sustainable Balance. A sustainable balance of environmental, economic, and social development must be reached when managing growth in each community (Sustainable Development Commission, 2011). Quaint and idyllic towns, such as Buckingham, are losing their identities as they are being swallowed up by the unmanaged and forced growth patterns that are occurring (New Market Towns, 2011). “A single centre defined by the walkable distance is unlikely to accommodate the population needed to support a community” (New Market Towns, 2011, p. 5).

Uncontrollable growth has shifted the urban center, creating major problems for historic downtowns. Some towns are creating new city centers to accommodate this additional growth and to promote growth management. Establishing a strong local center will help to achieve a reasonable target population in order to promote a viable and sustainable community. 


\section{Planning in England}

Planning procedures, policies, and projects in England have increased immensely throughout the last several decades due to an escalating population and the need for additional housing to support the residents (Dixon, 2009). The Garden City movement, a popular movement in England that began at the turn of the $20^{\text {th }}$ century (Howard, 1902), was one of the main factors that has led to urban sprawl in England. Individuals who are knowledgeable in planning, development studies, economics, land use policies, and other related fields are joining with Parliament to create strategies to support the healthy growth of citizens, housing, communities, and the English economy. The South East Plan directly concerns Buckingham, as it has been experiencing the effects of increased population growth and forced housing.

The South East Plan. The South East Plan concentrates on the regional level of planning in England. This plan provides further context for this study, located in Buckingham. The South East Plan is devoted to long term spatial planning for the South East region of England from 2006-2026 (The South East England Development Agency, 2011). Ten sub-regions have been identified for growth and regeneration in the South East region. Two cities, Milton Keynes, and Aylesbury Vale, have been identified; both are located in Buckinghamshire County (The South East England Development Agency, 2011). The market town of Buckingham is located between the two cities, placing it in an area of direct impact for forced growth and expansion.

The Buckingham Plan. The community of Buckingham understands that it needs to plan for the future. Members of the community have already initiated the planning process. The South East Plan (The South East England Development Agency, 
2011), created by Parliament, the highest government authority in England, has dictated that nearly 5,000 households will be built in the Buckingham area in the near future. This forced growth will have major implications for the community and its residents, historic downtown, and infrastructure, just to state a few. Studying the changes that are occurring in Buckingham through the perspectives of the individuals and involved citizens who are experiencing the challenges may also benefit other communities facing similar circumstances.

\section{Purpose of the Study}

The purpose of this study is to better understand the experiences and perspectives of the individuals and organizations dealing with change in an English market town. Employing the Learning History methodology developed at MIT (G. Roth \& Kleiner, 1995), this research will examine reported accounts of stakeholder experiences with change in Buckingham over the past 44 years. The resulting narrative has the potential to inform new stakeholders participating in current and future change processes. Ideally, this transfer of knowledge will serve locally to smooth transitions and sustain a productive change process in Buckingham. More broadly, use of the Learning History methodology will contribute to the existing body of knowledge regarding planning processes, strategies for community development and revitalization efforts, and the experiences of individuals involved with these planning procedures.

\section{Objectives}

The objectives of the study are reflected in the following research questions:

1. How are the citizens of Buckingham, England, experiencing change related to the current growth and future planning of the town? 
2. What can we learn from the planning procedures, growth issues, and projects that are occurring in Buckingham so that the information may be shared to assist other communities seeking to retain their identity amidst change?

\section{Delimitations and Limitations}

Delimitations. This research was delimited to a 44-year period in the market town of Buckingham, England (1967-2011), and a convenience sample of involved stakeholders. This particular time period was selected because of the designation of Milton Keynes; significant changes to Buckingham began after 1967. The convenience sample includes individuals who were asked to participate in the research study.

Limitations. The findings from this study are unique to its participants, location, and time. They may or may not be credible and useful in other situations. These findings will certainly inform design of future projects in Buckingham as they engage with the South East Plan. They may also have applications in similar small towns.

\section{Definitions}

Community Development. The combined effort of professionals, city officials, developers, involved citizens, and stakeholders to improve all aspects within a community (Bridger \& Luloff, 1999).

Dormitory town. Known as a bedroom community in America, a dormitory town refers to a town in which the residents travel to and from places of employment each day, leaving the community vacant during the daytime, then returning back home each night (Birch, 2009).

English market town. A town in England that holds a regular market at least once a week. Traditionally, the market served the needs of the community and was focused on 
the buying and selling of farm produce (Brown, 1986). Markets today offer a wide variety of produce, crafts, local goods, and vintage items.

New Urbanism. A movement created after the effects of urban sprawl began plaguing communities. New Urbanism encourages principles of walkability, sustainability, and connectivity in diverse mixed-use neighborhoods that promote a high quality of life for residents. Urban planning, architecture, urban design, and landscape architecture are all fields of interest within New Urbanism (Deitrick \& Ellis, 2004).

Place-based identity. The production of a destination identity of a place of various scales; usually critical to developing tourism (Dredge \& Jenkins, 2003). Placebased identity allows a town to develop its own unique identity through branding, small businesses, organizations, events, town activities, and distinct features in order to attract more residents and visitors to the area.

Revitalization. Wallace states that revitalization is defined as "a deliberate, organized, conscious effort by members of a society to construct a more satisfying culture” (1956, p. 265). Revitalization includes the act of research, planning, and development to successfully generate renewal in a declining downtown center or neighborhood. Characteristics of an area in need of revitalization include decaying physical conditions, limited number and quality of businesses, and poor perception of the area (Wallace, 1956).

Smart growth. A movement created to develop strategies to reduce urban sprawl. Ewing states smart growth encourages "practitioners and advocates to develop techniques and polices to manage growth and help regions avoid haphazard sprawl” (2002, p. 48). 
Sprawl. A population that is widely dispersed in low-density residential development (Ewing, Schmid, Killingsworth, Zlot, \& Raudenbush, 2008). There is a distinct separation of homes, businesses, and places of employment; an area of sprawl lacks a defined thriving center of activity, such as a downtown center (Ewing, et al., 2008, p. 48).

Learning History. A Learning History is a story about change told from the perspectives of the key individuals who had previously experienced, or are currently experiencing these changes (G. Roth \& Kleiner, 1995). The underlying theory used in the Learning History model represents a collaboration of existing fields such as system dynamics, action science, social psychology, group dynamics, and the creative process (G. L. Roth \& Senge, 1995). 


\section{CHAPTER II}

\section{Review of Literature}

This study was conceived within the disciplinary context of local planning and more specifically within England, in the southeast region of the country, in Buckingham, a market town. The review of literature is structured to explore the nested influences that have historically shaped the planning process in Buckingham, as well as those that inform current and future initiatives.

\section{Urban and Regional Planning}

\section{Planning in England}

Regional Planning in

South East England

Local Planning in

Buckingham

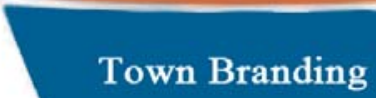

Market Town

Development

\section{Identity}

Figure 8. The Exploration of Planning in England, regarding Buckingham (Jennifer Parsons, 2012). 


\section{Urban and Regional Planning}

Urban and regional planning can historically be defined as the "design and regulation of the uses of space that focus on the physical form, economic functions, and social impacts of the urban environment and on the location of different activities within it” (Howard, 1898). It is a multidisciplinary field that includes architecture, landscape architecture, various forms of engineering, policy and law, social and behavioral sciences, and economics. It also includes multiple forms of design, from graphic to product and from space to service (Bacon, 1974). Urban and regional planning is on the rise in many industrialized countries, including England, as our culture has shifted from concentrating on the downtown to the new suburbia, which has led our society to its current state: overcrowded communities and decentralized cities (Kotkin, 2006).

Planning issues are both complex and dynamic, so systems thinking is a core requirement. Planners generally address systems within systems, in which "each system within a community directly affects others” (Flood, 2010). Because systems and departments within a municipality, such as economic development, parks and recreation, public finance, health and human services, and transportation are each dependent on one another (Kemp, 2007), these systems must all be considered when planning as one municipality working together and not as individual entities (Flood, 2010). For example, construction of a large new housing development might directly impact transportation, education, and infrastructure capacity (water, sewage, utilities, and other services, including fire and police). Planning employs a variety of forecasting strategies, planning processes, and design protocols to address both the built and the un-built environment. 
The combination of systems thinking, planning tools, and processes supports some capacity for stakeholder control of aspects crucial to effective community development.

Urban and Regional Planning Initiatives in England. Urban planning theories and procedures have evolved throughout time due to the changing conditions of society. Early evidence revealed that urban planning was heavily practiced in China, Egypt, and the Mediterranean world thousands of years ago (Fisherman, 2003). Select planning situations in England have had major impacts on Buckingham. It was not until the medieval period that urban planning theories were utilized for designing cities and villages in England (Chamberlin, 1985). Theories of urban planning appeared in the design of English market towns beginning around 900 A.D in regard to the structure of the town center, select buildings, and an established location for trade (Chamberlin, 1985). Additional urban planning theories, including the Garden City Movement, emerged in England around 1900 in response to the pressures of the Industrial Revolution. These initiatives changed how society interacted with the city and the suburbia (Fisherman, 2003). More recently, Buckingham has engaged in urban planning strategies dealing with the relationship between the University and the town. Additional theories related to sustainable planning, new urbanism, and redevelopment (or revitalization) strategies have also emerged as Buckingham continues to plan for its future. Information follows regarding these particular sets of concerns in relation to urban planning in Buckingham, England.

Market towns. Buckingham identifies itself as a "market town,” defined as “trading at a fixed time and place” (Chamberlin, 1985, p. 8). Market towns have been particularly fortunate during the recent recession. Studies show that high cost of living 
can be found in most market towns, as they are becoming highly desirable places to live. Over the years, many English residents have chosen to move from city centers to rural areas, prompting increased populations in market towns. These mostly high society newcomers have caused housing prices to soar in market towns (Press Association, 2011). Liam Bailey, head of a residential research department, states, "Properties in these prime market towns now attract a premium. They are attracting younger families, not just retirees. Buyers should expect to pay $10 \%$ to $20 \%$ more for a property in a market town than for a similar property in a larger town, suburb, or undesirable location” (Davies, 2008). In 2001, the average price of a home in a market town was $£ 114,718$, and in 2011 the average price reached $£ 233,416$, nearly doubling the housing market value of these desirable towns (Press Association, 2011). This desire on the part of individuals to move away from city centers in England has led to some degree of gentrification in market towns, which consequently has led to problems in the city centers (Davies, 2008).

Although Buckingham began to develop as a rudimentary trading center around 900 A.D. (Clarke, 1984), not until around 1500, when space was designated for the market in the city center, did market towns in England begin to benefit from urban planning strategies (Chamberlin, 1985). On January 17, 1554, the English Monarchy awarded Royal Charter to Buckingham, granting permission to hold a market (Close, 2009, p. 4). The Charter was important because not every town had the authority to hold a market. The English Monarchy had created a system to control which towns could establish a market. A town could not establish a new market if it was within a certain traveling distance of an existing market (Chamberlin, 1985). In medieval times this was 
generally interpreted as a protected radius of approximately six miles, which allowed a round trip to market and home again in one day.

As the markets have evolved, the physical structures of the towns and town centers have also adapted to these changes. Towns have had to expand to accommodate new housing, businesses, and recreational needs. Between 1750 and 1914, most town centers were rebuilt to adjust to these changes (Brown, 1986). Larger and wider roads were constructed, allowing inns to prosper from the additional coaching traffic and visitors (Chalklin, 2001). Trains also had an impact on the towns, causing railways and stations to be built close to the city centers.

Historically, the town hall anchored the market town, providing a meeting room and shelter for market vendors. It would later evolve into a town center, including a council chamber, office for the town clerk, and courtrooms as the focal point of the town center (Brown, 1986). However, police stations, public authorities, banks, commercial buildings, and libraries diluted that singular focus as they found their way to the town centers (Brown, 1986, p. 123).

Garden City Movement. Initiated by Ebenezer Howard, the Garden City Movement was created to control the population of cities and assist with the overcrowding of London (Fisherman, 2003). This movement changed the way that English society viewed urban planning. Each Garden City would be built in the countryside to accommodate 30,000 inhabitants. The land would remain the property of the community with a greenbelt surrounding the city limits to discourage sprawl, while allowing for valuable farming land (Howard, 1902). Citizens would have the choice of how they wished to work and live. The intent was to create bedroom communities in the 
countryside around London from which residents could easily commute (by rail or auto) to work in the city each day (Walker, 1994).

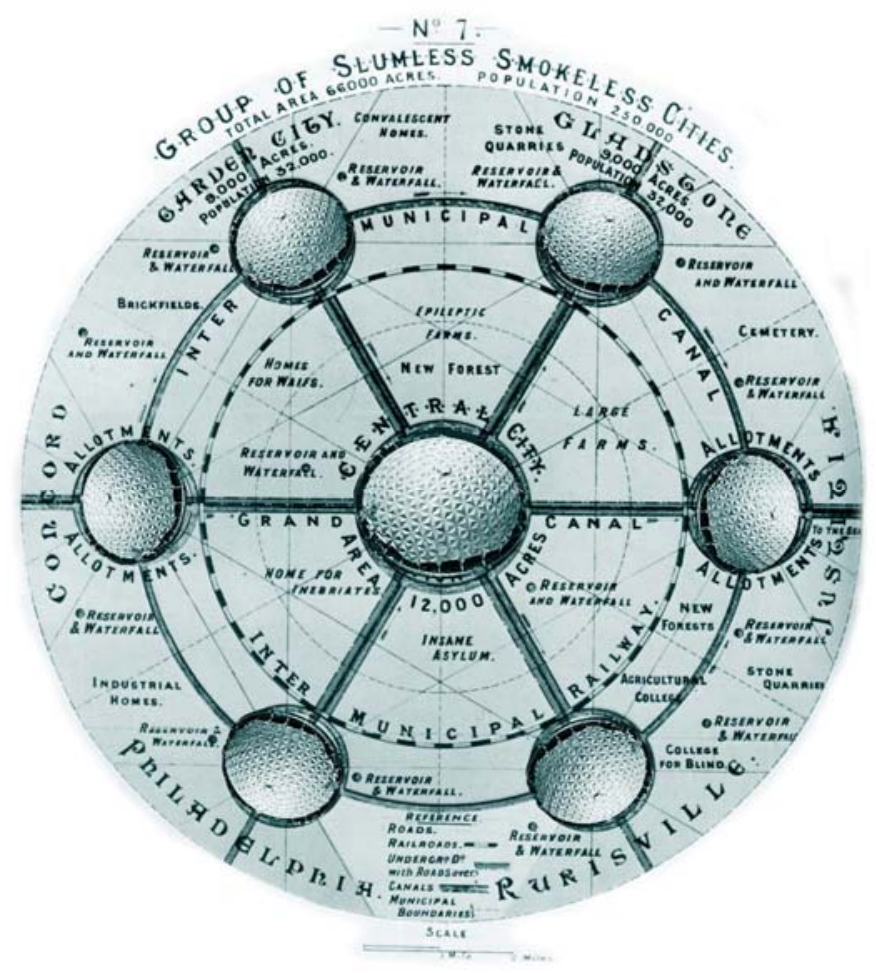

Figure 9. Principles of the Garden City Movement. Originally published in 1902 in “Garden Cities of To-morrow,” by E. Howard, 1902, London: S. Sonnenschein \& Co., Ltd. Copyright 1902.

Significant changes in Buckingham began with the creation of Milton Keynes. Milton Keynes is a New Town designated by Melvin Webber in 1967 (Walker, 1994). Milton Keynes is located approximately 15 miles from Buckingham and it is the primary source of growth in the area. This New Town was completely structured in a contemporary grid pattern, unlike the organic structure of most English towns. This more rigid formal structure attracted population but did not evolve gracefully. By the 1970s overflow population from Milton Keynes had begun moving to Buckingham and the surrounding communities and then commuting to Milton Keynes for employment. 
Ultimately, the growth around Milton Keynes affected the entire northern area of Buckinghamshire County, causing sprawl and uncontrollable infill development among and between cities that detracted from the city center (Fisherman, 2003).

Sustainable Principles, New Urbanism, and Revitalization. Restructuring existing cities and planning new urban development is a priority in the global push for sustainability (Soule, 2006). Because our current consumption levels exceed available resources, new planning strategies and policies must be implemented to ensure that cities continue to thrive and maintain citizens' quality of life (World Commission on Environment and Development, 1987).

Sustainable principles are reflected in common planning methods utilized in municipalities to effectively promote community development strategies and revitalization efforts. The Local Government and Improvement Agency in the UK highlights five guiding principles for sustainable development:

- Living within environmental limits

- Ensuring a strong, healthy, and just society

- Achieving a sustainable economy

- Promoting good governance

- Using sound science responsibly (2010b)

In addition to the five sustainable principles, The Local Government and Improvement Agency also lists four shared priorities for action in sustainability:

- Sustainable consumption and production

- Climate change and energy

- Natural resource protection and environmental enhancement

- Sustainable communities (2010b)

Specific community interpretations of these principles include the building of diverse, mixed-use neighborhoods with residential, commercial, and office space in downtown districts and other neighborhoods (Downs, 2001). Residents then live in 
proximity to local shops, restaurants, and leisure activities (Beaumont \& Tucker, 2002).

Other interpretations that promote sustainability principles include: increased public transportation, increased economic development and strong local businesses, and revitalization efforts that boost property values and increase city revenues (Sustainable Development Commission, 2011). A sustainable community can be created when economic, social, and environmental systems collaborate to promote a healthy, productive, and meaningful life for all community residents (Sustainability Reporting Program, 2004). Sustainable practices are quickly advancing throughout the world as cities and communities are utilizing sustainable theories in revitalization and community development efforts (Downs, 2001).

The New Urbanism principles, which are extremely beneficial to residents, businesses, and developers, emerged from radical changes of sustainable cities. The Congress for the New Urbanism lists the following New Urbanism principles necessary to promote sustainability:

- Livable streets arranged in compact, walkable blocks

- A range of housing choices to serve people of diverse ages and income levels

- Schools, stores, and other nearby destinations reachable by walking, bicycling, or transit service

- An affirming, human-scaled public realm where appropriately designed buildings define and enliven streets and other public spaces (Congress for the New Urbanism, 2011)

The benefits of New Urbanism principles include a higher quality of life, stable property values, and a better sense of community or place (Deitrick \& Ellis, 2004). Pedestrianfriendly communities persuade residents to live in close proximity to the city center and within walking distance of employment, shops, parks, and other amenities offered downtown (Fainstein \& Campbell, 2002). New land-use planning restrictions and 
initiatives contribute to residents' quality of life and thus the economy (K. B. Hall \& Porterfield, 2003).

Redevelopment planning strategies (revitalization strategies) have been successful in creating a revitalized city center. Amenities that city centers offer include restaurants, businesses, and places of employment (Wallace, 1956). Revitalized hotels and shopping districts of these inviting locations also appeal to tourists; these re-attract and retain individuals to the downtown area (Cohen, 1997). Other planning approaches should be addressed when revitalizing the city center to include the best interest and common good of all individuals in the community (Beatley, 2007). Problems arise when redevelopment strategies appeal to a limited number of individuals, particularly those in higher social classes. Urban movements are too often supported by unregulated, profit-driven expansion, leading to outcomes benefiting only a select few. All social classes should benefit from planning efforts, which incorporate sustainable mixed use and mixed socioeconomic levels (Fainstein \& Campbell, 2002).

\section{Urban and Regional Planning in England}

Over the past 20 years, select city councils in England have been working together to understand the role of large cities in the country (Local Government Improvement and Development, 2010a). Excluding London, targeted large cities were identified as Birmingham, Bristol, Leeds, Liverpool, Manchester, Newcastle upon Tyne, Nottingham, and Sheffield (Local Government Improvement and Development, 2010a). Factors that have been recognized as enabling communities to succeed include high levels of human capital, high qualities of life, effective local leadership, and strong 
regional connections (Centre for Cities, 2011a). Prosperity and growth in smaller communities located between these cities are generally addressed regionally.

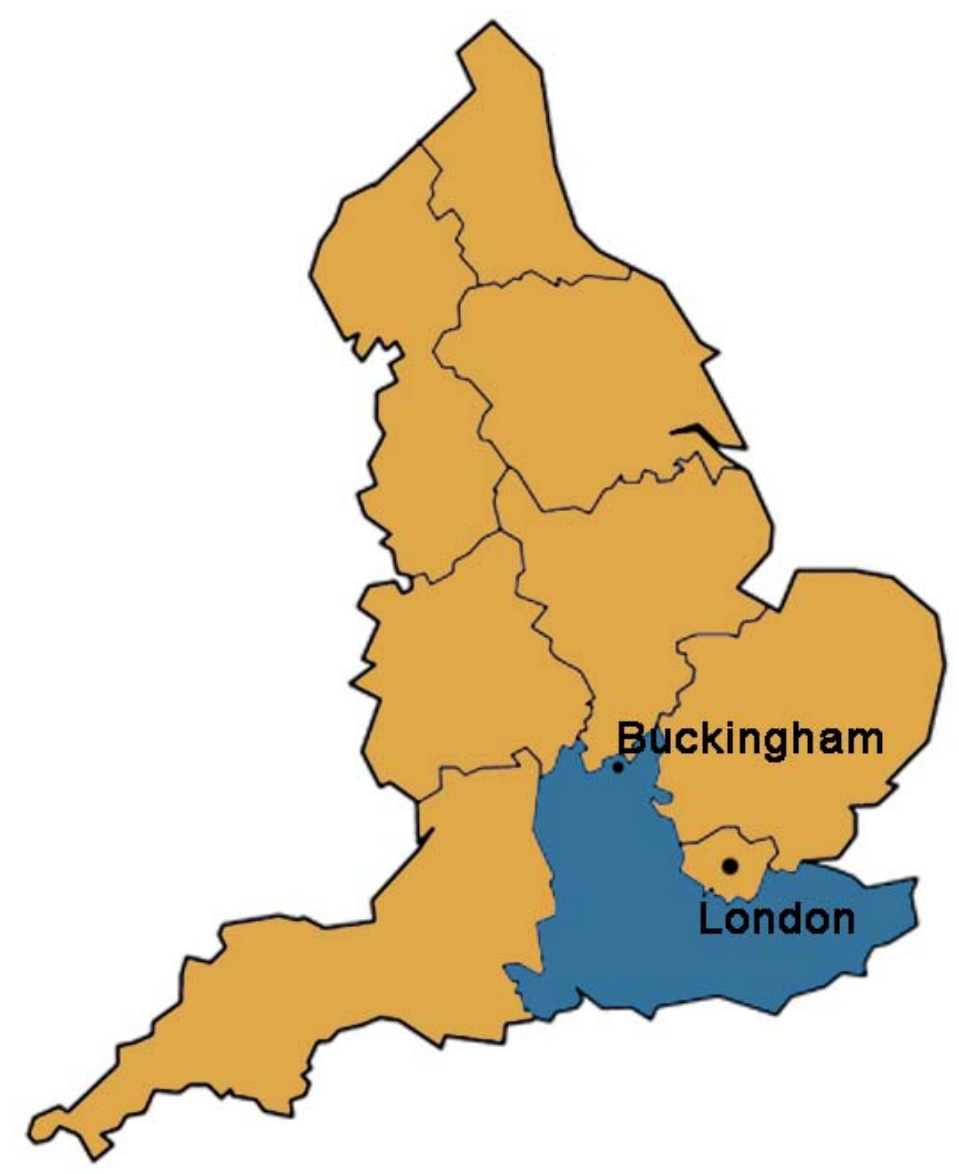

Figure 10. Map of the South East Region of England.

Regional Planning: The South East Plan. The South East Plan addresses longterm spatial planning for the South East region of England from 2006-2026 (The South East England Development Agency, 2011).

The plan is a key tool to help achieve more sustainable development, protect the environment and combat climate change. It provides a spatial context within which Local Development Frameworks and Local 
Transport Plans need to be prepared, as well as other regional and subregional strategies and programs that have a bearing on land use activities. (Government Office for the South East, 2009)

The plan is a government strategy to increase housing by $10 \%$ in all districts of southeast England, once again taking the pressure off of the London area (Buckinghamshire County Council, 2011b). Environment, transportation, higher education, research and development, culture, economy, employment and unemployment, and deprivation are the main areas of interest for the South East region (The South East England Development Agency, 2011).

Various policies are noted for the plan, including: "the scale and distribution of new housing; priorities for new infrastructure and economic development; the strategy for protecting the countryside, biodiversity and the built and historic environment; tackling climate change and safeguarding natural resources" (Government Office for the South East, 2009). Transportation strategies will also be noted in the plan. A total of ten sub-regions are identified in the South East Plan that will focus attention on growth and regeneration through increased housing, denser populations, and revitalization of downtown centers (Government Office for the South East, 2009). 


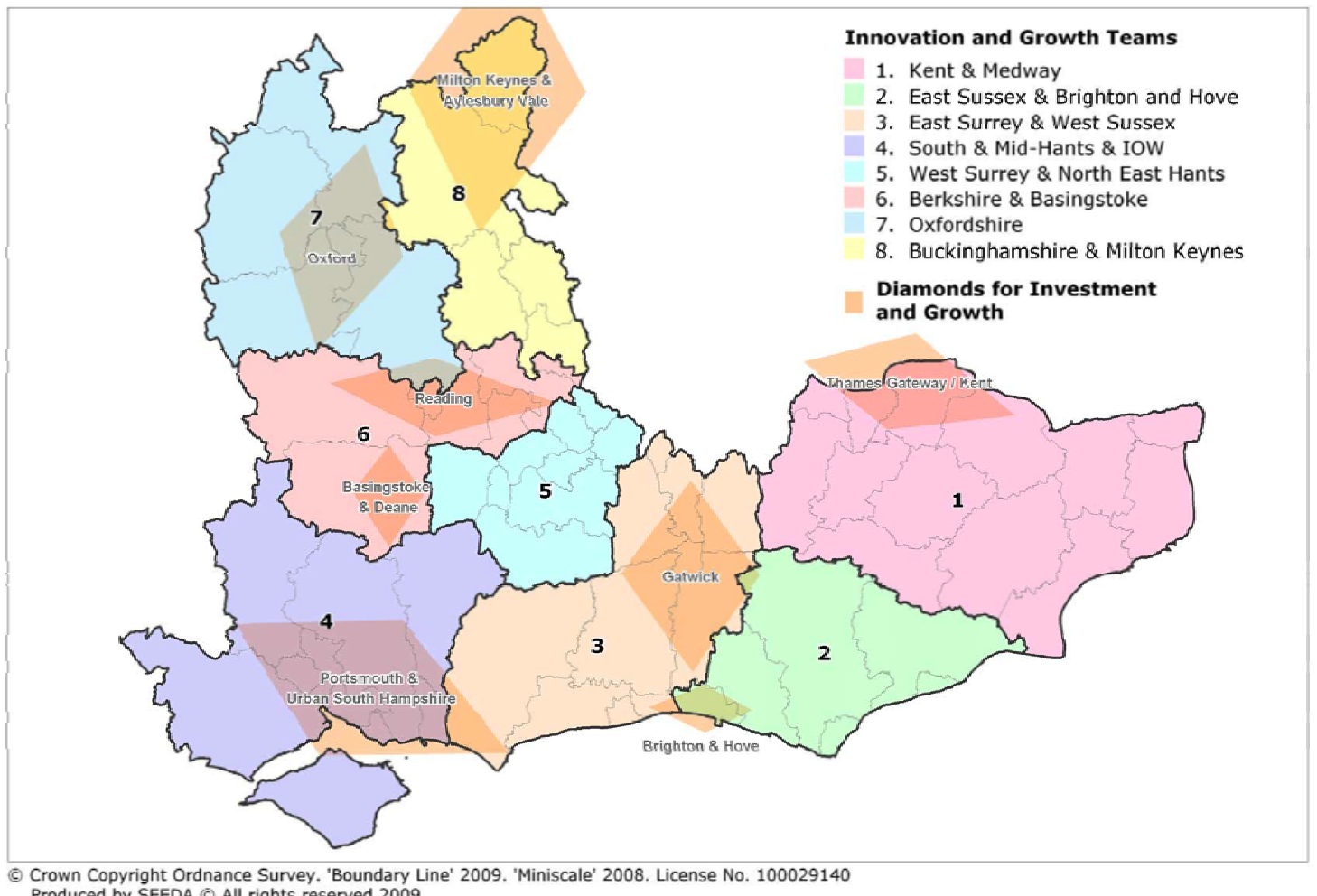

Line' 2009. 'Miniscale' 2008. License No. 10002914

Figure 11. Ten Areas Targeted for Growth and Regeneration in the South East Region. Adapted from “The South East Plan,” by The South East England Development Agency, 2009. Crown Copyright 2009.

In Buckinghamshire County, Milton Keynes and Aylesbury Vale are specifically targeted for additional growth. Buckingham, the market town utilized in this study, is located between Milton Keynes and Aylesbury Vale. The South East Plan continues to impact Buckingham. Requirements for construction of additional housing developments in South East England will help London cope with increasing population issues. A projected completion date of new homes in the South East region is 2026 (Buckinghamshire County Council, 2011b). To meet the standards of the South East Plan, Buckingham will need to construct 4,700 new homes in the area. These additional housing developments will have considerable impacts on the town. 


\section{Local Government Planning}

England provides two options for towns to select a form of local government: a unitary or two-tier structure (Buckinghamshire County Council, 2011a). With a unitary government, a city, such as Milton Keynes, can manage all local authority in its area. With a two-tier government, the main level of administrative authority is at the county level, and then the county is divided into districts (Buckinghamshire County Council, 2011a).

Buckingham has a two-tier structure of government. Therefore, the control of planning activities occurs at two levels: the Buckingham Town Council and the Aylesbury Vale District Council (Aylesbury Vale District Council, 2011). Planning decisions made at the local level in Buckingham must also be approved by the Aylesbury Vale District Council (Buckinghamshire County Council, 2011a). The Buckinghamshire County Council “manages services such as trading standards, highways, social care, school, libraries, and household waste sites. District councils run services including planning applications, environmental health, housing benefits, refuse collection, leisure services and council tax collection” (2011a).

Larger communities and cities throughout England have the resources to hire a city planner or planning staff. That is not always the case with each community. In smaller communities, like Buckingham, resources are not available to hire a full time city planner. Therefore, planning committees are created to direct planning decisions in the community. Town Council members have appointed Buckingham citizens to serve on the Planning Committee of Buckingham (Buckingham Town Council, 2010). Twice a 
month, the committee reviews planning and development proposals submitted by local residents and developers in an open public meeting.

The current economic recession has impacted planning in England and abroad. Centre for Cities states, "Public spending on infrastructure is vital for supporting future economic growth, but this type of expenditure is in for a squeeze” (2011a, p. 8). Cities across the country will be facing challenges with "tight budgets and increased responsibilities associated with localism” (Centre for Cities, 2011a, p. 8).

Power for planning at the local level is one of the most critical powers to obtain; issues surface regarding funding, land-use, development, making decisions in the best interest of the community, and political corruption when planning authority occurs at the local level. Current debates in England center around a Localism bill, which grants authority to the local level and councils (Parliament of England, 2012).

\section{Local Planning in Buckingham}

Two planning documents — The Buckingham Plan and The Buckingham Vision and Design Statement — will be central to future development in Buckingham. The town's leaders and concerned citizens are assuming responsibility and taking control of their community’s future. Various documents, strategic plans, and organizations have been created to address local characteristics and assist with the future planning of Buckingham. Community residents came together in various meetings and informational sessions to share their personal thoughts and needs.

The Buckingham Plan. Buckingham understands it has the ability to control some aspects of the market town's future. The Buckingham Town Council initiated a series of community meetings, workshops, verbal participation, online questionnaires, 
surveys, and informational sessions regarding the challenges of the economic climate and its impact on the local community, as well as the potential growth in the area (Buckingham Town Council, 2008). In 2008, after various consultations with the community, the Town Council and the Planning Committee of Buckingham created the Buckingham Plan, an in-house document to be utilized as a study tool for the community (Buckingham Town Council, 2008).

Forced growth is one of the main areas of concern addressed in the Buckingham Plan. Buckingham stakeholders understand that the town will be impacted by the larger cities in Buckinghamshire County, Milton Keynes and Aylesbury Vale; economic prosperity, increased populations, and controlled growth can also have positive effects on Buckingham because of its location between these two larger cities and distance to London. Key issues are noted in the plan to mitigate the forced growth, controlling some aspects of the community and attempting to make Buckingham a vibrant market town. The primary focus of the plan was Buckingham, but small parishes and local villages that rely on Buckingham are also noted. The plan states,

We are at risk of being impacted by major developments of the neighboring towns of Milton Keynes and Aylesbury, and the potential for large growth, where infrastructure investment will inevitably be concentrated. Buckingham must maintain its self-sufficiency to ensure future sustainable development—and avoid being turned into a dormitory town. (Buckingham Town Council, 2008, p. 5) 

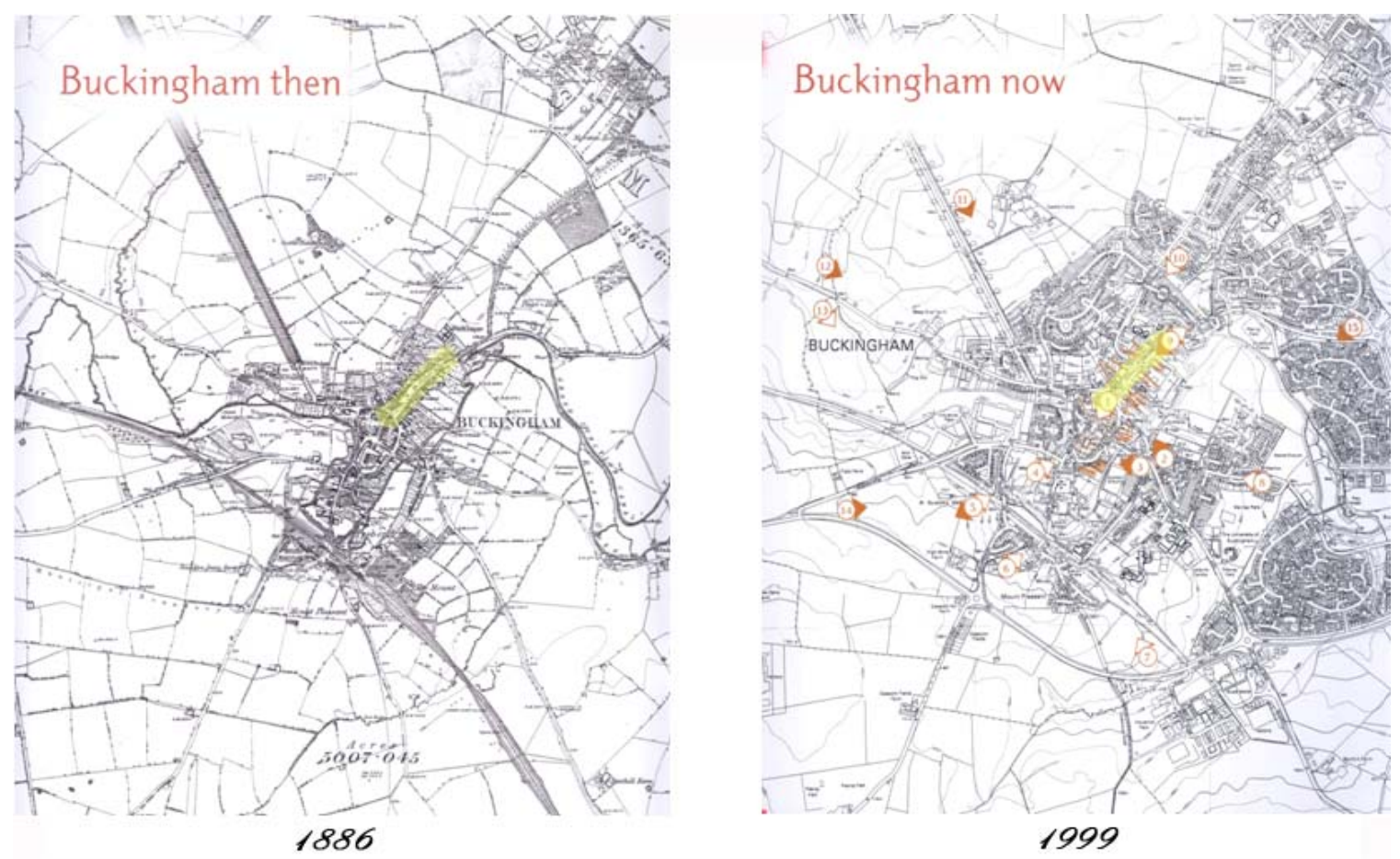

Figure 12. Buckingham Then and Now, 1886-1999. The yellow area in the plans designate Buckingham's town center. Adapted from "Buckingham Vision and Design Statement,” by The Buckingham Town Design Group. Crown Copyright.

Numerous challenges were addressed in the Buckingham Plan, including: development, infrastructure, town center and local economy, transportation, housing, conservation, children and young people, education and employment, health and leisure, and tourism and culture (Buckingham Town Council, 2008). Other major concerns addressed in the plan involved large retail shops (big-box stores) around the bypass outside of Buckingham. The plan states, "Encouraging retail trade to be accessed only by car is no longer appropriate; efforts must be made to ensure easy pedestrian and cycle access” (Buckingham Town Council, 2008, p. 15). Buckingham is encouraging sustainable principles such as walkability and easy access to shops and recreation as the town plans for future growth. 
Critical sites within the historic core of the town are also addressed in the Buckingham Plan. In regard to the town center, the plan states,

The vitality of the town center and its historic setting is one of the key features of the town, and one the Town Council wishes to cherish and nurture. It is one of the key factors in the consultation responses contributing to resident's positive feelings towards the town, and provides a key part of the social cohesion of the town by providing the area's key economic, social, and democratic activities. (Buckingham Town Council, 2008, p. 15)

It is evident that the residents of Buckingham are passionate about the market town in which they reside, and the Town Council takes note of that enthusiasm. Improving tourism in Buckingham is another challenge the town is facing. Focusing on the vibrancy of the downtown center will encourage increased tourism. Additional areas of interests for tourism include Stowe House, School, and Gardens, located close by, Silverstone racing track, and other various rural attractions (Buckingham Town Council, 2008). The Buckingham Plan was widely accepted by leaders and members of the community. The document continues to be used as a strategic plan for the future growth of the community.

Buckingham Vision and Design Statement. Quaint, charming, and picturesque are common terms used to describe market towns. A number of aesthetics are lost in the contemporary English market town. The continuous development and growth of these communities force new construction and renovated buildings in the city center and outside of town (Association of Small Historic Towns and Villages of the United Kingdom, 2011). The Buckingham Vision and Design Statement, produced by the 
Buckingham Town Design Group in 2001, is a guidebook for new construction in Buckingham. A group of community members came together with concerns about the appearance of newly constructed buildings fitting into the existing historic Georgian architecture of the town center (The Buckingham Design Group, 2001). The Buckingham Vision and Design Statement helped build cohesiveness in the design of the town and a sense of focus for the residents of the community. The guidebook for new construction and renovations in Buckingham includes a selection of material choices, roof pitches, window types, landscaping, and options for the re-use of empty downtown storefronts. Following the historical fire in 1725, most of Buckingham was rebuilt with a Georgian center (The Buckingham Design Group, 2001).

The Buckingham Vision and Design Statement helped build cohesiveness in the design of the town and a sense of focus for the residents of the community. The statement identified three key areas critical for all development, including, "be sensitive to the immediate locality, relate to the context of Buckingham, and respect the natural environment.” Leaders of the group consulted with the community during the design process of the guidebook through a series of competitions, presentations, and a thorough street assessment of the entire downtown (The Buckingham Design Group, 2001). 


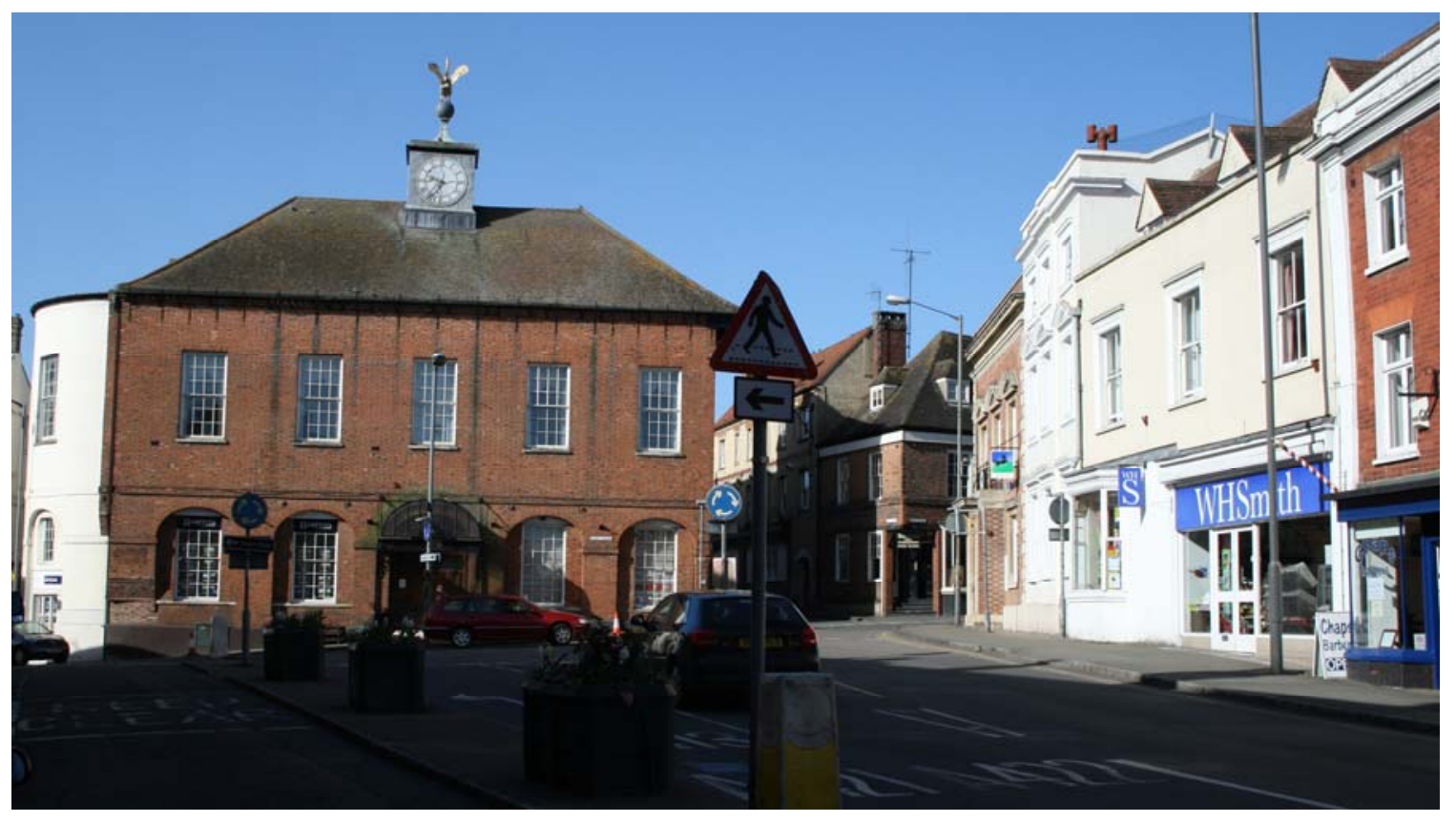

Figure 13. Historic Georgian architecture in Buckingham’s town center.

\section{Development of Buckingham, England}

The market town of Buckingham, England, is rich in history that dates back centuries. Located in the northern part of Buckinghamshire County along a bend in the great River Ouse, Buckingham is a rural market town that is a hub of activity to the small towns and villages in the surrounding area (Buckingham Town Council, 2008).

Buckingham residents and members of the surrounding communities and villages utilize the town for services, shopping, dining, and recreational activities. 


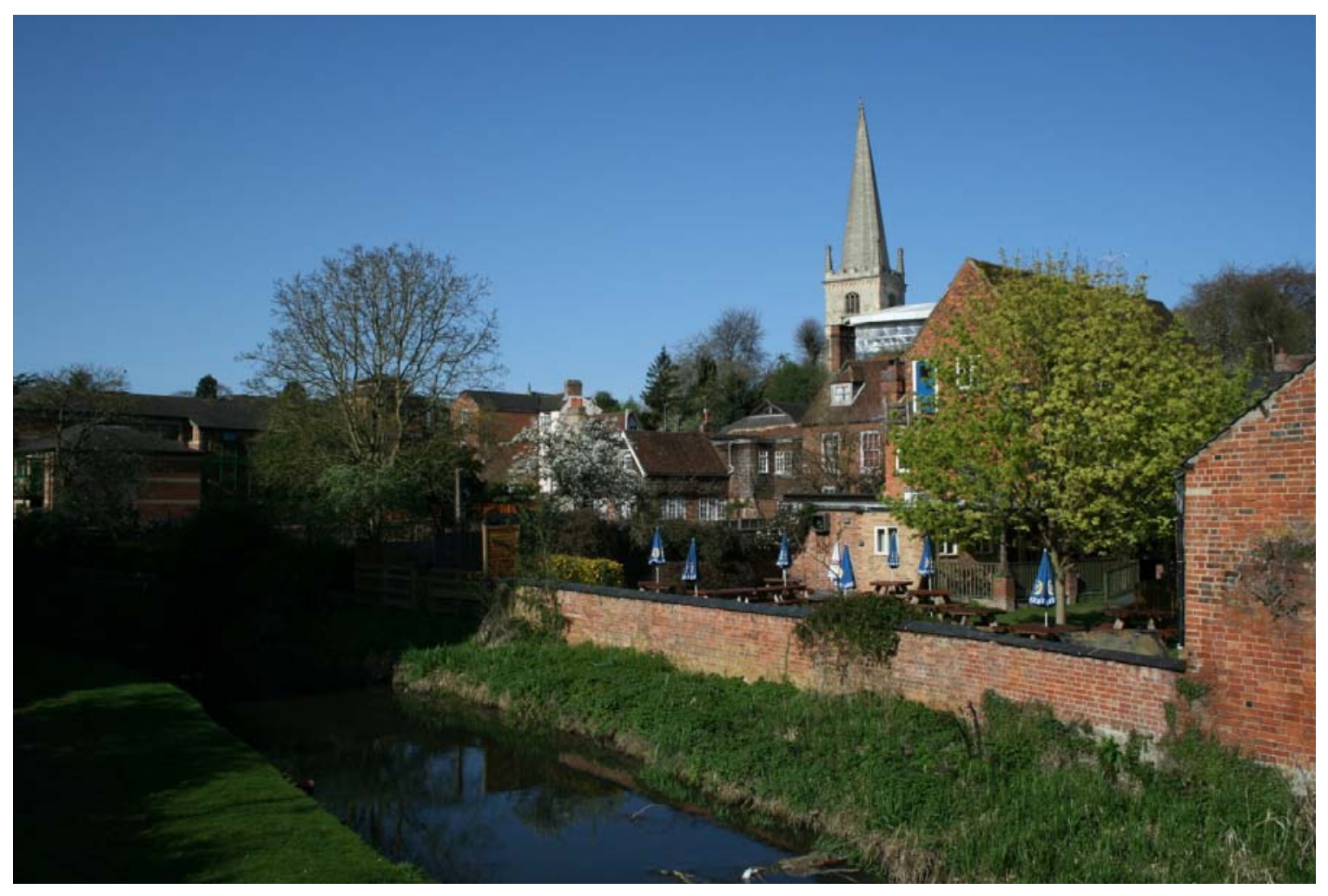

Figure 14. Buckingham’s River Walk.

The town was founded when Saxon Bucca settled with his tribe at this winding part in the river. It is assumed that Bucca and his followers settled in the bend in the river Ouse sometime between the $4^{\text {th }}$ and $5^{\text {th }}$ centuries (Elliott, 1975). The tribe cleared trees for their agricultural system and the river produced a great wealth of resources. The settlement was named Buckingham after their leader (Close, 2009). Elliott states the ancient origin of Buckingham means, “The very name of Buckingham 'Buccinghamme' - means the village or dwelling place of the people (followers) of Bucca” (1975, p. 1). 


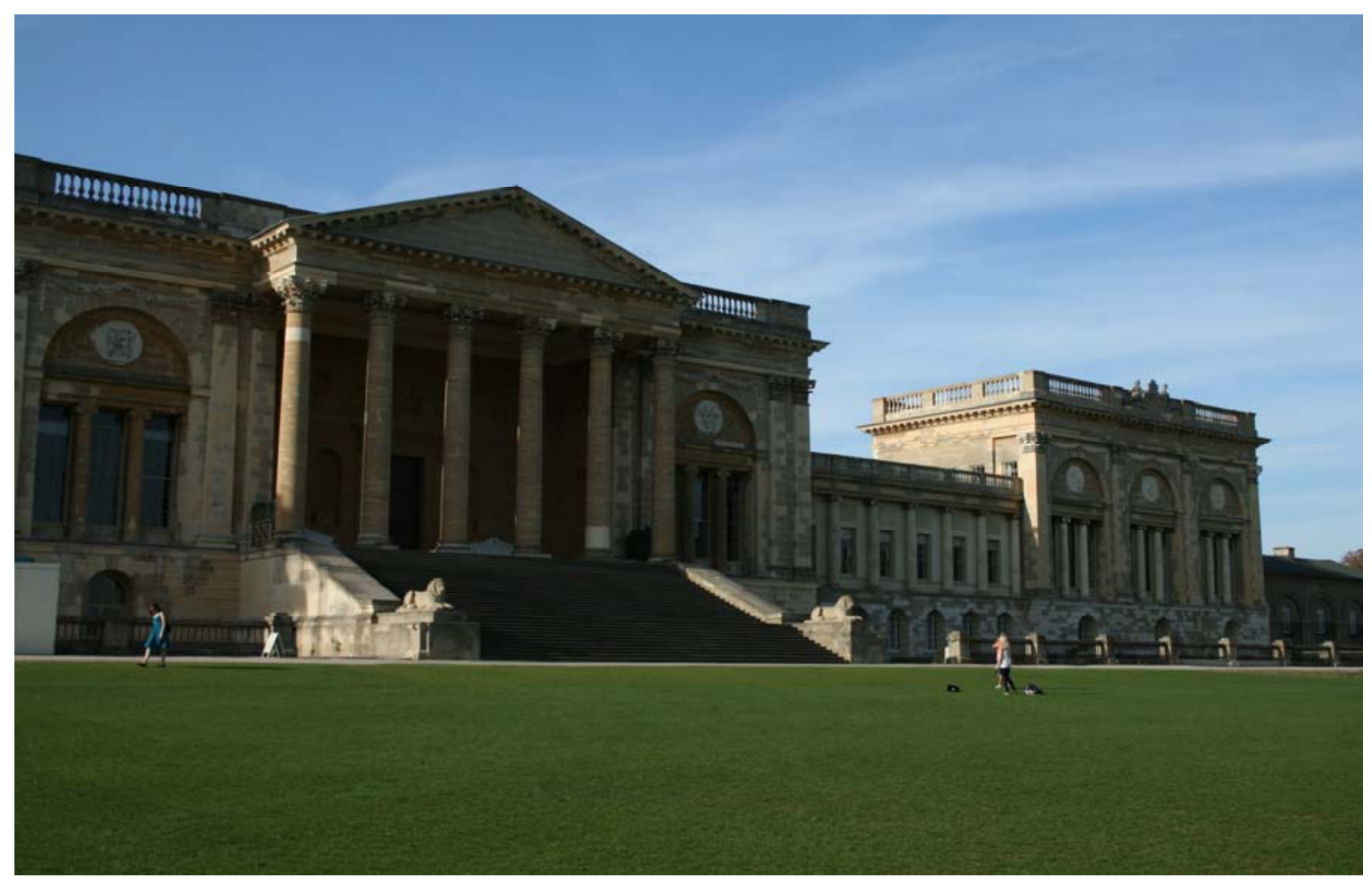

Figure 15. Stowe House and Stowe School.

Stowe House. Stowe House, a large estate home originally owned by the Temple family, is located two miles from Buckingham. Stowe House brought much prosperity and many positive aspects to Buckingham (Bevington, 2002). The house used services, goods, and products from Buckingham, and employed large numbers of Buckingham residents (Bonner \& Vernon, 1984). In 1848, the financial collapse of the Temple family had devastating effects on Buckingham and left the town in shambles. Years later, Stowe House was sold at auction in 1923, renovated, and adapted to become a prep school for young boys (Bevington, 2002). Landscape Gardens, Stowe House, and Stowe School are now owned by three separate organizations, all of which hold heritage and historic preservation in high regard (Bevington, 2002). 
University of Buckingham. The University of Buckingham was established in Buckingham in 1971. In 2010, The University of Buckingham announced plans to double in size, growing from approximately 1,000 students to 2,000 students in the following five to ten years. For a town of 12,000 like Buckingham, increasing the population of $18-24$ year old transients to $20 \%$ of the total will have a significant impact, particularly where student housing, transportation, retail, and food services are concerned (Wiewel, Gaffikin, \& Morrissey, 2000). Most university students now live in downtown Buckingham and take advantage of local shops and restaurants. With growth, additional housing for students, professors, and staff will be required. Currently, 97 new flats are being constructed behind the White Hart Hotel and Pub in the center of town. The University of Buckingham continues to be a positive influence in the town, encouraging retention of educated individuals in Buckingham.

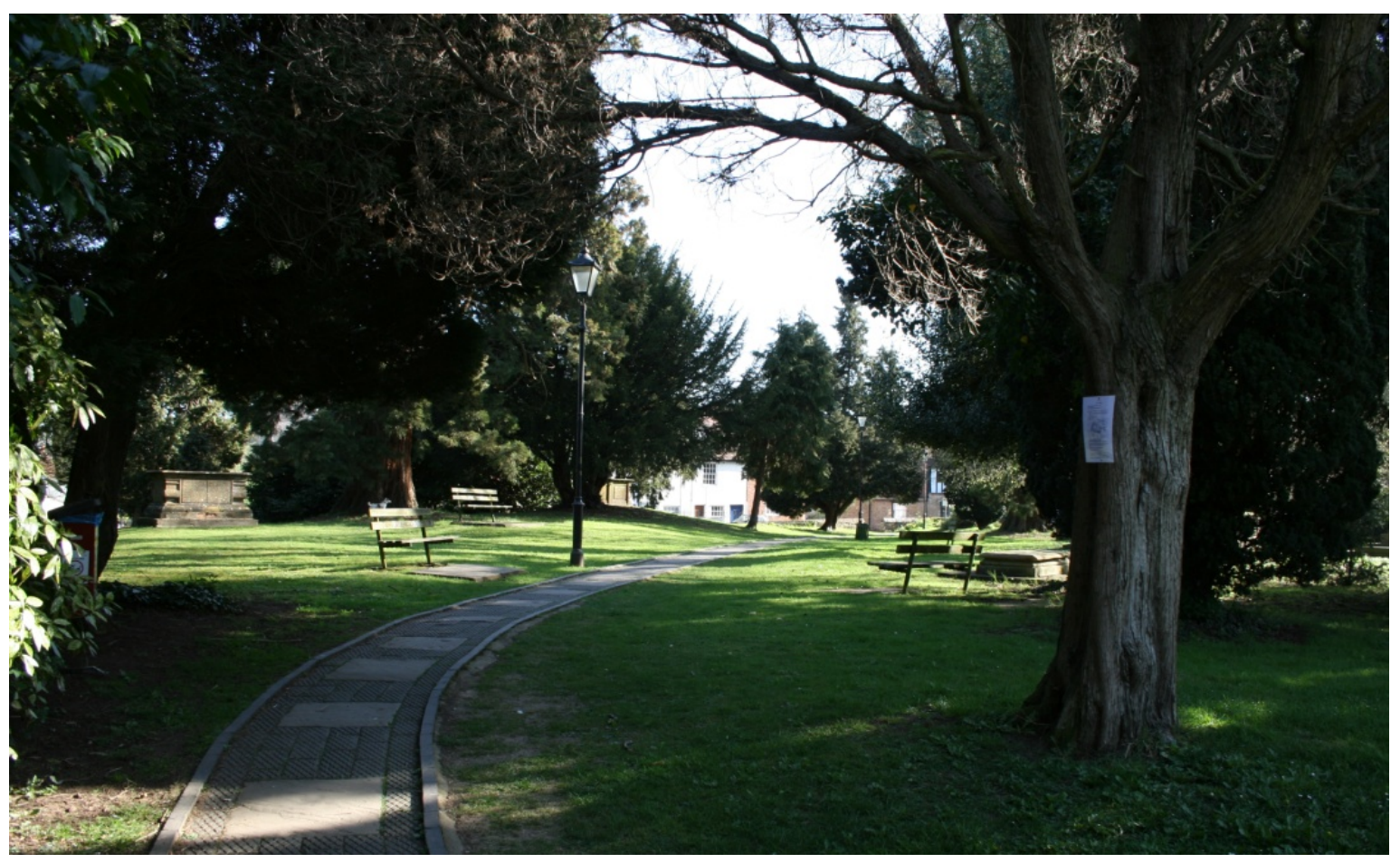

Figure 16. University of Buckingham Campus. 
Current Buckingham. Specific challenges that have affected Buckingham from 1967 to the present include large population increases, rapid growth and urban sprawl, the expansion of Milton Keynes, the use of big-box stores, and a declining downtown. A series of uncontrollable events and actions has brought Buckingham to its current state, causing major impacts on the physical condition of the town and the quality of life for residents. These changes have prompted concerns in Buckingham regarding infrastructure and housing, education, conservation and parks, cultural aspects of the town, and economic development.

Immediately after World War II, Buckingham began to notice a steady increase in population (see figure 17). Another major explosion in population occurred in the 1980s and 1990s; this massive population increase in the Buckingham area had major impacts on the town. Additional housing developments were needed as residents moved to the area for employment in Milton Keynes and London. Commuting residents initiated Buckingham’s dormitory town issue; residents would drive by car or bus to Milton Keynes or to take the train into London for employment, shopping, and other daily activities, leaving Buckingham vacant during the day. Since space was limited for housing in the town center, additional housing developments were constructed outside of Buckingham, encouraging sprawl and decreasing walkability (Clarke, 1984). 


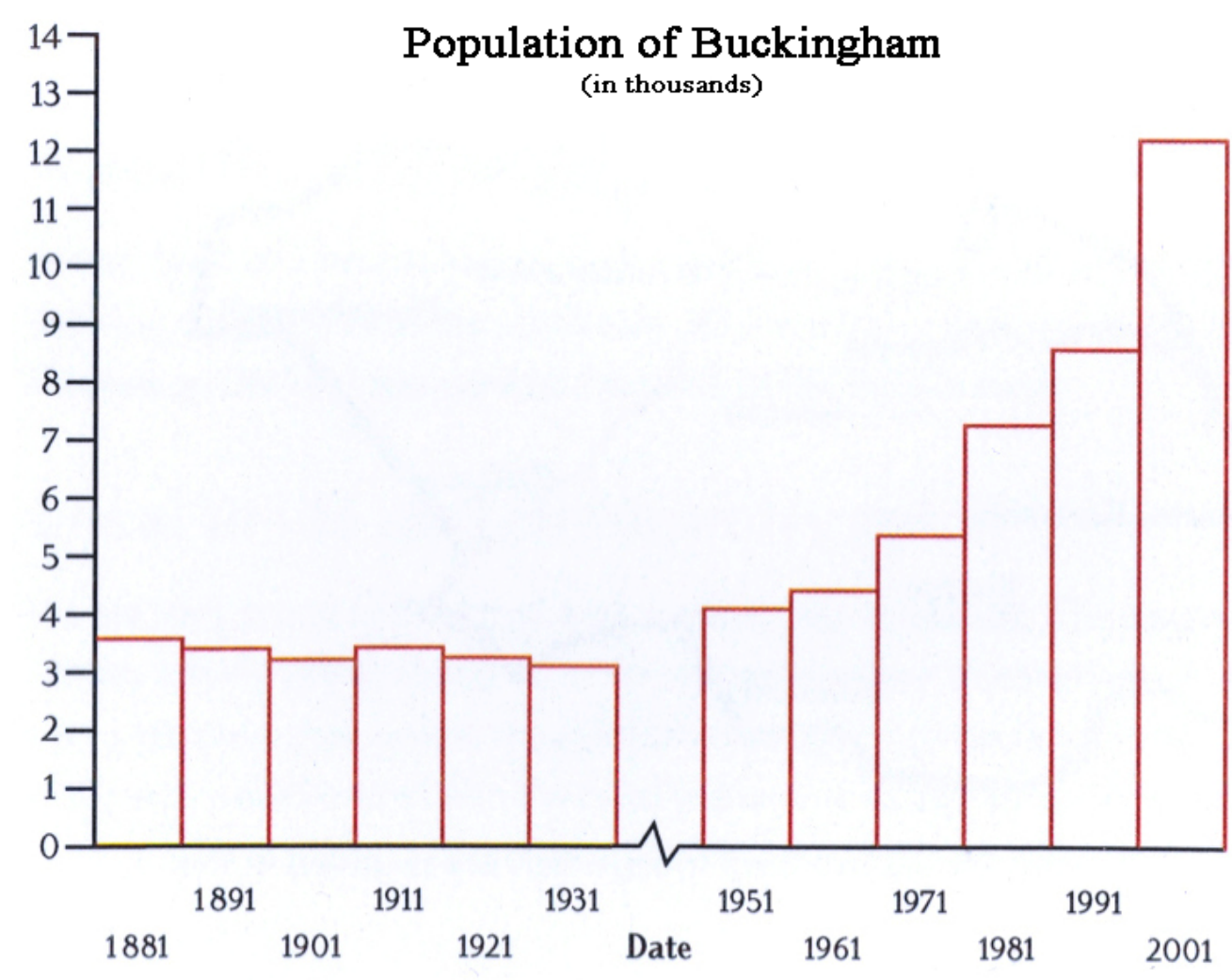

Figure 17: Population Increase in Buckingham. Adapted from "Buckingham Vision and Design Statement,” by The Buckingham Town Design Group, 2001.

In addition to the residential sprawl caused by housing developments in Buckingham, there was sprawl triggered by "big-box" stores. The big-box era hit Buckingham around 1991 when the first big-box store, Tesco, was built on the outskirts of town (Close, 2009). Tesco is comparable to Wal-Mart in the United States. A shift occurred in the mentality of residents in relation to utilizing local shops downtown. If the residents could make all their purchases in one store, there was no need to travel to downtown Buckingham for shopping. Big-box stores had huge impacts on downtown Buckingham; local stores and shops began to close. With time, the town lost a bakery, butcher, florist, and other specialty shops in the downtown district (Close, 2009). 
Key issues such as infrastructure and housing, education, conservation and parks, cultural aspects of the town, and economic development have all been impacted in some way due to the rapid increase in Buckingham's population. The town must learn to adapt to these changes in order to uphold the highest standards in providing a high quality of life to residents in the community. The current infrastructure, including transportation, education, water, sewage, and utilities, etc., does not have the capacity to provide these services to the new housing developments outside of town (Buckingham Town Council, 2008). Issues with funding to provide new infrastructure have also been a concern for the town (Buckingham Town Council, 2008). In regard to education, there is a growing

demand for larger schools and additional schools at each level—elementary, middle, and high schools—as classrooms are becoming overcrowded (Buckingham Town Council, 2008). The Royal Latin School, a local grammar school in Buckingham, is well known for providing a quality education to individuals who demonstrate exceptional skills and knowledge. Therefore, families are moving to the area so their children may receive a superior education in preparation for higher education (Buckingham Town Council, 2008).

\section{Community Identity and Sense of Place}

Successful town revitalization begins with the residents' ability to understand and recognize the problems and potential for the community (Cohen, 1997). Whatever the attraction is for new residents and tourists, it must also be attractive to the people who reside and work in the community. In this particular study, the term "sense of place" is utilized in relation to the identity of the town and how a resident perceives that identity. 
Design utilized for any part of a town should allow for modification and be extended over a broad area of the community (Bacon, 1974).

The growth and development of everyday life has severely threatened traditional concepts of community, civic place, and neighborhood, creating unhealthy and unappealing towns (Duany \& Plater-Zyberk, 1991). Market towns strive to keep their identities with the changing times and conditions of contemporary England by cultivating a strong sense of place and establishing a brand. This place-based identity encourages a greater enjoyment of the community and more community engagement and interaction among residents (Jacobs, 1961).

Branding in Buckingham. The Buckingham Traders’ Association, a voluntary organization comprised of business owners, has been very instrumental in supporting Buckingham's downtown center while also encouraging increased pedestrian activity and shopping. Developed by the Buckingham Traders’ Association, Aylesbury Vale District Council, and the Buckingham Town Council, as well as several local partners, Buckingham's brand incorporates aspects of both the history and modern culture of Buckingham (Buckingham UK, 2011). Buckingham’s logo is “part of a campaign to promote and develop Buckingham's retail, business and tourist opportunities to keep Buckingham thriving” (Buckingham UK, 2011). See figure 18. The Traders’ Association in Buckingham has been extremely proactive in promoting the market town's vibrancy and also encouraging local residents and tourists to shop, dine, and recreate in Buckingham (Buckingham UK, 2011). Buckingham hopes that if it can supply a thriving market town, then residents, tourists, and other citizens will be attracted and provide support. 


\section{Thoroughly MODERN BUCKINGHAM}

Figure 18. Buckingham’s Branding Logo. Adapted from “Thoroughly Modern Traditional Brand," by the Buckingham Traders’ Association, 2011. Permission granted by the Buckingham Traders’ Association.

The English Market Town: Traditional and Modern. To fully implement this brand, it is important to understand both the rich histories and traditions of market towns that date back centuries in the English culture and more current interpretations. The English market town was a valuable resource to towns and communities throughout the English countryside, mostly in rural areas. The market town served the needs of the countryside and the villagers (Brown, 1986). Buying and selling of produce and livestock from the local farms was one of the main objectives of the market town. The shopkeepers traded all day, the inns were bustling with visitors, and bankers received their farming patrons. When the market was over, the villagers would travel back to their villages and the town would be peaceful for a few days until another market came around (Chamberlin, 1985). This was the way of life for most rural villages; the townspeople could not travel long distances to large cities to get their everyday necessities. Therefore, they had to invent their own system of trading and selling for a way of life (Brown, 1986). In the 1830s, William Howitt described the heart of market town life, 
There are few things which give one such a feeling of the prosperity of the country, as seeing the country pour into a large town on market day. There they come, streaming along all the roads that lead to it from the wide country round. The footpaths are filled with a hardy and homely succession of pedestrians, men and women, with their baskets on their arms, containing their butter, eggs, apples, mushrooms, walnuts, nuts, elderberries, blackberries, bundles of herbs, young pigeons, fowls, or whatever happens to be in season... the carriage road is equally alive with people riding or driving along; farmers and country gentlemen, country clergymen, parish overseers, and various other personages, drawn to the market town by some real or imagined business, are rattling forward on horseback, or in carriages of various kinds... There are carriers' wagons, and covered carts without end, many of them shewing from their open fronts whole troops of women snugly seated... (Brown, 1986, p. 6) Market Towns in Contemporary England. Today, the markets are slowly disappearing; they are no longer a necessity to everyday life. These disappearing markets are the result of competition from other markets and change in community growth patterns, among other reasons. In 1748, the Magnae Britanniae Notitia quoted, "there are 681 market towns in England” (Brown, 1986, p. 14). By 1880, The Royal Commission on Market Rights and Tolls quoted the count to be at only 380 market towns (Brown, 1986, p. 14). The exact number of current market towns is unknown due to fluctuation of failing markets and losing their Royal Charter. 
Influences Shaping Contemporary Market Towns. The question remains

unanswered about what it means to be a market town. Various influences from historical, societal, and cultural systems continue to place pressures on the development of English market towns. Other factors have forced market towns to adapt to changing conditions, ultimately modifying the status of market town to fit the needs of the contemporary England.

Historical Influences: The definition of a market town continues to evolve with time as the history associated with the culture adapts to changing conditions. Hundreds of years ago, market towns were considered a way of life for the community (Chamberlin, 1985). The historical tradition of holding a regular market a few times a week still exists, but the purpose of having a market is not the same in contemporary England as it was hundreds of years ago. Figure 19 represents Buckingham's regular market. Population increases, dormitory town issues, and the rise of big-box stores have initiated a shift in thinking about market towns and residents' lifestyles (The Buckingham Design Group, 2001). These societal influences have prompted a lack of support for traditional markets and sustaining local services, terminating some regular markets and prompting a decline in city centers. 


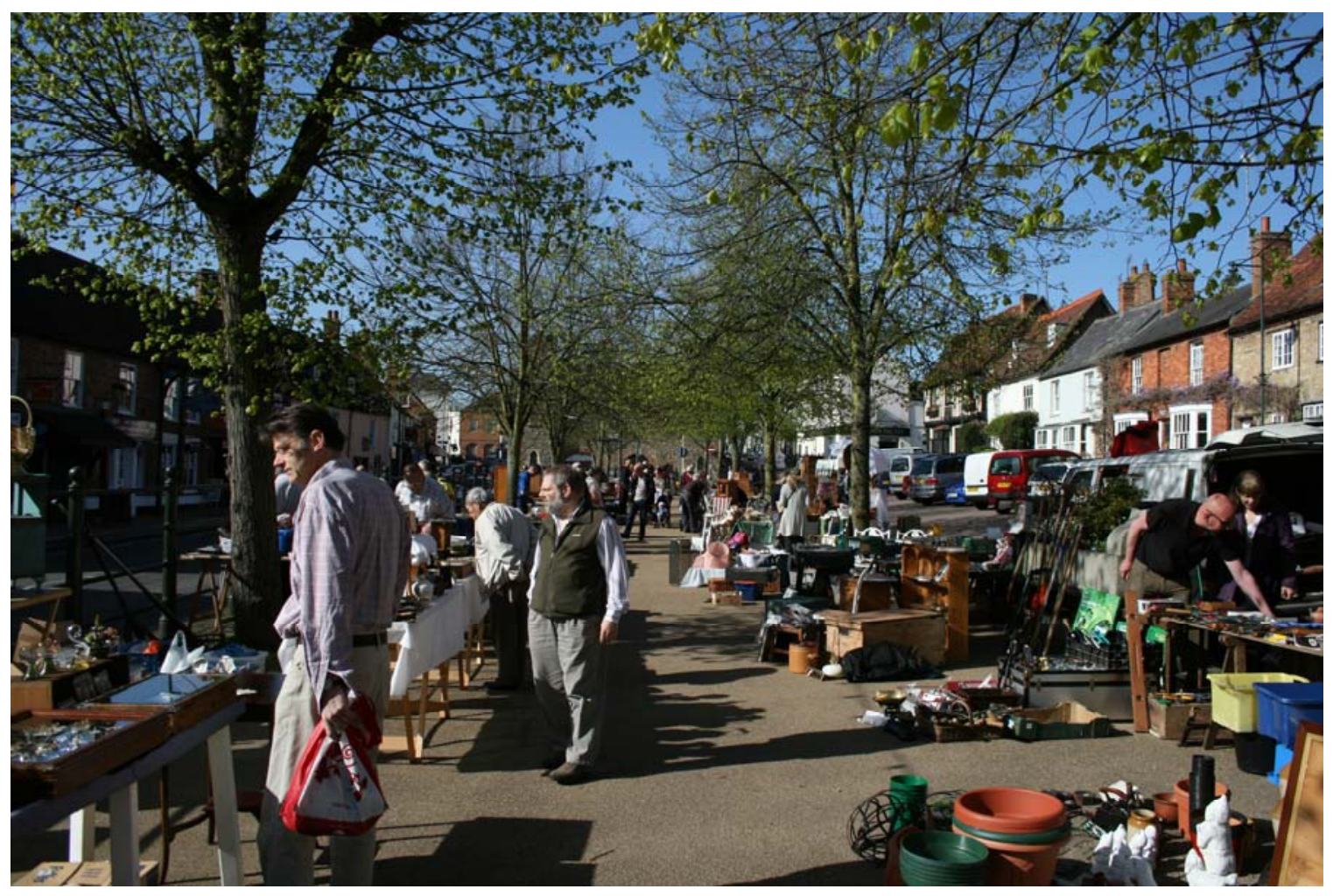

Figure 19. Buckingham’s Vintage Market.

Cultural Influences: Cultural influences continue to affect how individuals in contemporary England receive market towns. The traditional culture of the market town was established in rural areas among agriculture communities; farming was a way of life (Brown, 1986). Cultural influences, such as the shift from agriculture to manufacturing, have impacted the development of market towns in various ways (Chamberlin, 1985). An increase in manufacturing led to various forms of transportation, such as canal systems and trains, to deliver goods to larger cities (Brown, 1986). Train stations, canals, and large highways emerged in or around some market towns. The shift from agriculture to manufacturing was the beginning of a major shift altering the familiar way of life for market town residents. 
Societal Influences: As the rest of the England continued to rapidly progress, market towns developed in a different manner (Dyckhoff, 2009). Most market towns do not have a train station, nor do they have major roads connecting them to larger cities throughout the country. The lack of developmental influences has allowed the majority of market towns to remain secluded, but that is what makes market towns so desirable to citer goers who are choosing to leave urban centers for the countryside (Dyckhoff, 2009). Market towns are now suffering from population increases. Public school systems are becoming overcrowded, the number of vacant shops in the city centers is higher than in previous decades, and some downtown districts and High Streets are declining due to lack of support from the community (J. Hall, 2009). A shift in thinking has influenced traditional society's way of life and residents are showing less support to local businesses and restaurants, prompting declining downtowns in market towns.

\section{Summary}

As changes throughout history have impacted Buckingham in various ways, the market town continues to fight for its identity amidst constant growth and sprawl. The original purpose of a market town, to provide goods and services to the local community, no longer has the same meaning as it did hundreds of years ago. Market towns throughout England are adjusting to changing conditions and ways of life. Changes have prompted challenges to Buckingham in regard to residents, community leaders, and involved organizations as they all strive to uphold the highest standards for Buckingham. The town continues to persevere and adapt to the various changing conditions while creating strategic plans and guidelines to prepare for the future of the community. Buckingham understands the importance of a vibrant city center, as it has established 
branding principles to support the local Traders' and businesses. Downtown development strategies assist business leaders and citizens in improving the downtown district of Buckingham, gaining local support and additional customers who are utilizing the downtown area to its full potential. 


\section{CHAPTER III}

\section{Methodology}

\section{Purpose of the Study}

The purpose of this study is to better understand the experiences and perspectives of the individuals and organizations dealing with change in a specific English market town. The methodology chosen, a Learning History (G. Roth \& Kleiner, 1997), is a subset of qualitative research and case study methodology. Employing the Learning History methodology, this research will examine reported accounts of stakeholder experiences with change in Buckingham over the last 44 years. The resulting narrative might then serve to inform new stakeholders participating in current and future change processes in Buckingham. Ideally, this transfer of knowledge will serve locally to inform smoother transitions and sustain a productive change process. More broadly, use of the Learning History methodology in this way contributes to existing knowledge regarding planning processes, strategies for community development and revitalization efforts, and the experiences of individuals involved with these kinds of planning procedures.

\section{Specific Objectives}

This study specifically addresses community development and revitalization efforts as a response to overcrowded towns and communities dealing with suburban sprawl and poor planning decisions. The Learning History will be employed to follow

the experiences of various stakeholders and individuals who were involved with the planning processes focused on securing a better future for the town of Buckingham, England. 
The following research questions will be addressed:

1. How are the citizens of Buckingham, England, experiencing change related to the current growth and future planning of the town?

2. What can we learn from the planning procedures, growth issues, and projects that are occurring in Buckingham so that the information may be shared to assist other communities seeking to retain their identity amidst change?

In this way, I seek to better understand the experiences of the citizens and involved stakeholders of Buckingham amidst the various changes occurring as a result of sprawl and forced population increases.

\section{Research Traditions}

As a subset of Case Study methodology within the Qualitative Research tradition, the Learning History shares a rich research culture. A Case Study can be defined by simplistic statements such as "a slice of life" or a "depth examination of an instance” (Lincoln \& Guba, 1985, p. 360). A Case Study is common to the fields of social sciences and life sciences and be described as a rigorous analysis of a person, group, or event (Kincheloe \& McLaren, 2005). In Designerly Ways of Knowing, Nigel Cross identified three distinct research cultures (Cross, 2007). 
Table 1

Comparing Scientific, Humanities, and Design Research

\begin{tabular}{|c|l|l|l|}
\hline & \multicolumn{1}{|c|}{ Science } & \multicolumn{1}{c|}{ Humanities } & \multicolumn{1}{c|}{ Design } \\
\hline Focus & Natural world & Human experience & Man-made world \\
\hline Question & What is? & What does it mean to me? & How can I make it better? \\
\hline Methods & $\begin{array}{l}\text { Experiment } \\
\text { Pattern recognition } \\
\text { Analysis } \\
\text { Classification } \\
\text { Deduction }\end{array}$ & $\begin{array}{l}\text { Analogy } \\
\text { Metaphor } \\
\text { Criticism } \\
\text { Valuation } \\
\text { Induction }\end{array}$ & $\begin{array}{l}\text { Modeling } \\
\text { Pattern formation } \\
\text { Synthesis } \\
\text { Conjecture } \\
\text { Abduction }\end{array}$ \\
\hline Values & $\begin{array}{l}\text { Objectivity } \\
\text { Rationality } \\
\text { Neutrality } \\
\text { *Truth* }\end{array}$ & $\begin{array}{l}\text { Subjectivity } \\
\text { Imagination } \\
\text { Commitment } \\
\text { *Justice* }\end{array}$ & $\begin{array}{l}\text { Practicality } \\
\text { Creativity } \\
\text { Empathy } \\
\text { *Fit* }\end{array}$ \\
\hline
\end{tabular}

Note. Adapted from “Designerly ways of knowing,” by N. Cross, 2007, Boston: Birkhauser Verlag AG.

This study will be using a methodology from humanities research to explain human experience with a project from the Design culture. See figure 20. Participants may occasionally reference a scientific study commissioned to provide additional data. Scientific research is generally found in fields closely aligned with natural sciences such as biology, physics, or chemistry. Humanities research is most commonly aligned with fields of inquiry such as anthropology, sociology, philosophy, languages and literature, history, and performing arts and technology. Design research involves multiple disciplines and interactions between humans and their environments; common fields include design-related professions. 


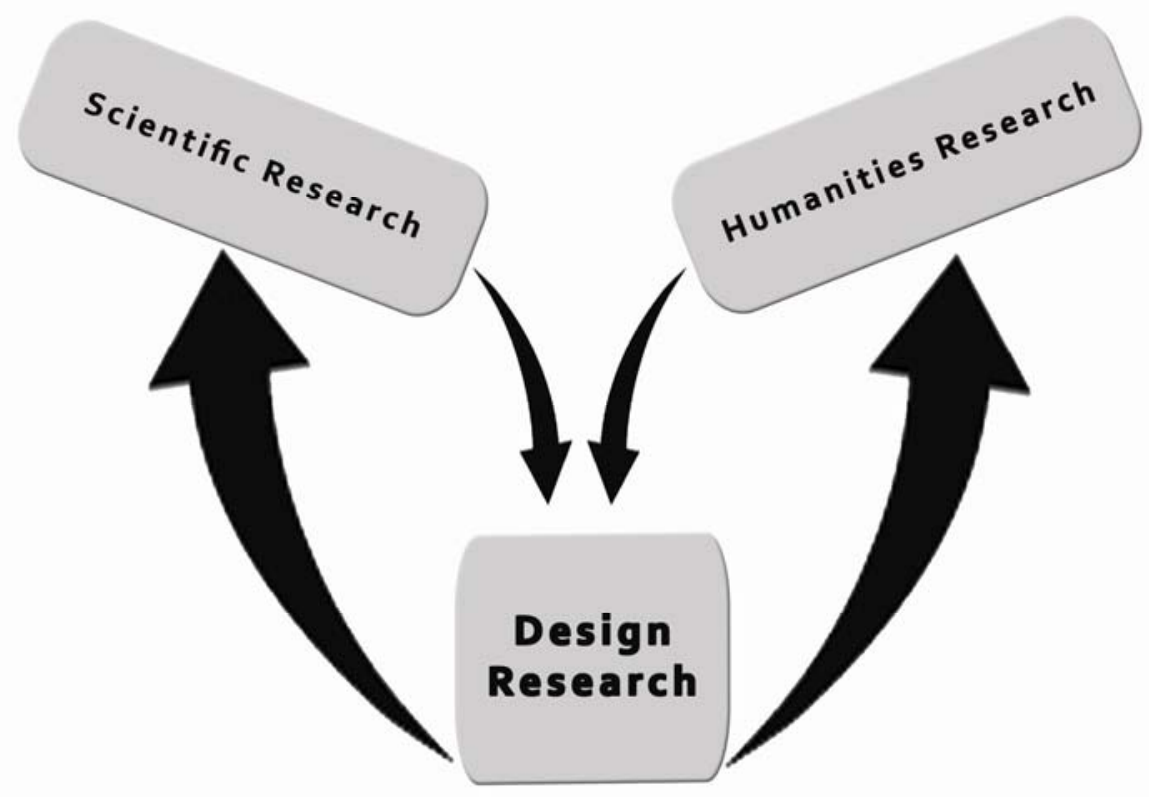

Figure 20. Design Research. Permission granted by B. McFall, 2012.

\section{Methodology: The Learning History}

The Learning History methodology was developed by Art Kleiner and George Roth (G. Roth \& Kleiner, 1995) at the Massachusetts Institute of Technology Center for Organizational Learning. The underlying theory used in the Learning History model represents a collaboration of existing fields such as system dynamics, action science, social psychology, group dynamics, and the creative process (G. L. Roth \& Senge, 1995, p. 7). Field Manual for the Learning Historian states that Learning Histories were invented as a response to the following concerns and needs:

- A "learning history" is a document, or a series of documents, possibly in audiovisual form that is disseminated in a deliberately structured manner. The document, and the dissemination, are both designed to help organizations become better aware of their own learning and change efforts.

- The learning history presents the experiences and understandings of participants, people who initiated, implemented and participated in organizational 
transformation efforts, or some collaborative learning experience, as well as nonparticipants who were affected by these efforts.

- The learning history tells the story in participants' own words, in a way that helps the rest of the organization move forward, without having to "re-invent" what a small group of learners have already discovered.

- The history includes reports of actions and results. It shows readers how learning is an approach to get what they want, and it illustrates how others have achieved the results they wanted.

- The history also includes descriptions of learning methods and techniques, the intent, tools, and design of an intervention. The history tells the story of how people learned to collectively inquire in new ways, generate insights, and then take actions which weren't thought possible before.

- Finally, the history includes descriptions of the underlying assumptions and reasoning that led to people's actions. In this way, the unwritten but powerful tacit knowledge and undiscussable myths are brought to surface, codified, and turned into a knowledge base.

- The history includes the perspectives of a variety of people (including people who did not support the effort).

- Learning history work goes beyond writing a history that documents a project. It is a critical element in_developing an organizational infrastructure to support learning.

- A learning history document becomes an artifact which is then used as a piece of directly observable data which becomes the basis for individuals, a team and an organization to share a common, collective history of what happened in the past.

- Learning history practice provides a philosophical and methodological basis for addressing issues related to how we measure and assess organizational learning. (Kleiner \& Roth, 1996)

Originally created to achieve a better understanding of administrative changes, a

Learning History was first utilized to explore large, well-known companies dealing with change (G. Roth \& Kleiner, 2000). Oil Change: Perspectives on Corporate Transformation (Kleiner \& Roth, 2000) and Car Launch: The Human Side of Managing Change (G. Roth \& Kleiner, 2000) are documents written by the founding engineers of the Learning History, Art Roth and George Kleiner.

The present study takes a different approach to the Learning History methodology; rather than examining a large Fortune 500 company, an English market town is the focus of the study. Buckingham, England, will serve as the focus for the 
Learning History, with the goal of better understanding the changes that occurred in the town between 1967 and 2011. This time period was selected because of the designation of Milton Keynes, a New Town, and its continuing expansion and growth. Key players, stakeholders, and involved citizens are among the participants who were interviewed to gain helpful insights and valuable perspectives of Buckingham’s changes.

Learning Histories are critical tools that can help organizations and individuals to better understand change that is occurring. In the article, Learning Histories: A New Tool for Turning Organization Experience into Action, Kleiner and Roth state, “in our personal lives, 'experience is often the best teacher'”(1997). A Learning History was created to help groups of people learn from other groups’ experiences; a “Learning History” is told by the people who directly took part in a critical organizational study (G. Roth \& Kleiner, 2000). In a time when changes continue to occur, it is a tool that allows others to learn from both the mistakes and good choices made by organizations and individuals. Therefore, we might avoid repeating mistakes that have been made by tailoring the intelligent decisions made by these individuals to our own personal projects and companies (Kleiner \& Roth, 1997). “As a response to the dilemma of traditional measurement, assessment, and evaluation approaches for capturing, reflecting upon and diffusing learning initiatives,” (p. 179) Roth and Kleiner hope the finished document will encourage the following:

- Stronger communication among organizations and individuals

- Increasing systems thinking

- Deeper collaboration among involved parties

- Future prevention of the same mistakes in other studies with similar problems 
A New Format of Story-Telling. The Learning History methodology uses single person accounts to gather data for the study. These accounts take the form of interviews, which are described in depth later in the chapter. The research focuses on the "exploration of the way people interpret and make sense of their experiences in the worlds in which they live, and how the contexts of events and situations and the placement of these within wider social environments have impacted on constructed understandings” (Grbich, 2007, p. 8).

The story of the Learning History is told from the perspectives of the individuals experiencing the change over an extended period of time (Kleiner \& Roth, 1997). In this study, the changes in Buckingham are noted from 1967 to 2011. Each individual has a unique "voice", and tells the story of the change they are experiencing. Reading the Buckingham story, you will "hear” the key players speak from their own perspective, telling their own accounts of the story. The reader may not agree with the voices and multiple perspectives of the participants and the reader does not have to accept any particular "perspective" to the story. The reader can develop his or her own understanding as to why things happened in Buckingham the way they did and relate their understanding as to how it affects their personal experience (Kleiner \& Roth, 2000).

Quotes from relevant stakeholders and commentary by the reporting researcher are presented in The Learning History narrative in a two-column format. The twocolumn format is used to keep the researchers comments separate from the participants' perspectives. The larger column, which can include sections of documents, meeting transcripts, narratives, and excerpts, provides various perspectives as told by the participants. The smaller column presents in italics the researcher's comments on the 
participants' narrative. The participants are only identified by position or pseudonym to ensure anonymity. It is recommended that the reader begin with the larger column, reading the participants' narrative first, and then reading the researcher's commentary and other thoughts in the smaller column. See Figure 21. This form is to be easily understood by readers so that they may make personal connections with the data presented in the study; it facilitates reflection upon the data provided so that individuals and organizations may apply new understandings to their own projects (Roth, 1996). 


\section{Sidebar: Example of a learning history}

This example describes part of a pilot program at a large manufacturing company. Since the learning history has not yet been released for public distribution, all specific references to people, places, and events have been altered. Everyone mentioned is a real person; in this learning history, we referred to all of them by titles only, except for Frank Jones, who was known publicly as one of the leaders of the project, and a few other similarly prominent individuals. Note the effort to keep each manager's voice distinct in the right-hand column, and the need to make the left-hand column as thought-provoking as possible.

The learning lab created an opportunity for people on the team to begin to address deeper issues, with the team leaders involved.

And managers, having promoted a climate of openness heard directly about the impact they had on engineers.

Which required them to answer honestly...

.... and that, in turn, allowed people to speak much more truthfully about underlying issues.

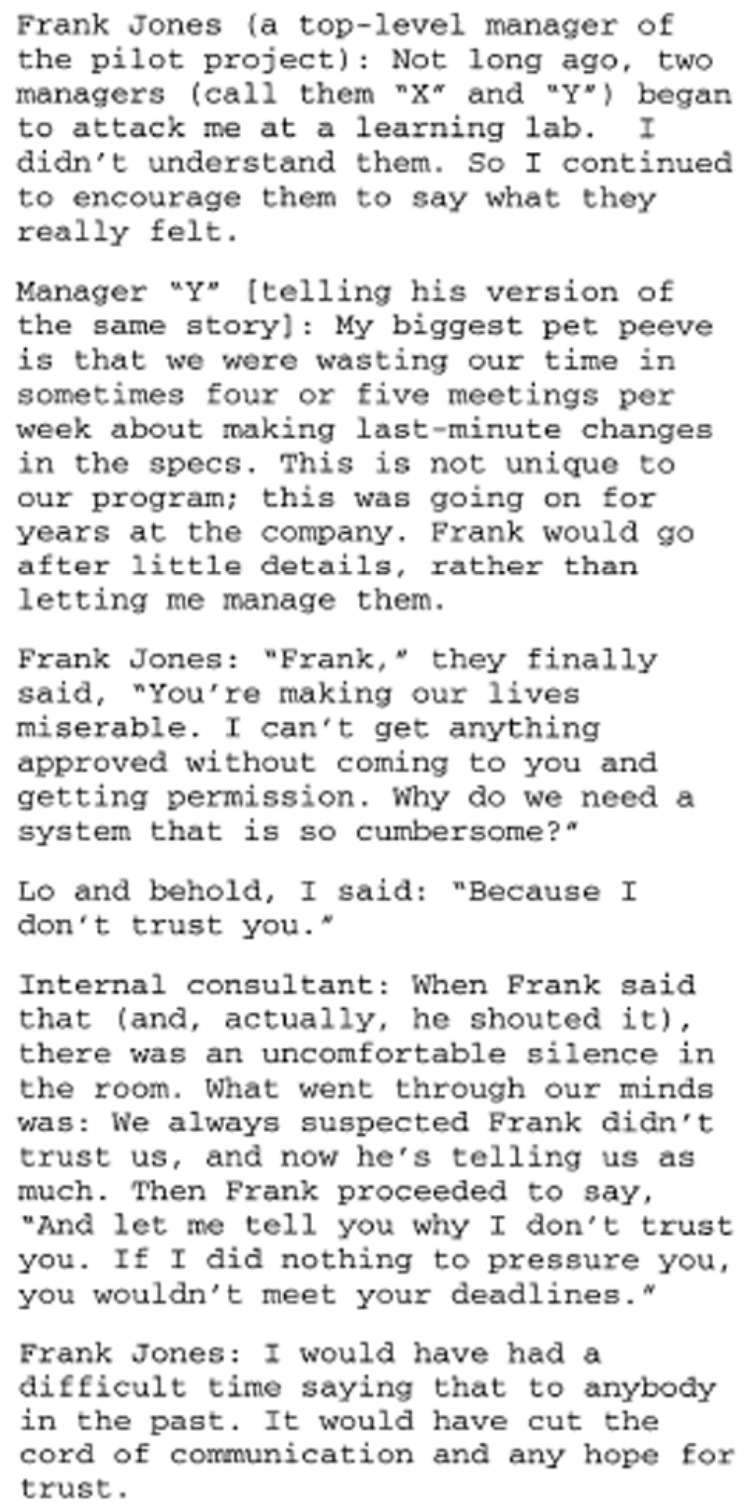

Figure 21. Example of the Learning History Format. Adapted from "Learning About Organizational Learning,” by G. Roth and A. Kleiner, 1997, Cambridge. 
Potential Benefits of a Learning History. Potential benefits of the Learning History methodology include helpful insights about community development, revitalization strategies, and planning projects and processes found in local communities. Planning processes and community development projects tend to be very involved, lengthy, and time consuming. Therefore, it is beneficial for individuals, organizations, and communities to have the opportunity to learn from other projects and processes to gain a deeper understanding about what methods are successful and which ones are not. A reader can then obtain a general idea as to how projects and processes explained in this study are successfully completed and/or implemented in the community.

\section{Credibility and Utility}

Denzin and Lincoln state, "Validity, credibility, and reliability are measured by the willingness of local stakeholders to act on the results of the research, thereby risking their welfare on the 'validity' of the outcomes meet their expectations” (2005, p. 54). As a narrative form, this research study relies on credibility and utility, rather than validity and reliability, which is commonly the standard for quantitative research (Silverman, 1998). Validity can be described as the extent to which a test measures what it claims to measure (Denzin \& Lincoln, 2005). The test must be valid in order for the results to be interpreted. In studies claiming validity, the researcher is making a claim of truth with valid knowledge; however, this knowledge is limited to like situations. With credibility, the researcher acknowledges the information provided by the contributor is truthful only from the contributor's unique perspective (Charmaz, 2005). In the present study, the participants utilized in the research were stakeholders, or had some level of expertise and familiarity with regard to the changes occurring in Buckingham, qualifying them to have 
a credible opinion in the study. Reliability refers to a consistency of a measure; if the test used in the study was considered reliable, then the same result should repeatedly occur (Denzin \& Lincoln, 2005). The information and knowledge presented in this study is not reliable, but rather it is useful, and the claim that the stakeholders made was a critique assessed by the researcher, which permits the information to be useful to the study.

Charmaz presented criteria for establishing the credibility and usefulness of a research study. The criteria for establishing credibility of the study are presented in the form of questions and include the following:

- Has the researcher archived intimate familiarity with the setting or topic?

- Are the data sufficient to merit the researcher's claims? Consider the range number, and depth of observations contained in the data.

- Has the researcher made systematic comparisons between observations and between categories?

- Do the categories cover a wide range of empirical observations?

- Are there strong logical links between the gathered data and the researcher's argument and analysis?

- Has the researcher provided enough evidence for his or her claims to allow the readers to from an independent assessment - and agree with the researcher's claims?

(Charmaz, 2005, p. 528)

The criteria for establishing usefulness of the study are presented in the form of questions and include the following:

- Does the analysis offer interpretations that people can use in their everyday worlds?

- Do the analytic categories speak to generic processes?

- Have these generic processes been examined for hidden social justice implications?

- Can the analysis spark further research in other substantive areas?

- How does the work contribute to making a better society? (Charmaz, 2005, p. 528)

During the credibility stage of the Learning History, several checks are designed to reestablish credibility of the study. After the data was transcribed, verification was 
sought from the participants that the researcher has captured their true voice (G. L. Roth \& Senge, 1995). Verification was conducted by asking participants to validate the transcribed interview. This credibility also assists in guaranteeing anonymity of the participants. The comments generated by the researcher in the Learning History commentary can be deemed credible because the involved stakeholder claimed that the information they provided is potentially useful and credible. Reflectionable knowledge also promotes credibility in the Learning History document.

"Reflectionable knowledge" often exists in the form of stories. It provides a context that makes it easy to assimilate and think about new information. It makes explicit the multiple mental models that operate in a given social setting. The knowledge is expressed at different levels of abstraction from observable data to interpretations, attributions, and generalizations in such a way that the communicator's thought processes are articulated. Reflectionable knowledge promotes further inquiry into these thought processes and into the differences between various participants’ assumptions. Having reflected, we build a store of knowledge, so that when we return to reflect next time, we are less likely to reinvent the wheel or spin our wheels. (Kleiner \& Roth, 1996)

Three additional steps in establishing credibility remain for further study. These steps include workshops, dissemination, and publication/outreach (Kleiner \& Roth, 1996). Credible workshops include select participants as well as other community stakeholders, who relive their experience and see how others’ observations compared to their own. The dissemination process allows the participants to discuss the document and 
the various stories to check for credibility. The dissemination process includes the application and transfer of learning of the data. Similar audiences, such as communities, city officials, and town organizations, can utilize the analyzed data presented in this Learning History to reflect upon and better their understanding of planning processes. The Learning History document then becomes part of the community and can be used for other applications (Kleiner \& Roth, 1996). The final step in the credibility process includes publication of the document and outreach to various communities, allowing others to benefit from this research study.

\section{Research Design}

Selecting a Potential Project. During the research design of the Learning History, I identified a potential project setting in which significant changes have taken place. Although the criteria utilized for the Learning History generally describes a business project, this study uses the Learning History criteria to understand the change that is occurring in a community setting. Roth and Senge state that criteria for selecting a Learning History project include:

- Wicked messes: from the perspective of the people in the system, they are facing difficult change issues, perhaps ones they feel are impossible to surmount; generality: business issues are generic, not idiosyncratic to one company or industry

- Significance: potential for business impact is high

- Leveragability: insights and new capabilities developed in this setting could potentially diffuse widely within the organization

- Line leadership: local line leaders with responsibility can form teams of people with "the power to take action" vis a vis the issues addressed

- Theoretical foundation: past research provides a foundation of prior theory that can be a starting point, especially in understanding systemic issues at play. (1995) 
Buckingham, England, was the town selected for this Learning History study. The same criteria used to understand change in businesses and large companies have been applied to Buckingham, England, to explore experiences with significant change prompted by uncontrollable development and population increases.

The transfer of learning allows organizations and individuals with similar interests to review the material presented in this study and apply it to challenges that are occurring in their communities. The changes occurring in Buckingham are common changes and problems that many communities and towns are facing in today's society. Some mistakes that have been made in Buckingham can be prevented in planning processes and projects that are occurring in other communities. The successful decisions with beneficial outcomes made by key players and stakeholders can also be analyzed and applied to other communities.

The community development, revitalization, and future planning efforts of the Buckingham community will provide helpful insight to other communities. Future efforts in planning and community development strategies could benefit greatly from the information provided by this Learning History. Researchers can learn from planning procedures, growth issues, and projects that are occurring in Buckingham and share the information to assist other communities seeking to retain their identity amidst change.

Designing the method. The method, or instrument, utilized for the Learning History was a questionnaire that was delivered through personal interviews with each participant. Topics discussed in the interviews consisted of personal background of the participant, sense of place, threats and changes to Buckingham, the planning process, financial planning, the future of Buckingham, and personal conclusions. 
When designing the method, biases of the researcher were also taken into consideration when asking the questions. These biases may include being an American female interested in the concepts of community development, revitalization, and ongoing growth patterns. In an attempt to remove biases, open-ended questions were asked so that the researcher would not influence the answer of the participant. Research questions are listed in Table 2.

Table 2

\section{Research Questions}

\section{Personal Background of Participant}

What is your official role in Buckingham?

Why did you become involved with the town? When?

What do you feel your responsibility is in Buckingham?

How you would you describe the role of the leaders in Buckingham?

What has your experience with the town been like?

Why do you enjoy living in Buckingham so much?

What are your experiences and/or connections with Stowe?

Are there any interesting stories you have about your involvement in Buckingham?

What has your experience been with your sense of connection to Buckingham?

\section{Sense of Place}

Describe the town in your own words.

What does it mean to be a market town?

What does Buckingham feel like, look like, how does it operate?

How is Buckingham still remaining a market town or not remaining a market town? How is Buckingham evolving?

What is it about Buckingham that is encourages members of the town to fight for its identity?

Do you consider Stowe to be a part of your identity with the town? 
How would you describe the relationship between Stowe and Buckingham?

\section{Threats and Changes to Buckingham}

What problems have challenged Buckingham in the past?

When did Buckingham noticeably begin to change?

What threats/problems are currently facing Buckingham?

What are some internal threats to Buckingham: i.e., loss, growth, and change of population, small businesses closing?

What are some external threats to Buckingham: i.e., Milton Keynes, railways, and roads, government pressures?

What organizations are/were active in stopping these threats?

\section{The Planning Process}

What research was involved in the planning for the future of Buckingham?

What do you think is the relationship between the residents and Buckingham?

How would you characterize the residents' general feeling about their town?

How was the public engaged in planning?

How do the townspeople feel about their town?

Why do you think the townspeople feel that way?

How is the town dealing with infrastructure to support its population?

\section{Financial Planning}

Are any projects currently being funded?

What are the available funding sources?

How is funding delegated to towns throughout the Buckinghamshire County?

How does Buckingham raise money for projects?

\section{The Future of Buckingham}

How is Buckingham responding to change?

Are any plans/strategies being implemented in Buckingham?

Where do you see the town going in the future?

What is a reasonable goal for the town? 
What would you like to see happen to Buckingham in the future?

What has been the community's role in planning for the future of Buckingham?

\section{Personal Conclusions}

Why do you think there is such strong community engagement in Buckingham?

How do you think the community perceives Buckingham?

What have you learned from being a part of this town?

Selecting the interviewees. Several parties were involved with the current changes in the town of Buckingham. Key stakeholders, elected officials, concerned residents, and numerous organizations were all significant players in the leadership of the town. Each of these parties or individuals was reporting to a different leader and each was working for a different organization (Roth and Senge, 1995). This variety in individuals' backgrounds, personal interests, and organizations created tension and conflicts among projects, funding allotments, and decision-making (G. Roth \& Kleiner, 2000, p. xii). This clash will help explain the process of changes in Buckingham.

A list of important entities, organizations, and key stakeholders in Buckingham was produced before conducting the research in the market town. Participants were determined once I was in Buckingham, England, and introduced to involved citizens and stakeholders. A convenience sample was selected for this research study. Table 3 illustrates the diversity of the interviewees selected for this research study. 
Table 3

Diversity of Interviewees

\title{
Organizations and individuals who participated in the study
}

\author{
Members of Town Council \\ Elected Officials \\ Buckingham Mayors \\ Members of the Buckingham Society \\ Members of Buckingham Historical Societies \\ Stowe School, Stowe House, and National Trust Employees \\ University of Buckingham Professors \\ Buckingham Architects \\ Buckingham Planners \\ Life-long residents of Buckingham
}

IRB Protocol. The West Virginia University Office of Research Compliance approved the research design utilized for this study under the IRB Protocol. See Appendix A. Challenges arose with the approval of the research design regarding the anonymity of the interviewees. Each participant would not be identified by name, but rather by pseudonym; therefore, it would be extremely challenging for the reader to identify specific participants in the research study.

Risks with social reputation and anonymity may arise if a participant's “voice” may be identifiable. Individuals may read the final document and be able to correlate the speaker to the report based upon their title or voice of the quotes from the interview. Therefore, if a participant has a particular manner of speaking, or if a reader could 
identify specific projects or committees of which a participant was a part, a participant's

"voice" may be identifiable. I attempted to prevent the participants "voice” from becoming recognizable in the Learning History analysis in Chapter Four. Continuing review was needed from the West Virginia University Office of Research Compliance for the IRB protocol to extend the approval of the research study. See Appendix B.

\section{Executing the Research Design}

Data Collection. Data collection for this study occurred in Buckingham, England, from January to April of 2011. During that time, I was able to collect documents about the town and research planning procedures, projects, and various changes that have occurred in Buckingham. Exploring the market town of Buckingham allowed me to make countless observations about the town's unique characteristics as well as to recognize some noticeable problems and physical challenges facing the town. Conversations were held with elected town officials, life-long residents, Buckingham shopkeepers, and other citizens and involved stakeholders. I regularly attended Buckingham Town Council meetings and Buckingham Planning Committee meetings to gain a better understanding of the challenges on hand.

Interview Process. Through observations, explorations, and meaningful conversations, I was able to identify key stakeholders and involved citizens who might be potential participants to interview in my Learning History study. To contact potential participants, I sent an email or letter explaining the intended study and how the information from the study would be used. See the Appendix C for the cover letter. Participants were then able to make an informed decision about whether to participate in the research or decline the interview. If the participant chose to consent, then an 
informed consent form, required by the IRB Protocol, was reviewed and signed by the participant before the interview was conducted. A copy of the informed consent form was given to the participant, and I kept the signed copy for my records in a concealed location. See the consent form in Appendix D.

A total of 12 participants consented to the research study and completed a full interview. It should be noted that additional individuals were identified as key stakeholders and involved citizens in Buckingham. Those individuals were also contacted by email or letter to participate in the study, but declined to be involved. Once the identified participants chose to consent to the study, I established a date and time for an interview and met with each interviewee individually. Participants were given the option to meet at a place of their choosing so that they would feel most comfortable in a familiar setting during the interview. The interviews were voice recorded in a private location and notes were taken on a variety of key topics during the interview.

Interviews conducted with the participants were structured around the research questions listed in Table 2. The question set discussed in each interview may have varied slightly due to differences in conversations with each participant. For example, if a participant answered a question yet to be asked while discussing another question, then I took that into consideration, rather than asking the participant to reiterate an answer to a question.

\section{Post Data Collection}

Transcribing the data. I remained in contact with each participant after the period of data collection, reassuring the participant about the anonymity of the 
interviewee. After conducting the interview with the participant, I transcribed each of the interviews with the assistance of a computer program.

Credibility of the data. Communicating through email, I sent a copy of the transcribed interview to each participant prior to analyzing the data. I then asked each participant to verify his or her transcribed interview. Of the 12 total interviews transcribed, I received consent from 11 of the participants: one participant did not provide consent for use of the transcribed interview. See Table 4. Participants had the opportunity to add or remove comments from their personal interviews. The consent from participants for use of their interviews in the research study increased the credibility of the data. Distillation or establishing themes occurred after the data had been deemed properly credible in the analysis phase of the research (Denzin \& Lincoln, 2005). The credible data was then analyzed, which is illustrated in Chapter Four, for the Learning History commentary in the two-column format.

Table 4

Interviewee Information

\begin{tabular}{lll}
\hline Participant & Date Interviewed & Date Consent \\
\hline Interviewee \#1 & April 7, 2011 & January 26, 2012 \\
Interviewee \#2 & April 8, 2011 & January 31, 2012 \\
Interviewee \#3 & March 30, 2011 & February 1, 2012 \\
Interviewee \#4 & April 5, 2011 & January 23, 2012 \\
Interviewee \#5 & April 6, 2011 & January16, 2012 \\
Interviewee \#6 & March 30, 201 & January 27, 2012 \\
Interviewee \#7 & April 7, 2011 & January 27, 2012 \\
Interviewee \#8 & March 24, 2011 & January 20, 2012 \\
Interviewee \#9 & March 29, 2011 & January 25, 2012 \\
Interviewee \#10 & April 5, 2011 & February 16, 2012 \\
Interviewee \#11 & April 6, 2011 & February 15, 2012 \\
\hline
\end{tabular}


Securing the data. After the interview process, the data collected from the participant on the voice recorder was properly stored in a safe location. After transferring the voice-recorded data to a computer, the files on the voice recorder were deleted. The transcribed interview files saved on a computer were password protected and the transcribed interview files in hard copy format were securely kept in a locked file cabinet. Once the research study is complete, the data will be destroyed.

Learning History narrative. I first began organizing the data into thematic sections from the participants' interviews. When establishing themes, Tedlock presents questions researchers should ask themselves,

Which issue questions bring out our concerns? Which issues seek our compelling uniquenesses? Which issues help reveal merits and shortcomings? Which issues facilitate the planning and activities of inquiry? What can be learned here that a reader needs to know? (Tedlock, 2005, pp. 448-449)

Using the questions illustrated by Tedlock to establish themes, I carefully evaluated the raw data from the interview process in order to establish key themes and recognize similarities in the interviews. I recognized similar patterns that were repeating in the interview data and each emerging theme created a different section in the research. My commentary in the left hand column is to be recognized as "objectable" comments and the right hand column, which tells the story from the participants' perspectives, is to be seen as “experiential” (G. Roth, 1996, p. 20).

Findings. The findings from the Learning History narrative will be filtered with the instrument of the SWOT Analysis matrix (Strengths, Weaknesses, Opportunities, and Threats) ("SWOT Analysis Template," 2011). SWOT Analysis is a strategic planning 
method used to identify internal strengths and weaknesses and external opportunities and threats for an organization ("SWOT Analysis Template," 2011).

\section{Summary}

The Learning History offers both a methodology for gathering and a format for presenting individual experience data for further consideration. This study applies that methodology to gather and report the experience of stakeholders in the market town of Buckingham, England, as they experienced, initiated, and responded to change over the past 44 years. 


\section{CHAPTER IV}

\section{A Learning History}

\section{Overview of the Participants}

It is a pleasure to present Buckingham through its residents’ own words. A convenience sample representing a cross section of stakeholders involved with the planning and growth issues occurring in Buckingham, England, contributed to the following narrative. Their diversity extends to the amount of time they have lived in Buckingham, their personal roles in the community, and their interest in Buckingham.

Some participants are life-long residents of Buckingham and others have moved to the town more recently.
\#1: The town is changed quite considerably since I was a boy. I have lived in and out of Buckingham for about 75 years now. Thirtyfive years ago I got elected onto the local authority and I have been involved with local government. I am still involved with the District. Now I am involved with the Town Council, District Council, and I'm a County Councilor.

\#2: My role in Buckingham is that of a retailer /shopkeeper. I have lived here for 25 years. We moved here when our daughter was born.

\#3: I have lived in the town for about 20-25 years. I am a member of the Buckingham Society. I also have a national role with the Association of Small Historic Towns of the United Kingdom, and that is an overarching body that looks out for small towns like Buckingham and represents our interests.

\#4: I moved here about 30 years ago.

Some participants have moved to Buckingham in more recent years, but became involved with the town very quickly.
\#5: I have lived in the town for seven years. I'm on the Town Council, which is the elected post by the residents of half of Buckingham. 
A diverse group of participants were selected for this research study to present numerous views on changes occurring in Buckingham.
\#6: I have lived here [in Buckingham] for over 30 years. I'm not a native.

\#7: I live in Buckingham and I am a professor at the university.

\#8: I'm the community engagement officer [for a local organization]. I grew up in Milton Keynes and recently moved back to the area.

\#9: I teach school at Stowe [School], and I live in Buckingham.

\#10: I was born and bred in the town, so that has been 60 -odd years. I am a member of the Buckingham Society.

\#11: I came back to this area about eight years ago and relocated here in Buckingham. I am a charged architect and I practice as an architect.

The participants enjoy living in Buckingham for a variety of reasons. The character of the town, size, historical cultural, availability of retail shops, and walkability to the town center are among the reasons why the participants chose to live in Buckingham.

\#1: It's [Buckingham] nice and relaxed. You are not overpowered with authority. You can do your own thing and nobody will interfere. Sometimes it can be very difficult, but most of the time it is pretty easygoing.

\#3: Because of its history. Perhaps it's a

Residents enjoy the slower pace of life that Buckingham offers. slightly slower pace of life. Most of what you need is here, in terms of culture. Stowe School and the University are here. We have a wide range of societal groups. There aren't many things you can't do here in Buckingham with a town of 12,000 . It [Buckingham] has a range of activities. It's out in the country. You don't have the roaring traffic and pollution of a large town here in Buckingham. 
Why is intimacy of a place or town so highly regarded?

Walkability to shops, restaurants, and activities is a key element residents desire when moving to a community.
Residents seek a community with abundant shopping in the town center without having to drive to different locations outside of a community.
\#4: I suppose its familiarity. It's very nice to walk down the street and be recognized. It's small and it is an intimate town. It really is. I think one of the characteristics of Buckingham is its intimacy. Streets are quite narrow, houses are quite narrow, there are one or two grand houses, of course, but on the whole, I think it's characterized by its intimacy that you perhaps associate with a rural market town.

\#5: It's very different to many other places I have lived. I have lived in three or four other places and when I first came to Buckingham by accident just for the day, I was struck at first. It's a nice, quiet, comfortable sort of place, with polite, laid-back people, and that's what encouraged me to move here.

\#9: It's useful being very close where we are and walking. We live quite close to the river, so it's got a beautiful outlook over the bank with the tall grass, fields, river, and trees. In the winter, we can see the spire of Buckingham Parish Church and even the gilded swan on top of the Old Town Hall, which is just visible across the top, so it's a lovely setting in that respect.

\#10: It's it where we were brought up. It is our home. It is a friendly place. A lot of newcomers that move here say how friendly it is.

\#11: I wanted a town that I could walk into town. I didn't want to drive in a rural town. I wanted to be able to do my daily shopping without having to drive all the time. I wanted the town to be of significant size with a reasonable amount of amenities so that I could get to know people, but yet you wouldn't know everyone. We thought Buckingham was a great compromise to having the facilities that you need: bank, pubs, restaurants, and great schools as well. 
Each person who became involved with Buckingham through Town Council, various societies, or simply as a concerned citizen, had a different reason for doing so. Individuals were involved because of their interest in preserving the rich history and culture of the town, the planning processes that are occurring due to current and past threats, and also because Buckingham is "home” to so many individuals and they are concerned for the well-being of the community. Individuals' involvement in Buckingham has included roles with the Traders' Association, the Buckingham Plan, Town Council, the Vision and Design Statement, and the Buckingham Society.

Ultimately, all of these organizations share a common goal, which is for Buckingham to thrive as a prosperous market town.

Buckingham is considered "home" by several individuals. Therefore, residents involve themselves with the community because they have a deep rooted connection to the town.

Everyone's reason for becoming involved with Buckingham is different, but a common goal for the town may be found throughout all the organizations and involved parties.
\#1: Buckingham has always been regarded my hometown. That always will be the case. This is where I went to school and Buckingham was our heritage and what we lived and worked for.

\#2: Since owning a shop, I have become involved with the other town Traders' and we have set up our local Traders' Association. We meet monthly and plan various shopping events and special days in the hope of bringing more people into the town.

\#4: Yes, I suppose in a way I do [have a responsibility to Buckingham]. I live here and you want to help the town and the community. The Buckingham Society is a civic society, one of about 900 civic societies in the country, and I am involved with that society. The civic society movement is an environmental watchdog; to celebrate the good and try and build on what is good and keep the vitality of the place alive with a distinctive character. 
Individuals understand that by becoming involved with the town activities they have the ability to make a difference in the community.
\#10: I have been involved with the Buckingham Society, a civic society, since the 1970's. My main interest is in planning, but also in the preservation of the town; trying to make what is new fit in with the old. I'm not saying "no" development, but we are trying to get the development that Buckingham needs.

\#11: I can make a difference for the county I live and work in; or attempt to make a difference. It's too easy to be on the sidelines, writing to the paper or shouting to a councillor, but if you want to truly make a difference and be a part of the difference, you have to be in the process.

Residents feel that they have a certain level of responsibility to the town because of their involvement with activities, projects, and processes in Buckingham. Some individuals feel their responsibility is to protect Buckingham, preserving its historical cultural; some are elected into office, therefore having a responsibility to the citizens who elected them; others feel they are responsible for maintaining the size of Buckingham due to forced growth and construction of new housing developments. Whatever the reason, individuals feel they have a responsibility to Buckingham and it encourages them to have a vested interest and become more involved with the town.

\#1: Buckingham has always been regarded my hometown. Buckingham has changed dramatically. There wasn't all the housing development here before. There was none of these housing developments here until about 25 years ago. I mean it is ridiculous, really. It has all grown over the last 40 years.

Some individuals feel they have a historical responsibility to protect Buckingham's character.
\#3: My responsibility is to make Buckingham protect what is worth protecting, but enhance it at the same time. 
Residents who have lived in Buckingham for some length of time have learned to respect the community.

Elected officials believe they have a responsibility to the public.

Stowe employees believe they have a responsibility to encourage Buckingham citizens to feel that Stowe is a part of their heritage.
\#4: Well I suppose as I said earlier that familiarity and the friendships that it creates. Responsibility. I think the fact that they have been here a long time has meant that there has been a growth of love for the community that they live in and respect. And if you are not moving on in five or six years, you need to look up to your place just as you might look after your house. If you are renting a house, you won't look after it the same ways that living there that you would over a period.

\#5: Essentially representing those that elected me into post, but the Mayor role was an additional tier on it, which is kind of an ambassadorial role, if you like. They used to call the Mayor the leading citizen. Certainly, to represent the town at various functions and around the area would be my responsibility.

\#8: I think every corporate entity has a responsibility to be relevant to the community and to give something back. I don't think this is especially my or Stowe's responsibility to Buckingham per se, but certainly towards the local community, we have a responsibility to make them feel that Stowe is a part of their shared heritage, and that it is a shared open space that is a part of them and something that is inherently meaningful and worthwhile.

Ultimately, heritage belongs to all of us and that is certainly what National Trust is all about. It's about conserving it for everyone, places for everyone.

\#9: Well it's a variety of things. That's an interesting choice of words... responsibility. One has a certain amount of involvement and interest in what's going on, and you know people around that live in developments and things like that, which is also true up here [at Stowe]. 


\section{Searching for the Identity of a Market Town}

Buckingham, England, is located in the northern part of Buckinghamshire

County, just 70 miles outside of greater London. Buckingham acts as a regional hub for the surrounding villages and towns providing shopping, retail, groceries, quality schools, and leisure activities. Milton Keynes and Aylesbury Vale are two larger cities located within close proximity to Buckingham, each about fifteen miles away. Buckingham's rural location has proved to be both helpful in keeping the town a self-sustaining market town and harmful in that residents desire a larger selection of shopping, retail, and leisure activities.

Lack of an efficient transport system (bus and rail) has had major effects on Buckingham and on encouraging residents from other local villages to visit the town.
The self-sustaining nature of the town helped Buckingham remain a market town much longer than other market towns throughout England.

Does Buckingham have enough facilities to keep it self-sustaining with the current population increase?
\#1: I think [the location] is beneficial to the town. Buckingham is always accommodating people into the town. It's better now than it was when I was a boy. We haven't got a good transport system. I wish we did, but we don't. Generally speaking, the people made the best of what of what we have. If there is a chance we will improve it, then we will. There are people in Buckingham who are looking for opportunities to do that.

\#6: We are quite isolated here. The nearest towns are so far away, that we are quite isolated. It's 20 miles to a town of any size. We have to be independent because there isn't anybody out there rooting for us.

\#10: We remained a market town a lot later than other places because we are rural. I do believe we are also a prosperous, wealthy area. We are supposed to be one of the wealthiest areas in England, but I can't see that.

11: I believe people like the idea of living in a small town with enough facilities to keep them going, but living close to a big city that 
provides all the things they might need throughout the year also poses problems.

In this study, "sense of place" refers to the identity of the town and how a resident perceives that identity. Sense of place will often hold a different meaning to each individual and, likewise, individuals can interpret their sense of place in regard to Buckingham in various ways. During the interview, participants were asked to describe the town in their own words. The descriptions varied based on each participant's view of Buckingham.

Preserving the cultural and historical heritage of the town is a common aspiration for residents of Buckingham.
\#1: People are always saying that Buckingham is sleepy. It isn't sleepy, but it is where it wants to be.

\#3: I would say that it is an ancient $(1,000$ years) market town surrounded by the River Ouse and set in rural countryside. It has always stayed a small town within a country setting, which appeals to me. I think with 12,000 people you can still have a range of activities going on, university, etc. There is a vibrant, cultural life, but we are still small enough that you can feel you are a part of the town and you know most of the people around and they know you.

\#5: It's a laid-back market town that preserves its historical background, which goes back over a thousand years, which is nevertheless looking into the future, and it is not totally against change.

\#6: It's a market town. It's a regional hub for the surrounding villages. Yes, we have facilities that the villages no longer have. Some don't even have a pub, post office, or shops. So, the people will come here. Equally, Buckingham is the sort of place where you can go down the street and you may not know the person's name, but you have been seeing them around for years. 
Residents enjoy knowing several people in the town and the chance of running into someone on the street. Familiarity is a commonly shared feeling by Buckingham residents.
Residents are aware of the pressures that could alter the character of the market town.
Perhaps you have seen them around at the school gate or from somewhere else. Here, you will know so many people. I cannot walk down the street and not run into someone I know, or someone I might not know, but I can recognize the face. People do not pass you by and not say hello. Complete strangers will pass you by and say, "Hello. What a lovely day!"

\#8: I think it has a very traditional High Street (also referred to as Main Street in America), but like all traditional High Streets, it will have facing pressures certainly from commercial corporate entities, and for example, the big Tesco Supermarket on the doorstep and you've got Milton Keynes and Brackley, which are commercial shopping designations. I think it inherently has competition. However, it will always have this quaint heritage and relevance to people, so if people are after different things, then I think that Buckingham will continue to be relevant.

\#9: Charming, old, historic, market town is how I would describe the town.

\#10: It's a traditional market town. I like to stick with that word traditional. We do still have a market. Now the market is mostly fruit and vegetables. Previously it was a cattle market and a farmer's market.

Buckingham has several unique characteristics that set it apart from other market towns and communities. In recent decades, Buckingham has become a wealthier community, supporting skilled employees at educational institutions in Buckingham such as Stowe School, the Grammar School, and The University of Buckingham. These educated individuals tend to invest a deeper interest in their community which increases the amount of community engagement in Buckingham. A variety of societies and 
organizations are present in Buckingham, encouraging residents to become involved and to find an issue or project that interests them.

The wealth in the area has attracted educated individuals to Buckingham who are more willing to become involved.

Stowe School, the University of Buckingham, and the Latin Grammar School bring educated people to the area.
\#3: In the country, I suppose there are about 400 similar market towns. Most of the people in the area know that Buckinghamshire is a very wealthy area, and therefore people are more willing to become involved in the community. If you were in an industrial area, you may not find the same level of interest as here in Buckingham. There is so much to do, and some people don't get involved. I think we have an atypical population here.

The people are more educated, and more interested in terms of identifying with the environment, good public schools, good Grammar Schools, the university. There is an attitude that was having always been an independent town. Why should we be bossed around? Sheer bloody mindedness I think sustains the community. Organization in that one or two people decided together that the fight was worth fighting and they would spend 10,20 , or 30 years of their time actually engaging in planning exercises and keeping up the market. They brought a certain type of life to Buckingham and they want that to sustain. They do that by getting other people to believe like they do.

\#5: That's one of the remarkable things about the town. There are over a hundred volunteer charity groups, for example; there are somewhere in the region of 30 community groups running various things - and this is a town with 13,000 or 14,000 people living in it. So, I don't know. One of the big issues that I've got is getting people involved in this place [Old Gaol]. There is just too much going on. Some individuals just stretch themselves that far. I have no explanation for you; it's just one of those strange things that there is a lot happening here. 
With a variety of organizations and societies established in Buckingham, it is easy for residents to get involved.

Buckingham has a unique community feel, welcoming residents and visitors to the town.
\#10: A lot of residents are involved, but with 200 societies, you tend to find the real people that are interested and involved with several organizations.

Well, it's just the way the town is. It's a friendly place. We do have quite a strong sense of place here in Buckingham. It's probably become more pronounced because the Town Council has gradually increased its profile and has been more outward looking. I think also, and this may come out wrong, but we have never had immigrants here. We have always been a stable population. The only immigrants that we have here in town are from the university and they are educated. Possibly, we have had a stable population and a stable employment bridge, and especially since we have had the university.

\#11: Buckingham has a nice community feel to it. On market days, there is a great sense of feeling like you belong to a town. The warmth of welcome coming to this town for Town Council, church, and residents has been very overwhelming. People who put efforts into the town, it is appreciated by the residents.

The traditional definition of a market town states "trading at a fixed time and place” (Chamberlin, 1985, p. 8). That definition has changed with time as communities are evolving with contemporary English traditions and ways of life. Participants were asked to describe what it means to be a market town. The traditional definition still applies for most individuals, which is holding a regular market once a week, but for others, a market town also possesses unique characteristics such as sense of scale, shops and restaurants, historical and cultural characteristics, and support from other local villages and towns. 
The traditional definition of a market town has been adapted to fit the needs of contemporary society.

Buckingham's sense of scale and market space makes it unique and different from other markets.
A market town is well connected to other places and supported by residents from other communities.
\#3: Market towns are about every 6-9 miles apart. It is a town where you could walk to in about 3 hours and do your daily shopping on market day. It was where the commerce was taking place. Now, of course, it is rather a memorial to a market town. The market itself and its vendors are getting fewer and fewer.

\#9: I think it's a focal point. It's quite interesting to look at a town and compare it with other focal points. In terms of population, I don't quite know how it [Buckingham] would compare with Winslow, but it seems to be configured, rather than more attractively, particularly with the open market so that you got a wider space in the center. Brackley is quite interesting. It's got a much wider space, but it's so wide that it becomes very impersonal, and it's also too long. Buckingham, being so concentrated, means so you go in and you're walking, you are very likely to meet someone that you know, and perhaps you might meet a lot of people that you know. It's only a short little circuit to go around. So, from that point of view, it works very well and people have gotten to know each other.

\#11: With a market town, it is about a sense of scale. It is not trying to be a city. It's not a village. It is in between. It's got a certain self containness to it that one could live and work and not leave the town for quite some time if you didn't need to, but it's also equally as well connected to other places so you are not isolated. It relies on people coming in from the surrounding areas to shop at the market and other shops.

Buckingham fills the traditional definition of a market town and holds a regular market twice a week. The market provides fresh produce, flowers, locally made products, and vintage items. Buckingham also has several characteristics of a market town such as the small sense of scale, specialty shops, historical architecture, and a town 
square. Buckingham residents are aware that these unique characteristics are being

threatened by Milton Keynes, big-box stores, forced growth, and lack of support from the community. Participants were asked to reflect upon Buckingham’s status as a market

town.

Some individuals do not want the town to change and would like it to continue the way it is.

Individuals feel that Buckingham is fulfilling the market town concept because it holds a regular market.

Does holding a regular market constitute a town to be titled a market town?
\#1: I think it will remain a market town and nobody will change that. There will be people like me who won't let it be changed because it would destroy Buckingham if we did. If we took the market town aspect away from Buckingham, it would be too much too soon. It will eventually change over the years, but who knows. I won't be around to see that.

\#3: I think people still think Buckingham is a market town. Most local people have lived here for a long time or who were born here regard the centre of Buckingham where the market is held twice a week and the sort of things that happens throughout the year, as very traditional activities and I think they would very much miss those things not happening. We must fight for these activities.

\#4: With the concept of a market town, I suspect that Buckingham fulfills that concept. It has a market square, which has a market twice a week, but really that is when people walked to the market town to do all their shopping (whether it is mending their shoes, or fixing their cavities); the reality is that now they will go to the out-of-town stores, and I'm afraid rather Americanized, an adoption that we should have never taken on, and do all their shopping under one roof.

\#5: By definition, if you hold a market, you are a market town.

\#6: Buckingham is still a market town. We have the twice-weekly street market. We have the flea market on Saturdays. We did 
Several individuals believe that Buckingham fits the traditional definition of a market town by holding a market and having unique characteristics common to market towns, but they are fearful that outside pressures may cause the market to cease. have a farmers' market, but that has gone downhill a bit. Farmers' market stalls are finding it hard to keep going and they have to go to the bigger markets to get their revenues. Our remaining farmers' market stalls are now incorporated into the street markets. I would say three or four times a year we hire in an international market with Italian, French, German things and give something new to people. There is always something going on in the town. Some of our festivals bring international quality musicians.

\#7: It depends on what definition you take of market town. My understanding of a market town is that it has a market, which I think is important, and it has reasonable range of facilities. You can't get everything that you want, but you can get most of the things. Of course, if you want more of the specialized things, then you will have to go further afield. Most day-to-day things you can get here. I think there must be at least some clear physical center of a market. It needs to have some iconic buildings and it needs to have a pretty strong sense of individual identity. Clearly there are things which may threaten achieving those criteria, in the case of Buckingham.

\#9: Market towns in the purer sense disappeared about 150 years ago because although there was an area called the cattle market, it doesn't actually sell cattle once a week. Although they have something called the market, it's not in a sense the old traditional market where people came from the outside bringing their goods, but it's what people these days may call a market or some criticisms that there are not as many stores as there should be. I think that probably from the view of most people, it's less the market on particular days, Tuesdays and Saturdays, although that has its attractions. There's more the feel of it with its smaller shops and the individual shops rather than the big chain 
Buckingham possesses the characteristics of a market town, such as a center for shopping, entertainment, and tourism.

Some individuals believe Buckingham will continue to be a market town, even if the market ceases, because it holds the characteristics of a traditional market town. shops. It could never have chain shops because it's not large enough, but I think people actually want them. They prefer to have their own approach.

\#10: Yes, because it is a local centre for shopping, specialized shops, entertainment, and for tourism.

\#11: It's challenging to maintain the market with the issues occurring. The concept of a market town won't go away, but being maintained and sustainability of a market town is the challenge. I suppose there is concern to keep the obviousness of the market, but I don't think it will stop being a market town if the market diminishes because it has all the other characteristics of a market town. The Town Council works very hard to keep the market going, but markets up and down the country are finding it very difficult to survive.

Buckingham has struggled to keep its identity of a quaint and charming market town for the past 40 years due to pressures such as forced growth, population increases, and new housing developments, among others. Buckingham is unique in that it has a large group of dedicated individuals willing to fight for the identity of the town. In comparison with other English communities its size, there is an increased level of encouragement for members of the community to fight for Buckingham's identity.

Why does Buckingham have a large number of dedicated individuals willing to fight for the identity of the town?
\#1: I think when people move into the town, they become a part of Buckingham and that's their attitude. I know it sounds terrible, really, but Buckingham grows on you. The longer you stay here, the more involved you become, and Buckingham becomes a part of your life. I know the years I was away during the service, I never thought I would come back to live here, but I did. There is something in the town that keeps you here [Buckingham]. I think it's the way of life. 
Loyal patrons of local businesses, shops, and restaurants are encouraging community members to fight for Buckingham's identity.
It's a personal choice for individuals to move to Buckingham; therefore, residents are more committed to improving their community and becoming involved.

Living in the same community for an extended period of time generates a sense of responsibility to the town.
It's not slow; it just jogs along at its own pace. Sometimes you just want it to get on with it, but that's not Buckingham.

\#2: Well, I think that the people of town do care about what's here and do want the High Street to survive. We have lots of very loyal customers who know that if they don't use the town's shops, then they will lose them. Other small towns nearby have lost their local shops and their High Streets (Main Streets), then start to look very sad and empty, and we do not want that to happen in Buckingham.

\#3: Because, I suppose, it's a very old town and a very old country. People value heritage more in some sectors than others. They want to make sure the old isn't spoiled. Trying to ensure things fit in rather than destroy them. The university helps. It is the only private university in the country. Obviously, let's face it; university people are more highly educated. They think and care more about the environment. Having a Grammar School helps Buckingham as well. Only selected students can attend the school. Because we have a Grammar School, people will send their children here, the cream of the cream, and sometimes families will move here to send their children to the school. We are getting the people that are likely to take an interest [in the town]. We are rather exclusive in the people that are thinking and working towards a better Buckingham.

\#4: I think that living in a place for a long time does generate a sense of responsibility and a sense of wanting to be a part of that community and to help to progress towards the different generations.

\#5: For the same reasons that I have expressed about my own enjoyment about the town. There is a lot of commonality of thought that it [Buckingham] is a pleasant place to live, and we don't want to become 
part of Milton Keynes or part of greater Aylesbury or anything like that. We want to retain our identity. We're fairly sensible. We do provide core or hub for the local villages around the north of the Vale and we are glad to do so. We do need to preserve our historical roots, if you like.

Every person has an opinion about how things should be in Buckingham. Should leaders be the only one who makes those decisions?
A common thought among residents is that several individuals living in Buckingham have lived in the town for an extended period of time. The retention rate in Buckingham is higher than other towns of a similar size. Therefore, these individuals who choose to live in Buckingham are more encouraged to be involved.
Every different person I speak to in town has a different opinion on how things are or how they should be. We are very fortunate that there are a lot of engaging people in Buckingham.

\#6: Because people are friendly to each other, people will think, "Maybe I could help with that organization.” If you haven't got the friendliness in a town, then people won't think like that. They think, "Why should I go and help with them?" Big cities don't have what Buckingham has because they don't have small enough units. Here, you have to have us, and if you like us, then you will stick around.

\#9: I suspect it's self-perpetuation in the sense that the sort of people who choose to live in that town do so because they like that environment, and therefore they see people changing it too much, they are going to feel upset and restrict it.

\#10: Because there are a lot of people that have lived here for some time. It is a fairly stable part of the nation because people that come here like it for what they see.

\#11: Over half of the current population of Buckingham has moved to the town since the 1975-1980 when the new housing estates were constructed. Those individuals made a conscious decision to move to a small town, rather than move to Milton Keynes or Aylesbury Vale. 
Stowe School and Stowe House are located two miles away from Buckingham.

Historically, the relationship between the Stowe Estate and Buckingham was a very close one; the town depended on Stowe for a place of employment, and Stowe relied on the town for employees, goods and services. Views of the participants differed as to whether Stowe is a part of the identity of the town.

Why do people in Buckingham show little acknowledgement for Stowe?
Some residents in Buckingham utilize the facilities provided by Stowe, such as the Landscape Gardens, swimming pool, lacrosse fields, etc.
\#1: I don't think that Stowe was ever that connected to Buckingham, but because the National Trust has taken over Stowe, I think people will begin to use Buckingham more. I just wish the links with Stowe were a bit closer than what they are. They are better now, but I think they could be even better. I don't think people in Buckingham are really bothered with Stowe. It's only people that come in from the outside who use Stowe and visit the grounds.

\#3: It [Stowe] influences the town, and it has built the town, but it is no longer necessary for the town. The town can stand without Stowe, and Stowe can stand without the town. If there were still a Duke at Stowe, would it be different? Probably so. Stowe does share some facilities with the town. The Buckingham Choral Society will go up there and sing.

\#6: There is a very close relationship with Buckingham and Stowe. A lot of people stay here because Stowe doesn't have overnight facilities. Therefore, we are the nearest hotel base. There are big events up at Stowe from time to time and they use the whole area. A lot of us use Stowe for its Public Park. Those of us who are National Trust members will get in for free and just stroll around the paths to see what is new with the plants, watch the ducks, etc. Sometimes we will have tea there.

\#8: Yes and No. Yes because certainly in the history of Stowe and its trading with 
Has the connection between Stowe and Buckingham changed over time so that residents no longer view Stowe as part of the identity of the town?
Buckingham, the Stowe estates, the tenancies, and all of those kinds of aspects, even down to the naming of the roads and perhaps the architecture I think, certainly yes. Whether it is now in the modern time, now that Buckingham town has its own marketing plan, not so much so, not in that way.

\#9: I think Buckingham would wish to stand on its own and probably Stowe would wish to be known on its own, but they're certainly linked very closely, so it would be hard to see them as entirely separate.

\#11: I probably do not see Stowe as part of the town. Historically, it was very, very much a part of the town. I suppose in most people's current mindset, yes, it is there and it was very important, but the physical connection or mental connection of perception is often forgotten about.

The Stowe Estate ceased several centuries ago due to the bankruptcy of the Temple-Grenville family. Stowe reopened as a boarding school for young boys in 1923. The relationship between Buckingham and Stowe did not carry on the way it once did. Stowe is commonly perceived by Buckingham residents as a wealthy historic building on the hillside. Only on occasion do some residents use the facilities at Stowe.

\#3: It's two parts of a family, really. I think the town would be concerned if Buckingham was not here and I think Buckingham would be concerned if Stowe left for some reason. The prime move to Buckingham has been

Teachers at Stowe live in Buckingham and use the town for their daily needs and shopping. There is still evidence of support for both entities. teachers at Stowe. We use each other when we need to, but we are very different and not dependent on each other now, like we were so many years ago.

\#4: Historically, it's huge. The Duke of Buckingham brought the canal to Buckingham. It was a pocket borough, basically he helped the town and was popular 
Because of Stowe's location, is it assumed that a strong connection to Buckingham is present?
Could Stowe and Buckingham collaborate in the future to increase tourism for both the town and the estate? and no doubt most of Buckingham trooped up there [Stowe] to work. And, of course, the avenue that runs straight from Stowe to Buckingham is a huge artery. But there is no longer one family in position at Stowe, so again it's a rather changing population. There is the school, teachers, and pupils, all moving in and out. Even the Headmasters are changing. I think the current one has only been there about 10 to 12 years. We talked about that continuity, and you don't see that as much now. Twenty years is a good fixed term for thinking in terms of continuity. I suspect a few people at Stowe live there for 20 years or more. So, that make a difference rather than having one family in which Stowe is regarded as their family estate and being handed down from generation to generation. That really does make a difference.

\#5: It's [Stowe] a neighbor with inevitable connections. I mean things have to be like that, especially with nearby attractions like Stowe. We benefit from Stowe being there, just as Stowe would benefit from having us nearby.

\#8: To them [people of Buckingham] it's an expensive place that's far out of reach and unobtainable. The groups and the partnerships that we have established relationships with are effectively community ambassadors for us and they spread the good word without us requesting them to. Certainly, among those networks are families, schools, youth groups, and special needs; I think we [Stowe] are quite well regarded.

\#9: In terms of Stowe, you have the house and grounds and you have to go into town if you want to shop and it is a separate place you might say or vice versa. Yes, they are two distinct places. I don't see much rivalry between the towns; they are just very much different types of places and what the future is, 
Stowe and Buckingham could potentially collaborate on becoming a connecting tourist destination. no one knows, but it is likely Buckingham will expand very much on this side.

\#10: We are working on our relationship. Unfortunately the managers of the National Trust tend to change rather frequently. By the time you have one manager trained and friendly and working with the town, you will get someone else who and then you will have to start all over again. So, we are trying to build our links with them. They have been so intent on raising money for themselves.

\section{Trading in Buckingham}

Buckingham offers a variety of locally owned specialty shops and trading activities in the town center and side streets connected to the town center. The independent and family owned shops are common to market towns. The Traders' Association of Buckingham is especially instrumental in increasing pedestrian activity and encouraging support from the residents to shop and dine locally.

Buckingham has not been affected by the current recession to the extent other market towns and towns of a similar size in England have been affected.

What improvements should Buckingham consider to encourage tourist?
\#1: If you talk to any of the people who work in the shops, they will say that it is a bit slow, but we wouldn't want it any other way. Most of them moan about trade not being good this week, or this has stopped, or that has stopped, but that is what happens. I don't think it is happening in Buckingham as quickly as it is happening in other places where people have moved away and they have lost money. It is not as good as it was, but then I don't think it is good anywhere in England and there is a depression. I think there are good opportunities for Buckingham to build upon and survive with what it has.

\#2: The town has always been a good one with lots of small independent and family shops. We are working hard to make Buckingham a destination rather than a brief stop en route to somewhere else. Visitors, 
Local residents need to understand the importance of shopping and dining locally. The town cannot thrive on tourist activity alone. If the local people do not support the town, then shops and restaurants will be forced to close.
One problem occurring with the population increase is that there are not enough shops, restaurants, and activities to support the new residents moving into the town. once you have them here, they love it. It's just getting them here and getting them to stay.

There are about 12,000 people in Buckingham and if we could get them all to shop and support their local town, it would be marvelous. They will be the first ones to grumble when shops close through lack of support and then the High Street will die. The other big thing that smaller shops have to contend with is online shopping. People will shop around to get best value on the computer. But, we like to think there is still the benefit of the touchy feely side to shopping ....which you can't get on a computer screen and you can't see how pretty things look. Online is a threat for us, though.

\#4: The concept of a market town is there and the picture of it is there, but actually the reality is that people's day-to-day needs are not met on the High Street as much as they are on the shopping avenues. There are a few exceptions and I am one of them; I will not shop in the out-of-town stores. I use the supermarket in town, but not the one on the edge of town. What I am trying to do is shop in all the little shops that I know for my bread, or whatever I need. Actually, there is no baker anymore in Buckingham. When we first came here 30 years ago, there were five butchers, two bakers, and we finally lost the last baker about two years ago, and there is only one butcher left.

There are not enough shops to support all these people that are moving into town, but now the problem is that they're working in the bigger city centers because there's not really enough employment in Buckingham. They shop where they work. There's not enough obviously in town. It's not completely dead; obviously there are shops that people who live here use. There was a fish market store we would visit twice a week 
Market vendors have stopped trading in Buckingham because there isn't enough support for the market.

Some individuals believe the town currently attracts enough visitors and residents to use the facilities and support the local shops and restaurants.
What will happen to the characteristics of Buckingham if the town continues to grow? when we first came here 30 years ago and he dropped down to once a week about 15 years ago. Just this last month he said he couldn't carry on coming into Buckingham. "It's just not the trade that it used to be, and I can't justify the time and the distance." he said. He's gone now; that is a little anecdotal story of how the market is shrinking and it's just not generally enough trade. It's sad, isn't it? It's changed. I don't think it's changed for the better, but it is changing.

\#7: I suppose the thing that people do worry about is if you see empty shops in the old center of the town. People notice that there are quite a lot of charity shops in Buckingham, which of course is actually a sign of landlords are not finding it easy to rent shops. With a charity shop you are going to get very low rents, but at least the charity shops are there. The center of the town is important and perhaps the presence of the Old Gaol here gives Buckingham a curiosity and focus to the center of town.

\#9: I think it's kept quite well [Buckingham] as a town and it seems to attract a lot of people coming in and having a number of facilities, which can be useful in terms of shops and all the rest, but you're never going to get any of the big clothing shops and it really wouldn't be the right place for it. They need a much bigger town.

\#10: Because we have small independent shops in the town, they have to work jolly hard to make a living. It is their business to be friendly and helpful. A part from Boots, Smiths, M \& Co, and Waitrose, the rest of the places are all locally owned and operated. Waitrose is a co-op store that employs local people.

\#11: I certainly get a sense that a lot of those people who moved to the town appreciate that it is getting bigger, but they came here for the 
characteristics of the town and they want to support that. I think the challenge is that those who move to the town now is to try to remind them of the importance of supporting the town rather than just hopping on the bypass and going straight to Milton Keynes.

The Traders’ Association launched a new branding logo for Buckingham in June of 2011. The new logo, Thoroughly Modern Traditional Buckingham, embraces the traditional aspects, culture, and architectural elements of Buckingham while enhancing the modern values and standard of service that is offered in the shops in Buckingham. The new logo was well supported by members of the Buckingham community.

Buckingham's new logo was a collaborative effort by the Town Council, Aylesbury Vale District Council, and the Traders' Association.
\#2: We worked last year with both the local Town Council (BTC) and Aylesbury Vale District Council (AVDC) in developing a new brand for the town. We received a grant from AVDC which enabled us to employ a creative agency to help us with some new ideas. We placed various advertisements in the paper asking the local people how they saw the town and what they wanted from it. Plus given what we were trying to do ...did anyone out there want to help!!

The new strap line that was chosen is "Thoroughly Modern Traditional Buckingham" and this embraces the traditional old world charm of the Georgian town that Buckingham is, along with the modern values and standard of service that we offer in our shops.

\#3: I suppose the shopkeepers come together and generate ideas, creating events and reasons to stay in town, or stay open later in the evening. If the people aren't here, then the shoppers aren't here. So, they are shopping out of town at cheaper stores and bigger supermarkets. Buckingham is not big enough to generate these types of businesses. 
Shopping in Buckingham is a deliberate effort to support the town. Some residents get "lazy" as they will travel to large shopping malls and do their shopping under one roof.
\#10: We also have a very healthy Traders' Association. They try very hard to promote Buckingham. They are promoting the new logo for the town in June 2011. Thoroughly Modern Traditional Buckingham is the Traders’ new logo for Buckingham.

\#11: One of the reasons the Traders' have launched a rebranding in the town is to try to remind people of what is on their doorstep. I think people get lazy and they forget that shopping in a traditional town obviously isn't as easy as shopping in a shopping centre. Actually, the prices are not that dissimilar. The effort is the same to go in each in every shop down the street as in going in each shop in a shopping centre. You might also have an interesting conversation at the same time with someone in town. It is hard to try and remind people that the traditional aspects of a market town are actually quite useful.

More recently, parking in Buckingham has become a concern for several individuals. Until September of 2010, car parking in Buckingham was free; the Town Council paid a yearly fee to the Aylesbury Vale District Council so that parking would be free in Buckingham's town center. When charges were initiated for car parking, it considerably affected trading in Buckingham and the number of people who travel to the town center.

It was inevitable that a fee for parking would happen in Buckingham, but residents are upset about the nominal charges.
\#2: When you talk to our towns visitors they say, "What a lovely quaint town, and the parking charges are very cheap.”

Parking has been a big issue recently in town as for years it was free and now there is a small charge. This was always going to happen, but the local people don't like it, but they'll get used to it in time. It is only 30p for two hours up to $£ 2.50$ for all day so compared to some areas, it is very reasonable. 
Will the free car parking at Tesco compete with the fee charged to park in the town center? Will this discourage residents from shopping in Buckingham's town center and support the big-box stores outside of town?
Is it more convenient to "pay on exit" of parking so that individuals are not limited to a prepaid amount of time, or to "pay and display" where individuals pay before they park?

Would "pay on exit" encourage more parking in the town center?
\#6: We thought we might have problems when the District Council introduced parking charges. Until last August, car parking was free. Now Tesco offers free parking. People go to Tesco's for things because parking is free. We thought we might have trouble with that, but we haven't had much yet. A lot of the buses from the villages don't go up the road to Tesco. They [the buses] stop in the town centre, which helps.

\#9: Car parking is always an issue.

Frequencies of buses and things like that have been an issue. Certainly, in the last ten years to park in Buckingham on a Saturday morning is much more difficult than it used to be, if not impossible. You can drive around and around and around looking for a car parking space, which then really reduces the quality of life that residents like, which is to be able to go in and stop and come out again very quickly.

\#10: If people have to go somewhere and pay before they park, they sometimes think that it is a lot of money and they are constantly thinking about it when they are shopping, but if they were to pay when they are leaving, they don't need to think about it. I'm sure if we had pay on the exit of parking, then Buckingham would do a lot better. People don't care as much for the "pay and display" that we have here in Buckingham.

Traditionally, parking [in Buckingham] was free because the Town Council made a contribution to Aylesbury Vale each year to keep the car parking free. That changed last September [2010] and now there is a charge for parking in Buckingham. Everyone was very much against it. The rates are very good, though, compared to other towns. The first hour is free to park. If you want to say for the next two hours, then you need to pay 30p. I think if you want to park for three hours, it's 50p. It is still very inexpensive. I noticed 
recently, walking through the car park, that it is getting back to its normal capacity and people are getting used to paying for the parking. We do need longer-stay parking for people that work in the town.

\section{Changes in Buckingham: 1967-2011}

Buckingham has experienced noticeable changes during the past four decades.

Most residents have noted that changes have occurred around the same time period.

Changes in Buckingham are due to the growth of Milton Keynes in the late 1960s and the creation of the University of Buckingham in 1971. The population of Buckingham continued to grow steadily since these changes occurred 40 years ago.

The creation of the University of Buckingham is recognized as a positive change in the town by most residents.

Since the end of World War II, Buckingham's population has continued to steadily increase over time.
\#1: About 40 years ago you can see when the town began to change. It had to change. The University came and in 1970 and that has been a good thing for Buckingham, I think anyways. It was something that Buckingham needed. Possibly it didn't work quickly enough. I don't think the town is perfect by any means, but it is becoming a bit more progressive and it's becoming better, as long as they don't try and rush things. They need to do it at Buckingham's pace.

It took a long time for the local people to appreciate what the university has done for the town. They are just beginning to realize that the university is an asset to the town and they need to build upon this.

\#3: Buckingham remained the same size of about 3,000 people from about 1200 to 1950 . In the last 40 years we have actually started to expand from about 3,000 to 6,000, and then from 6,000 then to 12,000 [people].

\#4: Well, I suppose maybe in the 80s you were aware. For example the taxi driver would say that, "I pick up people from the estates (a local neighborhood) and they say they have never been into Buckingham and 
How is it possible for some residents to move to Buckingham and never visit the town center or support the town in any way?

The bypass around Buckingham created more traffic issues and prompted the expansion of new housing development outside of the town. they live with a half a mile from the center of town." You live in this place and you have never been to the town? Then you recognize the very odd change afoot. When I began to notice the disadvantages that growth brings, then of course the lack of shops. I suppose one of the biggest changes is the growth of the retail terminal on the outskirts [of town], along with the Tesco superstores, which isn’t unique to Buckingham. Every town has one [Tesco].

\#6: It was the 1980s. We had a bad recession in the 1980s. House prices went up.

\#10: About the time of the University we began to see the town change. It all happened within a period of ten years or so. The late 1960s was when the bypass was built and that helped with heavy traffic from the lorries. Stowe Landscape gardens helped when it partnered with the National Trust.

Buckingham continues to evolve with time. The expansion of the town in terms of housing developments, new roads, population increases, and big-box stores on the outskirts of the town continues to prompt ongoing debates among the residents.

What is a reasonable target for the expansion of Buckingham?

Do all residents agree on a target goal for the expansion?

Will the identity of the market town be compromised if the town grows too much?
\#3: We have always set our target in Buckingham of not expanding too far, and that's what the Buckingham Society has done. It has been very easy for Buckingham to become a suburb of Milton Keynes. We would then lose our identity. We always said let's grow slowly. Now there are currently 200 houses going up along Moreton Road. I suppose that we would settle for 16,000 people, in total. I think if we get too large, then we lose that small market town identity. In a way, we are resisting too much growth, but the growth that we want must be good quality.

\#5: Mainly by expansion, building expansion. There is new housing just up the road; 200 
In what ways can the town provide more employment opportunities to support the new housing and residents?
What is the capacity for all the systems of a town? Who determines this capacity? houses up on Moreton Road. There is another two hundred planned on the back of that estate, and another seven hundred new homes planned for south of the bypass, that's what you might call the Tesco side. As part of the general population growth we need the additional housing. On top of that, of course, we have the university here, which needs student accommodation. They can't accommodate all of their students on campus; some of them are outside the town. So yes, inevitably it is going to expand, but it can be done sensitively and the Buckingham Plan explains some ways that you can do that without destroying the historic heart.

\#6: It is growing. Unfortunately, the housing is outrunning the employment and leisure facilities. This is something that is a real downfall. We can take all the housing we like, but those people need to go to school, they need a doctor, they have to work somewhere, and we [Buckingham] really don't want to become a dormitory town. We could just have a mass exit of people every morning and have people not be of the town, and they would just basically sleep here. They might find it more convenient to shop on their way home from work and not in the town.

\#9: That's quite an interesting one. I think there are a lot of towns in this country that face major problems. I mean you could swamp them very, very easily and all the towns would actually have a certain capacity within all its systems, so there would be room for the schools to expand, shopping, car parks, and the roads to be large. You go to a certain point where it all begins to get too much; probably Buckingham is getting to that point.

\#10: It is going to go on growing in population, unfortunately. I think we can try and control that growth to be where it makes sense to have that growth. 
Various challenges have placed pressure on Buckingham in past centuries.

Milton Keynes, the great fire of 1725, and population increases are among the past

challenges. Residents are aware of past challenges such as Milton Keynes,

uncontrollable growth and lack of employment, and the effects they have on

Buckingham.

Could Buckingham potentially become overpowered by Milton Keynes? What is Buckingham doing to prevent this from happening?
\#1: I think the major challenges are that we have always got to be aware of the pressures from Milton Keynes and the pressures from Aylesbury. I don't think the pressures are nasty, but they can be overbearing if you we allow it. We always need to be mindful of that fact. Then we will lose our character. If you know the history of Buckingham, you go back to the civil war of England, and you can see where we stemmed from. Buckingham is a surviving town. It will survive. We need to survive. It makes Buckingham work.

I think the biggest challenge is being overpowered by Milton Keynes. Milton Keynes would like to take certain parts of Buckingham and make it their jurisdiction if they had the opportunity. If the opportunity arose, they [Milton Keynes] would grab it. That is what I am concerned about. It would separate the people that made Buckingham. The surrounding villages of Buckingham, and there are 17 of them, would be separated. They rely on Buckingham.

\#3: The Great Fire of 1725 was one of the first setbacks for Buckingham. One-third of the town was burnt out of their homes. Aylesbury developed sort of a concrete desert and destroyed all of the $19^{\text {th }}$ century buildings. In a way, not being developed, we have kept the old and reestablished a new town with an old heart. The fire was a devastating setback. 
The loss of several men in World War

I \& II has impacted towns like

Buckingham in several ways.

It was a huge challenge to renew industries in the town after the war and the loss of several employees.
\#4: There have been major problems that have challenged Buckingham over the course of time. Within the last century, like most towns today, they lost an enormous part of their youth during the war. We're a hundred years later and we are probably in the final stages of recovery. When we are talking about challenges in the last century, some challenges that we also face nationally, but I think probably hit particularly rural towns, like Buckingham, much harder. It ended then and a rather impoverished after the First World War, in the twenties and thirties. Canals went downhill, and there was no young men to clean them; those sort of things. Then, I suppose, post-Second World War challenges were growth of new towns and new opportunities further afield; agriculture wasn't the natural progression of employment. Farms weren't employing the same number of people; if you go into a village around here, I'm sure you would find that every second or third house was a farm. The agriculture probably disappeared partly because of technological changes, which were partly a result of depression, and then after the Second World War, there just wasn't the vitality there to renew different industries. I think that was a huge challenge for Buckingham.

Additional changes to contemporary society have impacted Buckingham in a

variety of ways. The incremental growth of the last 40 years has been largely unplanned, therefore initiating areas of concern for the community. Some of the current threats and problems facing Buckingham include growth, development, the expansion of Milton Keynes, lack of employment, and the potential to become a dormitory town.

Maintaining the vibrancy of Buckingham is an important challenge to several residents.
\#3: Growth is an issue. Keeping the shops vibrant is also an issue. Across the country, probably about 15 percent of the shops are vacant or charity shops, which have lower rents and will sell second hand clothing. I think we only have about three or four charity 
Individuals are noticing an increased number of charity shops in the town center. This shows that shopkeepers can't afford high rents; lower rates for rent are provided for charity shops.

The participants recognized a wide range of challenges facing Buckingham. How can the town prioritize these challenges? shops in Buckingham, out of 60 or 70 shops. That is unusual. There are probably only two or three empty shops. Most market towns you would find more charity shops. We are reasonably vibrant here. The $31^{\text {st }}$ of March [2011] is a day when renters will renew their leases and I would say that there might be ten more empty shops. There are several places on the brink of closing with the current recession. It's not a healthy time to be a shopkeeper. We have, on the whole, kept our shops open, only just enough.

\#4: I think one of the current problems facing all of us is the wealth of information, including the vision the town is influenced by the planning that is development, which means planning laws, which means involvement of people. It's become so complicated and so weighty, and so paper driven, so bureaucratic, that it's actually very difficult for people to get their head around it. Unless you are prepared to devote a lot of free time, your free time, to try and find a standard, and therefore get involved, that is quite a challenge. The planning laws continue to change and are being revised; if only they were simplified and it would allow local interpretation and that might help a lot.

\#5: There have been some changes [in the seven years I have been here]. Not physical changes per se, other than the increase in housing and that sort of thing. One other thing that I have noticed is increased traffic. There has been an increase in traffic in narrow streets in that end of the town. It gets very narrow through the university area and you get a lot of congestion and problems caused there. We are suffering from heavy good vehicles as well. Ignore signs that say go that way. But these are all being addressed. You can't do everything in five minutes. 
Significant changes in Buckingham began with the creation of Milton Keynes.

Milton Keynes, a city approximately 15 miles from Buckingham and the primary source of growth in the area, is a New Town designated by Melvin Webber in 1967 (Walker, 1994) in slow response to the Garden City movement of the early 1900s. By the 1970s, overflow population from Milton Keynes had begun moving to Buckingham and the surrounding communities and then commuting to Milton Keynes for employment. Milton Keynes is viewed as both a positive and negative change to Buckingham.

Because Milton Keynes was expanding rapidly, it took the pressure off of Buckingham so that it would not need to grow as quickly.

People chose to live in Buckingham because of the scale and size of the town, but they enjoy having facilities and amenities within driving distance, such as those in Milton Keynes.
\#3: In a way, it [Milton Keynes] took pressure off of us because other places were expanding very fast, providing facilities that perhaps we needed, but we didn't mind going to travel 12 miles to access. Milton Keynes could have been Buckingham or Buckingham could have been Milton Keynes. People were resistant to that. There are very few people in Buckingham who would criticize Milton Keynes because the people enjoy the bigger facilities, the bigger supermarkets, the lovely theatre, and the nice cinemas. We draw on the benefits and we like the green belt between us and we are happy to cross that greenbelt to get there. People moved to Buckingham to be away from all of that [Milton Keynes], but enjoy the facilities that are on their doorstep. People still value the rural influence on their lives, and I think that most of the people still appreciate it. There is still a romantic view about the green belt. There is something nice about the green belt.

\#4: Another challenge is to try and cope with the dormitory flux, which may partly be from Milton Keynes, but I think it's more London. After all of the Garden Cities began in the beginning in the twentieth century as an alternative to living in London, and they were built as dormitory towns because London suddenly exploded in growth during the late Victorian period. The Garden Cities were 
Milton Keynes is causing pressure on Buckingham to become a dormitory town. Because Buckingham cannot provide enough employment for its residents, people have to drive to a place of employment, prompting issues of a dormitory town in Buckingham.

Some of the shops found in Milton Keynes will never be found in Buckingham because Buckingham does not have the capacity to support the major chain stores. actually a part of that movement to move people out into clean air; don't forget London was smog bound until really the fifties. In that growth of the Garden Cities, Milton Keynes was one of the last; it was planned in the sixties. Think about putting a stone into a pool; the ripple of growth was growing around London, wider and wider, and the Milton Keynes and Buckingham ripple reached us really in the mid-sixties. But it relied on people commuting to work and the growth of the railways. It actually began as a movement by where you separated industry from housing; inevitably, you had to travel. These cities were created for this purpose of commuting and we are now trying to reverse the entire situation. We always want our cake and eat it, too.

\#10: Milton Keynes has helped the town. It [Milton Keynes] is a threat because Buckingham became a bit of a dormitory town, but I think we're are overcoming that. It is also a threat because we don't want to be swallowed up by the development happening around Milton Keynes.

\#11: Milton Keynes is both a benefit and a strong competitor. I see it as both, and it means that Buckingham doesn't have to find space for new warehouses and buildings, and it also has the benefit of shops that will never be located in Buckingham because it is too small. Some major international chains can be within driving distance, but then some of the local shops are then in competition with the large chains.

Milton Keynes benefits the town so that Buckingham doesn't have to grow faster than it wants to. I don't think Buckingham ever wants to be a big city; it wants to remain a small market town. But then when it [Buckingham] is trying to attract investment or a business to locate in Buckingham, it has Milton Keynes with everything next door. 
The University of Buckingham was established in Buckingham in 1971. Most university students now live in downtown Buckingham and take advantage of local shops and restaurants. In 2010, The University of Buckingham announced plans to double in size, from approximately 1,000 students to 2,000 students. For a town of 12,000 like Buckingham, increasing the population of 18 -24 year old transients to $20 \%$ will have significant impact, particularly where student housing, transportation, retail, and food services are concerned (Wiewel, et al., 2000). The University of Buckingham continues to be a positive influence in the town, encouraging retention of educated individuals in Buckingham.

There is a common consensus that the University of Buckingham has improved the town is various ways: helping it maintain its self-sufficiency, increasing the amount of shops and restaurants in the town, and bringing wealth to the area.
\#1: It would have been difficult [for the town to survive without the university]. Very difficult. If the university had not come, we wouldn't have the opportunities that we have now. The part of the town where the university is would have been derelict. It would have taken an awful lot of money to fix that area up. The university has brought a lot of money into Buckingham and spent an awful lot of money to make the university what it is today. I think the university has done Buckingham a very good term. It is the only independent university in the country, and that makes a difference. When you have an independent university coming in and bringing money in to the town, which has to be better than a regular university.

\#4: Physically, it [the University] helped enormously. I am told that side of town was absolutely derelict. The university arrived here in 1975 and started quite small. They did an enormous amount of work to build up this derelict side of town and most of that part of town was regenerated or rebuilt. It [the University] also sits quite well in that area and it could have been a monster. It has done far more good for the town than people 
The town and gown divide may cause some issues to Buckingham as residents may see the university as a threat. realize. I am very involved with the film place; I help run a community cinema here. That is only possible through the generosity of the University to use here.

In any university town, there is a town and gown divide. People have quite entrenched ideas, I think, but the university, on the whole, does a lot for the town. Of course the students and again, people, are divided, to make use of the facilities.

\#7: I think it on the whole has been quite beneficial. This part of Buckingham was getting quite seriously run down in the 1950s and the 1960s. I think that if the deterioration had continued, the buildings would have to be demolished. I think the university has made a difference in other respects. Clearly, there have been people connected to the university that have come to live in the town and there is the presence of the students in the town.

\#10: The University of Buckingham has had a great influence on Buckingham. We have probably an overrepresentation of restaurants, hotels, and café because there are more people to go out and eat, stay at a hotel, etc. Also the range of eating places we have, Italian, Asian, English pubs, is all due to the University and has been so helpful with having these things here in town.

Employment continues to be an issue for the residents of Buckingham. New housing developments constructed on the outskirts of town will continue to increase the population of Buckingham. As the number of individuals in Buckingham increases, the town center cannot provide enough office space, nor can the industries and other companies throughout Buckingham provide employment for the new residents. Lack of employment in Buckingham is prompting residents to seek elsewhere for job opportunities, such as Milton Keynes, Aylesbury Vale, or London. Residents are then 
commuting to and from work, leaving Buckingham vacant during the daytime. Some individuals see regular commuting as a sign of potentially becoming a dormitory town.

Some residents do not see Buckingham as a dormitory town.

As house prices continue to rise, will current residents be able to afford housing in Buckingham?
Buckingham should not be solely dependent on tourism for employment and support of the local town center.
\#5: We don't see ourselves as a dormitory town; we are a stand-alone community.

\#6: It is a threat that people are commuting more and inflating the house prices. We have enough houses, but local people can't afford them. That is why we are getting a bigger proportion of incomers.

\#7: One of the big issues under discussion now of course is the expansion westwards of Milton Keynes. There is a possibility that Buckingham could become simply a kind of lost village within Milton Keynes, which I would greatly regret. It is also true that while there are people who live and work in Buckingham, there are quite a lot of people who actually work elsewhere. You can't stop that. It is inevitable. I wouldn't want Buckingham to become entirely a dormitory town. There clearly is some tendency in that direction. People commute to Milton Keynes, Oxford, and even some commute to London, which seems pretty tough to me on a daily basis, but nonetheless, people do it. That potentially, both the expansion of Milton Keynes and the idea of Buckingham becoming a dormitory place in which people just sleep, I think those things will threaten the position of a market town.

\#10: Employment is another problem. Well, if we could have a light factory that would stay here for a while, that would be beneficial to the people. Tourism is not something that we can depend on. Some kind of light factory would be great. We have a lot of offices and office type work, but we haven't traditionally had a lot of industry and we have lost quite a lot, too. We are going more towards the service industry to service the university and 
tourism. We wouldn't object to some kind of industry moving to Buckingham if we felt it was appropriate. It is hard for industry to fit into our structure of Buckingham with the lorries and transport, that sort of thing.

\#11: I think the concern is that the recent housing growth in the last ten years has not been supported by the town in terms of employment, offices, and infrastructure. We've been very lucky that some businesses have grown organically, locally. Some businesses have chosen to relocate here because it is a nice place. More contemporary, I think many people of the town are concerned that employment space, business space, and housing space, that people have to commute to Milton Keynes, Aylesbury Vale, Oxford, or even into London, which means that you do lose a certain vitality of the town if people are having to commute out.

\section{Growth in Buckingham}

England has been experiencing growth as the population of the country continues to rise. The residents of Buckingham have diverse opinions about the growth that is occurring in Buckingham. Some individuals feel the growth is necessary in order for Buckingham to survive, while others believe the town should remain in the same condition that it is. It is inevitable that the town will continue to grow; how the townspeople and residents will deal with that growth presents a dilemma.

\#3: I think the older people would like it [Buckingham] to stay as it is and younger

Do different generations of Buckingham residents have common feelings about the growth of the town? people think we should grow. I don't see it like that, but I'm sure you hear it often. Many people would think if you can expand, you protect yourself, sales in the market, and sales in the shops. You're a bigger player. Most people always see us [Buckingham] as second best to Aylesbury because they [Aylesbury] 
How can people define too much growth for Buckingham?

The Buckingham Plan approached citizens about their thoughts on the growth in Buckingham. A general consensus believed some growth should occur, but the growth should be controlled. will always dictate. We don't have as much of a voice. I don't think that is necessarily always true. A smaller voice still has power.

\#6: I don't think people here mind the growth. Growth keeps the shops viable. Growth puts pressure on facilities, but then that might mean we get more facilities.

\#9: I think most people would define growth as too much after they have arrived there because they get used to what it's like when they move and they develop another estate. I don't know how large you let it to grow. Actually, the structure in the center of the town can't probably take too much more in terms of traffic without beginning to grind or halt or perhaps some people won't drive through town because it is too busy most of the time and it would just take too long.

\#11: The overall consensus in the Buckingham Plan was that there was an appetite for real growth, but it was targeted growth. I think that surprises a lot of people that most wanted some sustainable of growth; if the town wants certain facilities, then the town has to grow. I think that was refreshing and it showed that the town was aware of the reality of hand. It showed that most people wanted to get engaged with the project and town's change over time. People realized that if the town did not change and evolve over time, it would stagnate. The town wants to get engaged in how Buckingham grows. Yes, we want growth, but not at any cost.

The government has been focusing policies toward increasing the level of homebuilding, especially in the South East region of the country (Dixon, 2009). Buckingham has been experiencing this increase in growth through increased housing developments and the continuous expansion and pressures of Milton Keynes and Aylesbury. 
Buckingham is regarded as a desirable place to live, and it is within proximity to Milton Keynes and London.

The South East Plan mandates Buckingham to build several hundred new houses. How will this affect Buckingham? Employment? The town center? Traffic? Infrastructure?
\#3: The main reason for growth in Buckingham stemmed from two things. First, prospective developers know that housing prices are higher in Buckingham than they are ten miles away because it is regarded as close to London and a nice place to live. Therefore, if you can persuade the local authority to build more houses, then you get greater value out of the homes. There is that pressure. For instance, if you go down to the river from here, you will see a large development of 193 flats that are just being built. That has nothing to do with government-inspired money. It is called windfall. It protects our position here in Buckingham. People who don't want to expand too fast; you don't have to plan for extra housing in Buckingham because it will happen through natural growth, through windfall.

But on the other side of it, there are government plans. They [government] would recommend 1,600 houses in Buckingham. The Buckingham Society would then try and fight it. Winslow, a town six miles away, would take 700-800 houses and Aylesbury would take 10,000 houses. They think that the houses would generate jobs, greater businesses and shops, etc. On the whole, Buckingham says, we are happy where we are and we don't want extra people. Maybe we are wrong in terms of thriving, in terms of making sure that is what we need in Buckingham. Would we be sustainable if petrol prices doubled again in the next two years? A lot of petrol goes into driving to Milton Keynes and back, doesn't it? I go on the bus so I don't worry!

\#8: I think it [Buckingham] will continue to grow, and I'm sure that there will be lots of groups resistant to that. It is a fact of life and I think all towns are likely to grow. Certainly, we'll have increasing pressures. I think it will not have the same pressures that Milton Keynes have because it is much bigger and a 
community town with many more condensed and compact community. I think certainly it might have its pressures, but because Buckingham is a smaller place, I think its pressures seem greater. So, I think it's perception.

The South East Plan addresses long-term spatial planning for the South East region of England from 2006-2026 (The South East England Development Agency, 2011). The plan is a government strategy to increase housing by $10 \%$ in all districts of southeast England, once again taking the pressure off the London area (Buckinghamshire County Council, 2011b). In Buckinghamshire County, Milton Keynes and Aylesbury Vale are specifically targeted for additional growth. Buckingham is located between Milton Keynes and Aylesbury Vale. To meet the standards of the South East Plan Buckingham will need to construct 4,700 new homes in the area by 2026. These additional housing developments will have considerable impacts on the town.

Where will the land come from for the new houses of the South East Plan?

How will communities find employment for thousands of new residents?
\#4: Because the regional plan, the South East Regional Plan is what is dictating the number of houses that each district in the southeast region should take. Aylesbury Vale, which is our district, had been allocated to provide 26,000 houses by 2026, and the district does not know how it will be providing land for 26,000 houses.

The other key element is trying to find people 12,000 jobs for these households within the district. The southeast region has always had London to attract so much of our southeast economy. We never had a large volume business, for example, in Aylesbury Vale, which is such a rural, agriculturally based area. Everywhere else the state sector seems to employ more than the private sector, the manufacturing sector. In other words, you still need somebody to make something and some wealth to pay the state side. It's quite a 
Will more authority at the local level help communities plan for targeted growth?

This mandate for growth is a threat to Buckingham.

At what point does the town decide to stop growing? difficult equation to attract new businesses, particularly private enterprises, into the region to create jobs in order to sustain that level of houses. This current government came in and abolished the southeast regional plan. There will be less emphasis on a regional target and greater autonomy given to local authorities to specify what growth they can achieve.

Buckingham was due to take about 2,500 houses, which is a lot. That's one-fifth of the current population of the town. From when this town was founded somewhere in the eighth century, it grew to about 6,000 people by 1980 , and, then in less than a quarter of a century to, 12,000 people; and in another 20 years, it was going to be 20,000 . It is quite a tall order. It will have to be very carefully thought out [the Localism Bill]. Yes, I hope the town will have some sort of say in how much it can take. It's still not exactly written in law as to what are rights and what decisions can be made.

The increase in population throughout England has prompted an increase in housing developments. Since space was limited for housing in the town center, additional housing developments were constructed outside of Buckingham, encouraging sprawl and decreasing walkability. Developer-led housing developments often cannot be stopped once a developer has obtained land. Residents of Buckingham continue to fight against unplanned housing developments that are physically less connected to the town.

Uncontrollable growth initiated by developers, such as large housing developments, has huge implications on Buckingham and can be seen as a threat.
\#1: I think there are too many buildings for housing in town. I'm not being prejudiced, but I think it will bring in the wrong crowd of people, such as lower income flats. That means that you will get a different type of people. They are not oriented towards a market town, but because of housing costs. If we are not careful, we can become the wasteland of people that are not the caliber that we are used to. That bothers me a little. 
How will Buckingham cope with schools, hospitals, and employment for the new residents of the housing developments?

A developer does not see the detrimental impact of hundreds of new homes in a community. Developers commonly do not live in the community where they are building the homes.
\#4: Unfortunately, we're about to be landed with a severe blot as I described earlier. I mean for Buckingham, 700 houses is a very big development. It's coming with a school, employment, and health surgery. I really don't know what they mean yet. It's one of those lovely promises. There is certainly a formula that you need to take into account; you got to have so much open space, so many educational places, etc., etc. That is actually not a very good planning lore, because it allows the developer to swamp places with huge numbers of dwellings on the provision that they will then provide the school, parks, etc. ... opportunity profit margins which do it, so in a way you are actually encouraging a bigger development by saying you need to do this, that, and the other. I think there are better ways of doing it.

Developers, if they're given a chance to build seven hundred houses, they're not going to design seven hundred individual houses, are they? It's really a question of scale. It's difficult to get it right, and if you put 700 houses in a city like London, it won't be anything new, but if you put 700 houses in this small market town, it's the wrong disproportion of size. Scale makes a huge difference.

\#9: I definitely think we need to be careful about how much housing we have. I have written to the Town Council; I have suggested that Stowe and the National Trust here that they should get into cycle-ways (bicycle lanes). It's actually ludicrous building this new estate up on Moreton Road without putting in proper side lanes. Some lanes are too narrow and dangerous for the cyclists. If the National trust would allow cycle routes, it would be very positive and people would enjoy that type of experience all around the countryside.

\#10: Unfortunately, we have just had the planning application granted for seven 
hundred houses opposite the Tesco's. Unfortunately, it [the new housing development] is going to be a self-contained unit because that [location] is on the other side of the ring road (bypass). It is divorced from the town. That development is the kind we have been trying to avoid because it has nothing to tie it to the town. Once you have a bypass, like we have, and you have filled the land in from the town up to the bypass, then you need to go beyond [the bypass]. Obviously you don't want too much development to go out towards Stowe because of the Stowe Landscape gardens, and also again, it is a lovely rural area there. \#11: In the last ten years, the housing development has been developers seeking out Buckingham as a nice place to develop. Unfortunately, when it is developer-led, it is what they want to develop and not what the town wants them to do.

In addition to the residential sprawl caused by housing developments in Buckingham, there was sprawl triggered by big-box stores. The big-box era hit Buckingham around 1991 when the first big-box store, Tesco, was built on the outskirts of town (Close, 2009). Tesco is comparable to Wal-Mart in the United States. A shift occurred in the mentality of residents in relation to utilizing local shops downtown. Bigbox stores have severely impacted downtown Buckingham.

\#4: Tesco came to Buckingham about 20 years ago, maybe less, but not more. But that really did alter the objectives of the High Street. People no longer had a need to come to Buckingham at all. If you lived in one of the estates and worked in Milton Keynes, then you probably would have done your shopping in Milton Keynes and not come into Buckingham. They used to come to the library, the bank, the post office... all those things, and now it's all under one roof in Tesco's. That store has probably done more 
Tesco is comparable to Wal-Mart in the United States. Tesco has negatively impacted the community. Citizens are showing less support for downtown shops in Buckingham.

Big-box stores on the outskirts of the town are causing an increase in turnover of shops in Buckingham's town center.

Will the economic center of Buckingham shift with the increased support for big-box stores and less support for the town center?

How is Buckingham preventing bigbox stores from entering the town center? to change this country than any other business has. It's exactly like your Wal-Mart in the states. People that have lived here all their lives go up to Tesco now. They do produce goods under one roof, it is quite a good value, but if you balance the value they [Tesco] offer against the value of the environment that you live in, it's not [that good of a value].

\#6: The turnover of shops in the town centre is another challenge. We haven't lost many of our independent shops, except for Woolworths. Man, did we miss Woolworths when it folded. You could get anything in the town centre. We miss that. We used to have a major hardware store, everything from gardening and household things to do-ityourself materials, wood, glass, and paint. That closed. We are losing some of our useful stores because of the big out-of-town shops. People are going to Milton Keynes or Aylesbury to shop. They want the big chain shops. We still have people that do shoe repairs, cut keys, and look after your bike. We still have all those little stores and we are really doing quite well compared with other market towns. Other market towns are actually losing their market.

\#7: Of course, one of the big concerns is if the economic center will shift to places like the Tesco's site and the industrial state. I think to have a depressed or abandoned, or semi-abandoned center, is a terribly bad feature in any town. It sort of knocks the identity and sense of care, and sense of commitment when the shops are boarded up.

\#9: It’s [Buckingham] managed to keep away traffic and Tesco from the center as well.

Continuous growth, an increase in housing developments outside of town, big-box stores, and commuting residents to places of employment have all initiated increased traffic in and around Buckingham. In the late 1960s, a bypass was constructed around 
the market town. Over the past four decades, the town has expanded beyond the bypass, increasing the number of drivers and forcing Buckingham to be less walkable for residents.

The schools in Buckingham-the Grammar School, Buckingham School, and Stowe School-all increase the amount of traffic in the mornings.

The bypass is no longer adequate to support the amount of traffic that utilizes the road.
\#9: At what point will we see them [Buckingham] try to put in some extra relief road on this side [north side of Buckingham] or even build some massive road to link up the main roads, but of course it then encourages people to expand out to that point. The schools in Buckingham have a tremendous impact, as they do anywhere, but in particular, the three big primary schools and there are a number of other primary schools as well, and then of course you have the Grammar School, which is selective more than Buckingham school. And then a vast number of private schools on the edge of Buckingham are all very, very close together. So there is a lot of traffic in the morning; people driving from the villages in and out and all over the place. It's quite a phenomenon, and then it dies down very much so after that.

\#10: The other problem with Buckingham, from a transport point of view, is that we are very much on an east /west road. With the road system, the east west road system isn't really adequate, especially around the Buckingham bypass. It is not adequate for the amount of traffic that wants to use it. The bypass is very congested.

A series of uncontrollable events and actions have brought Buckingham to its current state affecting the physical condition of the town and the quality of life for the residents. These uncontrollable events include the expansion of Milton Keynes, forced growth and construction of new housing developments. These changes have prompted 
concerns in Buckingham regarding infrastructure and housing, education, conservation

and parks, cultural aspects of the town, and economic development.

Infrastructure development needs to happen simultaneously with housing development. The current infrastructure in the town cannot support the increase in housing developments.
Should developers be responsible for providing proper infrastructure to the housing developments?
\#5: What we're doing is pressing the planning authorities, which is the District Council, to ensure there is infrastructure development at the same time as there is housing development. Not to follow it, but at the same time. So we need the sewers in before we have the houses there. We need the roads sorted out before the houses get built. We need to know what the schools' situations are going to be. We need to know that the electrical supply facilities and other infrastructures are going to cope. They need to line up, side by side. And there is a section 106 levy on development, it's a wad of money which is taken from developers for specific purposes - it might be for improving the roads, or putting crossings in, this, that and the other, but all providing facilities. And we get involved in that stage, but we are watching the District Council to make sure they don’t do anything stupid.

\#6: We will have more housing, but I don't think we will have as many second homeowners or commuters as we have now. If we get more employment, people will be able to walk or cycle to work. If we could get a really decent bus service, then people from the villages could use it more.

\#10: Lack of investment in infrastructure has been a major problem. Because we are so north in the county, we have some crossborder-county problems. Therefore, we get lost and the money gets spent on Aylesbury.

\#11: The lack of investment from the County in terms of general countywide infrastructure is another threat. The roads and schools are important to the development that is occurring and also to alleviate some of the issues that are currently faced by the town. That might 
be more on the lines of better capacity of the roads, better drainage, better water capacity, and broadband is a big issue. Businesses will not relocate to an area that does not have good connections.

\section{Local Government, District Council, and County Council}

England provides two options for towns to select a form of local government: a unitary or two-tier structure (Buckinghamshire County Council, 2011a). Buckingham has a two-tier structure of government, reporting to both the Town Council and Aylesbury Vale District Council. On occasion, decisions will be made at the county level of government. Participants were asked to describe some of the leaders of Buckingham; diverse views were provided regarding elected leaders in the community.

\#3: I think the Mayor is the primary leader in the town. Then you have three layers of councils-Town, District, and County-all elected officials by the people. There are three sets of different representatives, all of which will take a different view of Buckingham. Then above the County Council would be Parliament.

A mix of personalities in a community will create tension, but also provides a broad spectrum of ideas and comments for the local government system.
\#4: Some of them have been there for a long, long time; they are a very mixed sort of bunch of people from all walks of life. On the whole, I think that most of them have lived here for a long time. Well most people that actually commit to the societies in the town feel some sort of belongingness, very eccentric word, to the town.

\#5: Essentially representing those that elected me into post, but the Mayor role was an additional tier on it, which is kind of an ambassadorial role, if you like. They used to call the Mayor the leading citizen. Certainly to represent the town at various functions and around the area would be my responsibility. 
The councilors in Buckingham are involved with various activities in the town, including involvement of younger generations.
Several residents feel distrust toward the County Council, particularly when a lack of funding is provided for Buckingham.
\#6: Our councilors are known. They will come to events. They will come to fairs. They will go to the schools to talk about the history of Buckingham. Because we are isolated, I suppose we are internal looking. We look towards ourselves, and basically Buckingham looks after itself. There's no point looking to anybody else.

\#10: We are very English in that respect of our leaders. We don't sort of set our chair people on pedestals. We are very much mixed in with them because we are very much still a market town. Members of the Town Council are obviously elected, so they represent only a cross section of the local people. They have quite divergent views. They don't have much power to run the planning application, because that happens mostly at the District level.

\#11: Politically, I think there is a certain amount of distrust. There is some distrust on County Council and its aspirations and what it wants to achieve countywide.

Buckingham has a two-tier structure of government. Therefore, the control of planning activities occurs at two levels: the Buckingham Town Council and the Aylesbury Vale District Council (Aylesbury Vale District Council, 2011). Planning decisions made at the local level in Buckingham must also be approved by the Aylesbury Vale District Council (Buckinghamshire County Council, 2011a). Because Aylesbury was once the county town, animosity is still present between the two towns.

\#3: I think it’s fair to say that Buckingham and its councilors and Aylesbury Vale and its councilors historically when the county town was set up, they took Buckingham assets and made them Aylesbury Vale assets. So they [Aylesbury Vale] stripped the town [Buckingham]. This happened more recently. I suppose Aylesbury Vale District Council 
A feeling of animosity still exists between the two towns.

It is a common thought among residents that Aylesbury Vale District Council will allocate more funding for projects to the town of Aylesbury than it will for Buckingham.
Because Aylesbury Vale District Council has the authority to make planning decisions over Buckingham Town Council, it is often thought that Aylesbury Vale District Council does not show enough support for Buckingham. was set up about 30 years ago. It came with a feeling of resentment and still to this day, between our town and Aylesbury Vale, there is almost a figure of warfare. They [Aylesbury Vale] determine things and then enforce issues on us, the people of Buckingham. It's not a friendly relationship.

\#5: District Council, which is the next tier of government, they don't always think as sympathetically as they might of Buckingham before making decisions which affect us in a fairly major way. They seem preoccupied south of the Vale.

\#6: Aylesbury Vale [District Council] likes to spend money on itself, and not money on us. They spent 8.5 million on Town Council offices, and it's a long walk out of the town centre. If enough people jump up and say, "Hey Aylesbury District Council. You just paid how many millions for a new theatre, and we haven't got one here. Why isn't Buckingham getting investments, too?”

\#10: There is huge debate about who owns things in Buckingham. If you want to fix a lamppost, it could be owned by one of three authorities. It depends on where it is in the town. The footpath could be owned by one of three different councils. Town, District, or County Council. It's madness.

\#11: The Town Council has been reminding both county and district that we are aware of the big issues, but a market town also needs appropriate support to make sure that it is not forgotten about. I think that is one of the big issues in Buckingham and it has been for a while. The developers come in occasionally and they want to build 100,200 , or 500 houses, and the District Council doesn't really have a plan. Then there really isn't anyone to fight the developer. People in Buckingham feel forgotten about. 
The Town Council has very few statutory rules in terms of planning. The key statutory rule is that the District Council and County Council have to consult with the Town Council on some issues, generally planning permission, changes on development control, and strategic planning issues.

Current debates in England involve a Localism bill, which grants authority to the local level and councils (Parliament of England, 2012). Most towns are in favor of the Localism bill, but the bill had not yet been passed by Parliament when the interviews were conducted in spring of 2011. The Parliament website notes that the Localism bill, now titled the Local Powers Act, received Royal Assent on November 15, 2011 (Parliament of England, 2012). Power for planning at the local level is one of the most critical powers to obtain; issues surface regarding funding, land-use, development, and making decisions in the best interest of the community.

Should local autonomy be given to small towns and communities that do not have proper management and resources?
\#4: The Southeast Regional Plan is being replaced with a new emphasis on Localism.

\#5: I will wait till the bill is finished before I make my decision because things get changed. It's kind of scary at the moment. Localism, I somewhat cynically think, is taking responsibility away from the national taxpayer and putting it onto the local council taxpayer. It may be taking work away from professional people who are qualified and experienced to do the job, and putting it on local volunteers who might have an idea, but aren't equipped to think far enough ahead to see some of the consequences to their ideas. So, there are a lot of issues that need resolving here.

With this new Localism bill, we can start asking for things and hope that we get them. That's what we are looking for: sustainable transport, cycling, and safe walking areas. 
Many of the community members in Buckingham are in favor of the new Localism bill, which would allow for more decisions to be made at the local level, instead of Aylesbury Vale District Council or County Council making the decisions.
We are looking to keep everything back in Buckingham again so you don't need to go out anywhere. We [Buckingham] would like to keep ourselves to ourselves, and not have to be dependent on others.

\#10: The Localism bill is trying to give more say to the local people. So, instead of going from the top-down, it will be a bottom-up approach. There is a lot of good in this new bill. It would be a national bill. I think we are also trying to get away from the boundaries and calling each of these regions in the county by a different boundary name. A lot of our issues are cross border issues. We also wish for more communication with the other counties, since we are on the edge of Buckinghamshire County. I think the Localism bill will allow us to do a bit more flexible.

\#11: The Localism bill covers a wide range of issues and [elaborates] on how local authorities deliver services and how planning is conducted: a bottom up approach. I suppose the way the Localism bill is going through parliament at the moment is to local groups, parishes, local councils, what they say is important and it should be considered and accommodating to planning and provision of services giving more focus to a local issues. There is great hope the Localism bill might make things like the Buckingham Plan be listened to more rigorously. Other authorities have to listen to it, rather than just pretend to listen to the Buckingham Plan. Locally driven grassroots campaigns will get some mileage. The Localism bill will become very important when issues begin to cross boundaries of towns, to districts, to counties, and regions. 


\section{Buckingham Planning Projects}

Buckingham understands it has the ability to control some aspects of the market town's future. The Buckingham Plan addressed the challenges of the economic climate and the impact it has on the local community, as well as the potential growth in the area. After various consultations with the community, the Town Council and the Planning Committee of Buckingham created the Buckingham Plan in 2008, an in-house document utilized as a study tool for the community. Numerous challenges were addressed in the Buckingham Plan. These challenges include: development, infrastructure, town center and local economy, transportation, housing, conservation, children and young people, education and employment, health and leisure, and tourism and culture.

The Buckingham Plan was a joint collaboration from all members of the Buckingham community. Residents, leaders, and stakeholders came together to plan for the future of Buckingham.
\#1: I think some of it is good for Buckingham and some of it isn't. It can work. There is a lot of thought that has gone into the plan and it will work. People will take time to stop, pick it up and read it, and talk about it. It will be beneficial, in my opinion. One of the chaps is an architect and he is in charge of planning with the Buckingham Town Council. He has helped draw this plan up with other people. I don't think that all of it [Buckingham Plan] is good, but the vast majority has been beneficial to Buckingham. I'd like to think so, anyway.

\#3: They did commissions with people and such [for the Buckingham Plan]. I actually run a disabilities group in Buckingham and my role in the Buckingham Plan was to inform them about areas of the town where they couldn't run a wheelchair or the sidewalk needs to be more accessible, etc. We are constantly talking to the local council and the planning authorities.

\#5: All of the Town Council was involved in some greater or lesser measurecertainly involved with some of the 
There was a tremendous amount of support from the community for the Buckingham Plan. A common positive feeling of appreciation and gratitude for the Buckingham Plan was noted from the residents of the community.

Planning for long-term issues in Buckingham was a major concern for the designers of the Buckingham Plan. stakeholder groups - and we report together to formulate that and discuss the issues that are arising from that. We started with talking to the public. "What do you want?" "How do you see it going?” By public, I mean stakeholder groups predominantly, like the Buckingham Society, and businesses in the community, the Traders', and so forth.

\#11: I suppose one of the problems of the Buckingham Plan was that it was very much a localism, layperson plan. We had members from the Buckingham Society, Town Council, and people from the University, the Traders' Association, and other interest groups on the committee. We called it the stakeholder group. The purpose behind the Buckingham Plan was to take all the anecdotal evidence and all the aspirations, both small scale and large scale, into one authoritative document. We draw in all the problems that we know. The Buckingham Plan was centralized around localism. It was not answering the central government question of what a market town should be. We also tried to find out what residents thought about the sense of place in Buckingham. We also wanted to look at long-term issues. The overall consensus in the Buckingham Plan was that there was an appetite for real growth, but it was targeted growth.

With most planning applications, housing, shopping, retail, any normal development, it is [Aylesbury Vale] District Council's responsibility. They're called the planning authority. Certain things are actually determined by the County Council and they will improve schools, power stations, waste plants, and those sorts of things. It is an odd mix.

There was a considerable amount of consultation with the public for the Buckingham Plan. The Buckingham Town Council initiated a series of community meetings, workshops, verbal participation, online questionnaires, surveys, and 
informational sessions. Leaders of the Buckingham Plan could gain valuable information from the residents in regard to the town's growth and where they would see the town in the future.

Most participants believe the public was heavily engaged for the development of the Buckingham Plan. Surveys, questionnaires, letters, and informational sessions were just a few ways in which the Town Council involved the public.
\#1: I wouldn't say the public was heavily engaged, but all the right people outside of the Town Council were all involved with the Plan. Every household in Buckingham received a questionnaire. They encouraged residents to fill those out for information. I think they had about $38 \%$ of the people in Buckingham responded in some way. It was something new that the town did, as well. Councils in the past have been a bit mundane, but they are more forward thinking now.

\#3: There was a tremendous amount of consultation. We have a special way of consulting in this country. Usually, consultation consists of, "You might like this version, we will call it Plan $A$, or this version, Plan B." "Would you like to vote for Plan A or Plan B?" Rather than starting with a green flat field and say to the people, "Now what would you like to see here?" and letting the people form their own vision. One is clearly superior to the other. You can't actually vote for what you want because neither plan actually has your opinion, and you try and judge to see which one has more of your vision in it. It is a predetermined voice. The Buckingham Plan was similar to that.

Everyone does give his or her input in the plan, but in the end you are asked to pick a version. They [creators of the Buckingham Plan] know what they want and go about it quite cleverly.

\#11: It was a good amount of support. The Town Council was fully behind the project. Some of the groups in town, such as the Buckingham Society, were really in support of the plan. Some of the churches became involved. A few members of the public just 
The group asked questions about the future of Buckingham, such as what the residents would like to see happen, and how they thought it could reach that state. turned up. We had a booth at the market one day, we had a meeting at the community centre, and we reached out to various other people. We have questionnaires on the websites. We tried to get students and other people who wouldn't necessarily have been engaged to try and come to meetings. It was very much collecting a local view of what the resident and people thought their town should be. We had very simplistic questions such as:

What do you like about Buckingham? What do you not like about Buckingham? What do you think of your town?

We chose questions like that instead of asking:

Where do you want Buckingham to go in the future?

What is Buckingham now?

What should it become?

It is already suggested that growth has to happen, but all you can say is where it can go. It was really meant to be from a grassroots perspective. Some of the survey results were discussed in the Buckingham Plan.

Generally, people liked the scale and the size of the town and the opportunities the town gave people, but there were concerns that it could not maintain that if it did not develop in a certain way.

After struggling for many years with new construction designs and buildings, the Buckingham Vision and Design Statement was produced in 2001 by the Buckingham Town Design Group. A group of community members came together with concerns about the appearance of newly constructed buildings fitting into the existing historic Georgian architecture of the town center. The document helped build cohesiveness in the design of the town while providing a sense of focus for the residents of the community. 
The guidebook for new construction and renovations includes a selection of material choices, roof pitches, window types, landscaping, and options for the re-use of empty downtown storefronts.

The Vision and Design Statement was a guidebook for new developers. The document emphasizes to developers the unique characteristics of the market town, why Buckingham is special, and how they can preserve that uniqueness.
\#4: I led a group called the Buckingham Town Design Group, and we set out to produce a vision in terms of guidelines for developers coming into the town and try and pin them down a little bit as to what may be making our town so special and get them to build on it and integrate with it. In other words, the importance of looking at the place where you intend to build rather than just coming in with some pocket book design. We produced the Buckingham Vision \& Design Statement. I led the group that produced that document. That was one of my personal contributions.

It took two years in the making. One of the things we really tried to do was involve the town and it's quite difficult to involve people, for the researchers to collect information. It's a complicated process. We had to devise ways of making it attractive for people to come and comment. It wouldn't have been valid, unless we had a certain amount of involvement from the town. We set about doing it in different ways; there were quite a lot of workshops and photographic competitions. We went around speaking to people, groups and things. That was our research and it took two years. Our research involved the community just as much as the other research we did. Fatigue creeps in. We've just been asked to do our Census, which is once every ten years, but changes of government and so forth have all tried to put their own stamp on things. This neighborhood planning thing, it's a very good idea, but you got to get in with the fatigue divide. It's so easy to lose interest in people if their thoughts and ideas aren't capitalized on. So that's a challenge. 
Buckingham has unique

characteristics of a market town that the Vision and Design Statement are trying to preserve.

The Buckingham Society was heavily involved in creating the Vision and Design Statement.
\#6: We have the Buckingham Vision and Design Statement, which look at the typical design guidelines. We have very steep roofs here. We don't have shallow roofs like some parts of the country. We don't have a lot of stonework. We have brickwork and it's a dark red brick. These sorts of things are why we want to keep new buildings in our town, not identical, but in keeping. Milton Keynes and other towns have their colour brick and we have our colour brick here. We have our pitched roofs. We have dormer windows. We have curved buildings. We like these things in our town the way they are.

\#10: The Vision and Design Statement was something the Buckingham Society contributed greatly to. We had workshops and things like that and that [The Vision and Design Statement] grew out of that. That was to define the character of the town to try and get some kind of blueprint as to what kind of development Buckingham felt would be acceptable within the town. Design guidelines were created as to what the development should look like and fit in with the rest of the town. The Town Council then took that further with the Buckingham Plan.

Finances very much influence the extent of work that can and will be completed for a planning project or construction of a building. A limited amount of funding was available for current projects in Buckingham. The Town Council was the main funding source for the Buckingham Plan whereas the Buckingham Society and the Buckingham Design Group supported the Vision and Design Statement. Housing developments constructed in Buckingham were all privately funded by developers.

Some grants utilized for smaller projects were provided by organizations such as the English Heritage, which focuses on preservation and restoration.
\#3: Mainly by developers, but sometimes we get grants from organizations like the English Heritage, which preserves historic assets. Having a local society that cares also helps to get grants for the town. We have done fairly 
Most projects occurring in Buckingham are privately funded by developers and independent contractors. well. The Old Gaol [ex-Prison and now a local museum] has had 60,000 [pounds] spent on it in the last year from grants that were government funded, but then you need the people who are willing to put the man-hours in and complete the application and push the grants forward.

Government funding was used for parts of the bypass around town. The bypass on the outside of town has helped our infrastructure. We now have a big Tesco, and this has created problems because there is no reason for people to come to the centre of town. A lot of people will sleep and live on the outskirts of town and drive to work and will not come into the town centre. It changed the centre of Buckingham, to some extent. That is a huge risk to create that peripheral environment. We are in danger of losing our heart [Buckingham's Centre].

\#10: They [projects] are mostly independent or commercial. The developer comes along and buys the land, builds the houses and then sells them.

\section{The Future of Buckingham}

It is evident that a significant amount of public concern for the future of Buckingham exists among residents of the community. In particular, residents are concerned with how new development will impact the characteristics and compactness of the town that is universally liked. Participants were asked to reflect upon the relationship between residents of the community and Buckingham. Participants' comments illustrate that Buckingham residents have a vested interest in their community. The responses have the potential to guide future leaders and stakeholders in their decisions with planning processes and projects. 
Residents choose to live in Buckingham because of the unique characteristics it offers and its proximity to London, Milton Keynes, and Aylesbury.

Why is a strong determination presented by residents to protect Buckingham?
Residents continue to have an opinion about what is happening in Buckingham. The opinions may not be similar, but it encourages diversity and involvement with the town.
\#1: I think the people in Buckingham now are in Buckingham because they want to be in Buckingham. What you have to remember is that because Buckingham is located where it is, London an hour away, Aylesbury, Milton Keynes, which is the main link to London, but this is Buckingham's advantage. These people have moved out of London, or places like that, to live in Buckingham. There are three very good schools here [Buckingham] and then they all come back to the university. The schools attract people to the town.

\#3: Pride. Fairly independent. There are lots of area, county or national concerns. There is determination of protection [for Buckingham] in mind.

\#4: On the whole, positively. I would have thought if you talk to anyone on the streets, 90 percent of them would say, "It's a good place to be.” There would be grumbles about some things. A decent in-town market is quite a good thing. Refurbished library is a very good thing. A riverside walk is a very good thing. They are lovely things that have been included in the town, which has really made a difference.

\#5: People are concerned about the town; they do have a vested interest in their lives, what they do, where they live, and the rest of it. It's not difficult, if you go out there and speak to anybody who lives in Buckingham and ask, "What do you think about so and so?" Every person would have an opinion. They wouldn't just say “There's nothing I can do about it." You'll never hear that in Buckingham.

\#7: There are quite a lot of organizations that tries to link the university and the town such as the Friends of the University. I would hope to do rather more of the town things when I retire, but I think that most of the 
people in the university who live in Buckingham do take some part in the life of the town.

\#10: A lot of residents are involved, but with 200 societies, you tend to find the real people that are interested are involved with several organizations. Just a few residents are doing a lot of work and other people are going off doing their own things around and about. You also need to remember that we are a country town and people want to keep to themselves sometimes. Sometimes it is difficult to get people to come out and really take part.

In most communities, a core group of individuals tend to take action into their

own hands, becoming involved with groups, societies, projects, and various processes in a town. On most occasions, these individuals are generally consisting of an older generation. The same is true for Buckingham; the majority of leaders, stakeholders, members of organizations, and involved citizens in Buckingham consist of an older generation of individuals. In the future, more support and generated interest from younger individuals will be needed to maintain Buckingham as a vibrant market town.

Will it be a struggle to retain younger educated individuals in Buckingham?
\#4: The younger generations are encouraged to become involved, but it's not enough. Not enough. I think going back to that region there is not enough employment for educated young people. A lot of young people do come back and live here, but they don't tend to get involved in civic groups. I think there are quite a lot of single pressure groups that become involved in parents and toddlers groups, for example. I think that would be of great interest to a young family. My own children are post-university and they don't live here anymore, for example. People may come back in future years and maybe one of the great employers of Buckingham would be the university. It would be a great employer. 
It is a common concern that older generations guide community engagement activities in Buckingham, and these activities therefore lack interest from younger individuals.

How can Buckingham's citizens encourage younger generations to become involved with the town?
Leaders of the community are working with the school systems to teach children about the importance of preserving the unique characteristics of Buckingham.
I think young people don't want to live and work forever in a place today. Also, a market town was, by definition, based on an agricultural intellect. So you were, by necessity, tied to one place. Social mobility didn't really exist. If you were working on a farm, there was a seasonal pattern of life and it would be quite difficult to go off and work.

\#5: I have to say though, that a lot of community engagement is steered by the older generations, rather than the younger ones. That is a worry. I guess the younger ones are too busy building their careers, bringing up kids, etc.

\#7: I think one of the interesting things about Buckingham is there is a fairly large, young, cohort of people in their late 60s, early 70s. These people are pretty active in the community and now, people who are in midcareer; probably just don't have that much time to involve themselves very much in local things. I think one of the undoubted changes of the last 20 years is that people are working harder than they used to and they have less free time than they used to. One of the challenges to a community in an environment in which people are busier is really to find a group of people who do have some sufficient time to be active in the community. Buckingham is quite fortunate about that. That may be a demographic factor. One doesn't know what will happen when that generation passes on.

\#10: I think it [Buckingham] will get watered down with time and it will depend on who comes into the town and who will take control after our generation is gone. We need to instill the same values that our generation has in younger generations, so that they can carry on. We work closely with the school systems here to teach the children what we are preserving here in the town. We have been lucky that people who come to Buckingham 
do appreciate what we have and what to preserve the town.

No one knows what the future holds for Buckingham, but it is evident that the town will continue to grow in some way or another. The representatives of Buckingham have examined their town, each with a different view on how to improve and develop the community for future years. Some individuals would like the town to remain at its current state, with no growth, population increases, or additional housing developments. Others believe for the town to survive, it must continue to grow, but this growth must be monitored and gradual.

Buckingham has the potential to stand on its own with no help from Milton Keynes or Aylesbury Vale.

Can Buckingham survive as a vibrant market town if it continues on its current path?
If Buckingham reaches a target population, will additional facilities be constructed in the town?
\#1: Buckingham has the opportunity to be a very successful town. In fact, they could be so successful, that it could do anything it wants to do on its own. It doesn't need the influence of Milton Keynes. It doesn't need the influence of the Aylesbury Vale. It needs to be a complete member of Aylesbury Vale, which is the whole area in its entirety.

\#3: I'm not sure. I'm not sure it is big enough to survive happily as it is now. I was actually advised that we need to perhaps double in size, but I don't say that publicly. We need a gradual increase to about 25,000 [people] in order to generate sustainability in terms of size. I think the sustainable unit, as an architect, is increasing in size. Therefore, you have to hit that increased size in order to hit that optimum sustainable unit. For example, we don't have a cinema; if we hit that sustainable unit, we might get a cinema. There is still much talk of the Golden Days when we did have a cinema.

We need a reasonable range of facilities that I think Buckingham could have if it doubled in size. We then might be able to survive as a viable, vibrant community because I don't want to survive as a dormitory town. I hate 
If Town Council and community members obtained more authority with the development and decisions of a market town, could the town progress more efficiently in the future?
A common assumption among residents is that Buckingham will continue to grow in the future. dormitory towns where everybody goes out to work and there is no centre of activity. That could happen. That is one end of the spectrum. We increase in size and have no community spirit. I want to gradually increase and keep the community spirit. Institutions, functions, schools, shops, etc., all make it possible to live here without needing Milton Keynes and Aylesbury. We need to grow in a smart way so that we preserve our town. It may take 25-30 years for us to hit a goal of doubling in size.

\#4: Where do I see it and where I would like it are two rather different things. I think Buckingham probably has got some crossroads where there is a far greater respect for its heritage than there was years ago, which is good. Unfortunately, it is still subject to too many outside influences, which is bad. Town Councils, communities don't get enough say in the development of their area and I think that is difficult. If you want to see it progress in a group, then I would like to see higher tech industries, or businesses, move into the area for employment. I would like to see some innovative, but distinguished new architecture integrated into the new development areas, and not built by itself. I think architecture is very important. I think it really does shape your mind and shape your attitude to place. It's just the architecture, but it's also the spaces in between the architecture. You don't do really well unless you have some proper creative input into that. Those are the places that I would like to see go. I suspect that we're not big enough or ever going to have enough clout within the district to really see those things come to life; there will be pockets of good stuff and pockets of bad stuff and it will sort of jog along.

\#6: I see it growing. It's inevitable; it will grow. We have some of the facilities that the people need and the villages don't. Petrol is going to get more expensive and people think 
they would like to live in a country house and drive to get whatever they need, but they are

not going to be able to afford it. You are going to have to live somewhere where you can walk to go to the library, post office, and for shopping. We could do with more cycling facilities and encouraging more cycling. I shop every day because I am here in town.

\#9: I should think it would grow to be slightly larger over the years. Perhaps take another couple of estates and that's about it, but who knows.

\#10: I would like to see it going on developing the way it is without getting too big. Unfortunately, Buckingham has to grow to survive. People have to have places to live and things to do. We hope that we can go on growing fairly gradually, but unfortunately you get the investment without the big developments. By going smaller all the time, you don't get the investments in your infrastructure, and downtown area, and things like that where you need funding to survive and keep the town vibrant. To grow you have to accept bigger growth to get the investment. It's getting to be a bit difficult.

Debate still continues about a reasonable goal for growth in the community. The residents' vision is to maintain and enhance Buckingham's vibrant market town character and to improve the appeal of the town, making it more attractive for visitors and new residents, while also reducing the amount of travel outside the town to other communities. To accommodate this vision Buckingham must decide if it can continue to grow and still maintain its vibrancy. The majority of residents are in favor of growth, but the growth must be incremental and thoroughly planned.

Have the limits for growth already been exceeded in Buckingham?
\#5: The goals for growth have already been exceeded. The 700 houses to the south of the bypass and 400 plus up here [Moreton Road] 
How can the community protect Buckingham's town center with the continued growth that is occurring?

Is there a specific target population that the town should agree upon and then prevent future growth once that population target is reached? and proposal on the other side of town are probably excessive. Therefore, we need to be very careful that we safeguard the core of the town, and ensure we also could accommodate everything that such an increase in population will cause. Like the road infrastructure is a major problem. That is part of some of the changes that we need to face.

\#9: I don't know. Maybe 10,000 [more residents]? When I first came to Stowe in the 1970s, it was said that Buckingham hadn't grown since when it was in its medieval times. It was about 3,000 people then.

\#11: I suppose you do get the question of when is enough enough? When a country is growing, or a region is growing, do you have concentrated growth in some places and then have it shut off in other locations? The challenge is can you welcome some of that growth and investment continuously or do you have to periodically stop it? I don't know if that is a problem in the short-term or the long term. Also, can the town centre grow with the population size? Can it grow to fit the services the town needs if it grew in population? So all these are arguments that... yes, the town could grow, but will it lose its reasons for being a market town if it continued to grow forever? Then we end up with a sprawling city.

\section{Participants' Conclusions}

At the conclusion of each interview, the participant was asked to reflect on what they have learned from being a part of the Buckingham community. A sense of belonging to a community has a different meaning for each participant in the research study. Responses illustrate that participants have gained a better understanding of what it means to become a part of a community and that they have the ability to make a difference in the community. Residents show a great deal of concern for the future of 
Buckingham, and they are excited to have the opportunity to improve the Buckingham

community.

Individuals can make a difference in the community by becoming involved.

To maintain the vibrancy of the town, new activities need to be generated.
\#3: It is very important to identify what is happening and get involved to change it. Write letters. Stand on a street corner and argue. Don't take no for an answer. Find other people with a similar idea. It is nice to see some of the things happen that you are for. It makes you feel like you have done something good for the town. Some people will actually say that you have resisted progress. You have to be thoughtful and aware in this environment, not just say this is the new environment, and pity on you. You can base ideas on it and draw from the experiences, but don't copy it.

\#4: In my conclusion, the importance of place is being undervalued and I suspect it will always be undervalued because people don't devote enough time and attention to it.

\#6: It's the size of the place, not the geographical whereabouts of the place. A lot of small places have a spirit. You can say there is a Buckingham spirit. People will back Buckingham against Aylesbury or Milton Keynes. If we can keep Buckingham vibrant, and we are aiming to keep the town vibrant with new things to do and see, then we become very much a hub in the northern end of the county. We can make a much bigger and better town, providing that people aren't just sleeping here and working and shopping somewhere else. People are actually a part of the town. That's what we've got to do. We've got to make people think, "I am a Buckingham person." 
It should be noted that the same problems will always repeat themselves in a community. What can Buckingham do to prevent problems from recurring?
\#10: I have learned that you nearly always have a repeat of the same problems. There always has been a parking problem. There has always been a flooding problem with the river and there always will be because you can't control it. There have always been traffic problems and if it grows, it will get worse. There are very rarely any new problems. All repeats. 


\section{CHAPTER V}

\section{Discussion}

\section{Findings}

Analysis in the Learning History revealed recurring themes. These themes are presented in the SWOT Analysis (Strengths, Weaknesses, Opportunities, and Threats) in Table 5 (Humphrey, 2005). The SWOT Analysis is a strategic planning method used to identify internal strengths and weaknesses and external opportunities and threats (Humphrey, 2005). Short-term and long-term goals may then be created to leverage strengths and opportunities and to ameliorate weaknesses and threats.

Table 5

SWOT Analysis

\begin{tabular}{|c|c|}
\hline Strengths & Weaknesses \\
\hline $\begin{array}{l}\text { - } \quad \text { Deep sense of community and successful } \\
\text { - } \quad \text { A Tommunity engagement efforts } \\
\text { - } \text { Buckingham's future } \\
\text { - } \quad \text { Proactive Traders' Association } \\
\text { - } \text { Buckinghing documents created by the } \\
\text { - } \quad \text { Univet Town identity } \\
\text { - } \quad \text { Stowe School and Grammar School }\end{array}$ & $\begin{array}{l}\text { - Repeat of the same problems in } \\
\text { Buckingham (flooding, traffic, parking) } \\
\text { Shared governance with Buckingham } \\
\text { Town Council, Aylesbury Vale District } \\
\text { Council, Buckinghamshire County } \\
\text { Council }\end{array}$ \\
\hline Opportunities & Threats \\
\hline $\begin{array}{l}\text { - Local Powers Act (Parliament of England, } \\
\text { 2012) } \\
\text { - External national and regional dedication } \\
\text { to long-term planning strategies } \\
\text { - Sustainable growth }\end{array}$ & 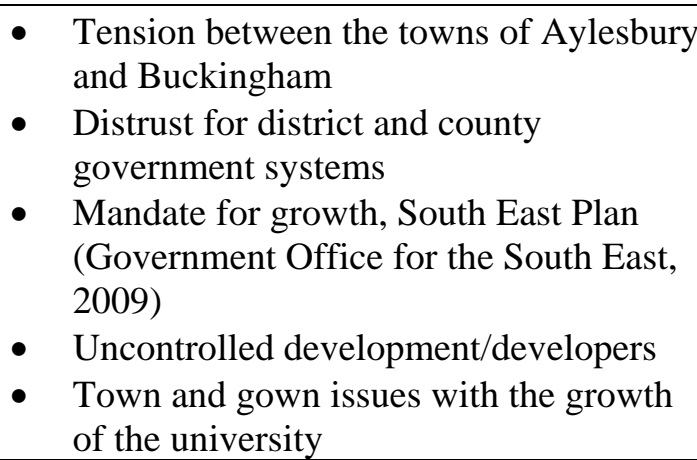 \\
\hline
\end{tabular}

Note. Adapted from “SWOT Analysis for Management Consulting,” by Albert S. Humphrey, 2005. 
Strengths. SWOT Analysis defines internal strengths as areas in which an organization has excelled or illustrated distinctive competencies over others ("SWOT Analysis Template," 2011). Buckingham has presented several positive strengths, including successful strategies, processes, and projects that have the potential to assist other communities that may be facing similar challenges such as those that Buckingham experienced.

Buckingham has several unique characteristics that set it apart from other market towns and communities. A deep sense of community and successful community engagement efforts show that residents are highly dedicated to improving the future of Buckingham, fighting for the identity of the town, and preserving the unique and charming characteristics found throughout the community. In recent decades, Buckingham has become a wealthier community, supporting skilled employees at educational institutions in Buckingham such as Stowe School, the Grammar School, and The University of Buckingham. These educated individuals tend to invest a deeper interest in their community, which in turn increases the amount of community engagement in Buckingham. A variety of societies and organizations are also present in Buckingham, which encourage residents to become involved and to find an issue or project that interests them.

Town Councils are commonly found in communities throughout England, but Buckingham’s Town Council is unique in many ways. Other communities may benefit from the example set by the Buckingham Town Council. The Buckingham Town Council office is located in the heart of the town center. I found that Town Council employees are very welcoming, encouraging the public's opinions with issues or 
comments in regard to Buckingham. Aylesbury, the county town in Buckinghamshire County, does not have a Town Council office in the town center. In talking with the residents, it was revealed that the physical disconnect of the Town Council Office and center of the town in Aylesbury has lessened community engagement and participation among residents. The Buckingham Town Council was also heavily involved in creating the Buckingham Plan and other local planning documents, strengthening community relationships by including citizens in the planning process from the beginning.

The Buckingham Traders’ Association is extremely proactive in supporting the economic development and tourism base of the Buckingham community. Traders' are dedicated to improving the town center by creating events and festivals. Traders' also encourage support from residents to shop and dine locally to increase pedestrian activity in the town center. In contemporary society, it is more common for local residents to commute to Milton Keynes or Aylesbury to do their shopping in a large shopping mall where commercial and chain stores can be found under one roof. The Buckingham Traders' Association reminds residents of the importance of supporting local independent shops in the town rather than traveling to the out-of-town big-box stores. Other communities could examine strategies the Buckingham Traders’ Association has utilized to improve the economic development of Buckingham such as organizing regular meetings and events, and visiting other communities for inspiration.

Buckingham understands that it has the ability to control some aspects of the market town's future. The Town Council and leaders of the Buckingham community heavily engaged the public, various organizations, and societies when creating planning documents such as the Buckingham Plan (2008) and the Vision and Design Statement 
(2001) in recent years. The Buckingham Town Council initiated a series of community meetings, workshops, online questionnaires, surveys, and informational sessions in regard to the challenges of the economic climate and the impact it has on the local community, as well as the potential growth in the area. Outside planning firms provided limited assistance for Buckingham’s planning documents. Therefore, Town Council members, stakeholders, planners, architects, and residents created these in-house strategic plans and guidebooks to assist with the long-term planning and future development of Buckingham. Collaboration among Buckingham's residents and leaders has increased community engagement. Participants revealed in the interviews that it was critical for the Buckingham Town Council to consult with the public through surveys, questionnaires, and meetings when creating these documents and not an outside planning firm.

Buckingham residents understand the community better than outside professionals and know what they would like to see happen with the future of the town. Involving citizens at the beginning of the process to get their thoughts, ideas, and suggestions allows them to be a part of the process. Community leaders and stakeholders will be able to read the Learning History to gain a better understanding of successful citizen engagement in a community.

Weaknesses. SWOT Analysis defines internal weaknesses as an area of performance that poses problems and disadvantages to an organization or community ("SWOT Analysis Template," 2011). Participants noted in the current study that the same problems repeat over and over again in Buckingham. Consistent problems include flooding of the River Ouse, lack of parking in the town center, problems arising from increased traffic in the town center, challenges in accommodating lorries (large trucks 
used to transport goods), and concerns about congestion on the bypass around town. Community leaders and stakeholders will be able to read the Learning History and gain a better understanding of those issues as they are described by the participants so that they may generate solutions for the issues at hand.

Opportunities. SWOT Analysis defines opportunities as external environmental factors that would allow an organization or community to improve ("SWOT Analysis Template," 2011). The Learning History revealed opportunities for the Buckingham community to improve and include a proposal for local autonomy, such as the Localism bill (Parliament of England, 2012), and continuing dedication to long-term planning strategies from all three tiers of government systems: local, district, and county.

In recent decades, there has been a push for decentralized governmental systems, lessening the power of centralized governmental systems. Participants in this study revealed the need for local autonomy and power to make critical decisions at the local level within each community. Current debates in England surround a Localism bill, which grants authority to the local level and councils (Parliament of England, 2012). Most towns are in favor of the Local Powers Act, which received Royal Assent on November 15, 2011 (Parliament of England, 2012). Critical decisions in the community may now be made by local Buckingham citizens, rather than people outside the community, who do not always know what is best for the town. Buckingham could benefit greatly from the Local Powers Act, gaining power to manage future growth and improve planning projects and procedures that are currently in place.

The Buckingham Community is dedicated to initiating long-term planning strategies for its future. Long-term planning is a critical part of the planning process. 
Buckingham residents understand they are threatened by continuous growth, new housing developments, expansion of Milton Keynes, and becoming a dormitory town. Most importantly, population growth and increased housing will continue to impact the Buckingham community for several years into the future. Therefore, these challenges should be addressed with long-term support with integration from all three tiers of government: local, district, and county.

Threats. Participants noted various shortcomings and negative attributes in the Learning History narrative. SWOT Analysis defines threats as external factors that can hinder achieving goals and objectives ("SWOT Analysis Template," 2011). The Buckingham community may continue to work on issues such as uncontrolled growth and division among local government systems to promote a better future for the town. These threats include disconnected local government relationships, lack of cooperation among government systems, tension between the towns of Aylesbury and Buckingham, distrust for district and county government systems, and mandates for growth, such as the South East Plan (Government Office for the South East, 2009), uncontrolled development/ developers, and town and gown issues with the growth of the university. The noted shortcomings may be prevented or avoided in the future with use of the Learning History narrative.

A distinctive philosophical divide exists between Aylesbury, the county town of Buckinghamshire County, and Buckingham, a regional hub located in the northern section of the county. Several centuries ago, Buckingham was the county town in Buckinghamshire County. A lack of cooperation between the two towns is evident through lack of cooperation and sharing of community funding. Participants revealed 
feelings of animosity and disgust toward Aylesbury, mostly because of issues regarding the distribution of funding. Nearly all the participants noted that Buckingham does not receive proper support and funding from the county to maintain the vibrancy of the market town. Buckingham is aware of its issues and challenges, but it needs appropriate support to ensure that it is not forgotten in the county. The Learning History has the potential to assist other communities that struggle with challenges in regard to relationships among towns in a county or region.

During the interview process, participants revealed that there is a certain amount of distrust for district and county government systems. This distrust has somewhat stemmed from the lack of cooperation between the Buckingham Town Council, Aylesbury Vale District Council, and the Buckinghamshire County Council. Participants revealed that the Aylesbury Vale District Council often does not deliver the necessary processes, funding, and support for the Buckingham community. Participants would like to see better cohesiveness and cooperation among the local, district, and county tiers of government as they establish goals and try to meet the needs of the region. Improving collaboration among the systems and increasing planning efforts for the region will help enhance both the urban centers and towns throughout the county.

Assessing the Methodology. A secondary finding from this process came from the effective use of the Learning History to study community change. As I experienced the Learning History, the methodology demonstrated both shortcomings and positive merits. It was a beneficial experience to gain a deep understanding of Buckingham, learning how an unfamiliar community operates, functions, and accomplishes daily tasks. I created valuable relationships with the leaders and stakeholders of the community, 
while also learning how to gain a better understanding of a town through various perspectives. A select few shortcomings can also be noted in relation to the Learning History methodology. As a researcher, I was only able to interview a convenience sample of participants due to my time constraints in England. Therefore, the perspectives and opinions of the entire Buckingham community were not represented in this study.

This Learning History has the ability to specifically draw attention to significant issues that that are common to numerous communities throughout the world, such as lack of support for the downtown, uncontrollable growth, and the need for local government authority. The significant issue this research study seeks to understand is how a community can grow while maintaining its identity. The Learning History revealed that it is possible for the town to grow and maintain its identity of a quaint and charming market town, preserving the unique characteristics. Communities have options. Buckingham needs to make the choice as to what kind of community it wants to be and then move toward that goal with long-term planning initiatives. In order to maintain the vibrancy of Buckingham, most participants indicated that the town needs to grow. A select few residents wish to see the town remain the same, but the majority of residents would like Buckingham to continue growing at a sensible pace.

Leaders and community members must understand how to wisely manage the growth and plan long-term, examining current and future challenges and pressures. This Learning History has the potential to assist other towns and communities facing similar challenges initiated by uncontrollable growth. Those communities can take note of the positive merits and faulty decisions that were revealed in the Learning History narrative and apply those decisions to their own community. 


\section{Further Research}

Additional steps to increase credibility of the research remain for further study using the Learning History methodology. These steps include workshops, dissemination, and publication/outreach (Kleiner \& Roth, 1996). Workshops would include select participants as well as other stakeholders in the community who would relive their experience and see how others’ observations from the research compared to their own. The dissemination process would allow the participants to discuss the document and the various stories to check for credibility. The dissemination process would include the application and transfer of knowledge of the data. Communities, city officials, and town organizations can utilize the analyzed data presented in this Learning History to reflect upon and improve their understanding of planning processes. The Learning History document would then become part of the community and used for other applications (Kleiner \& Roth, 1996). The final step in the credibility process includes outreach to various communities, allowing others to benefit from this research study.

Further research would also include a comparison of English and American planning initiatives and local government procedures. Planning activities in the United States and England have similarities as well as differences. Both countries use various forms of public participation to encourage community engagement. From my experience in town planning, observations made in England illustrate that the United Kingdom better understands how to cultivate a sense of community engagement in local residents than does the United States. Observations made in England illustrate greater numbers of supporters and engaged citizens attended the planning meetings, town council meetings, and activities held by the town of Buckingham compared to towns of a similar size in the 
United States. Buckingham residents deeply care about the future development of their community and believe their voice is acknowledged.

Additional research could include replicating the Learning History process with the Buckingham community after some time has passed. The researcher would then be able to observe what the Buckingham community had learned from the information provided by this Learning History and examine any change that has occurred. Analysis would again include planning processes, community development strategies, strategies for managing growth, and community engagement.

\section{Conclusions}

This study analyzed the lived experience of change in the small market town of Buckingham, England, with specific emphasis on issues of growth, urban sprawl, and the decline of the historic downtown area. The problems Buckingham encountered did not make the town unique in any way; the town faced many common challenges that small market towns and other communities similar to Buckingham are experiencing. Buckingham stands out from other communities because residents are deeply passionate about the town, demonstrating strong community engagement and enthusiasm to fight for the identity of the market town and the distinctive characteristics that make it unique.

Projects in community development and planning generally involve individuals from various levels of government, community members and residents, and key stakeholders. Each person in this study became involved with the Buckingham community or a specific project for their own personal reasons and added diverse knowledge, education, opinions, and lived experiences to the existing body of knowledge. 
Small towns in both England and America are seeking to gain local autonomy. In the United States, many towns desire the power of home rule, but home rule is a power granted by the state. Therefore, each municipality has different amounts of authority to make decisions at the local level. Similar to a home rule charter in the United States, current debates in England discuss a Localism bill titled Local Powers Act, which grants authority to local governments and councils. Through conversations with local officials in both countries, the debates are similar for local autonomy. Power for planning at the local level is one of the most critical powers to obtain; issues surface regarding funding, land-use, development, making decisions in the best interest of the community, and political corruption when planning authority occurs at the local level. Local autonomy would allow communities to make local decisions regarding critical issues such as those that Buckingham is experiencing with growth and maintaining an identity.

The findings of this study were presented in a relatively new and unique format, a Learning History, which was developed at the Massachusetts Institute of Technology (Kleiner \& Roth, 1997). The methodology was designed to gather information directly from the individuals and key stakeholders involved in change efforts in large corporations. Here it was used to record change regarding community development and planning projects in Buckingham, England, from 1967-2011. The information provided by the participants in the interviews combined with the thoughts and comments of the researcher to provide helpful insights. The findings from this study have the potential to inform new stakeholders participating in current and future change processes in Buckingham. These findings reveal both negative and positive merits of the Buckingham community. Ideally, this transfer of knowledge will serve locally to inform smoother 
transitions and sustain a productive change process. More broadly, use of the Learning History methodology in this way contributes to existing knowledge regarding planning processes, strategies for community development and revitalization efforts. Therefore, the findings of this study have the potential to assist other communities that may be facing similar challenges such as those that Buckingham experienced. There is much to be learned from the experiences of others. 


\section{REFERENCES}

Association of Small Historic Towns and Villages of the United Kingdom. (2011). About Retrieved March 15, 2011, from http://www.ashtav.org.uk/styled/

Aylesbury Vale District Council. (2011). Aylesbury Vale local strategic partnership. Retrieved December 12, 2011, from http://www.aylesburyvaledc.gov.uk/community-living/community-planningpartnerships/local-strategic-partnership/

Bacon, E. M. (1974). Design of cities. New York: Penguin Group.

Beatley, T. (2007). Envisioning solar cities: Urban futures powered by sustainable energy. Journal of Urban Technology, 14(2), 31-46. doi: $10.1080 / 10630730701531682$

Beaumont, C. E., \& Tucker, L. (2002). Big-box sprawl (and how to control it). Municipal Lawyer, 43(2), 7-10.

Bevington, M. (2002). Stowe house. London: Paul Hoberton publishing.

Birch, E. L. (Ed.). (2009). The urban and regional planning reader. New York: Routledge.

Bonner, D. C., \& Vernon, M. T. (1984). Buckingham: a history of a country market town. Milton Keynes: Grillford Ltd.

Bridger, J. C., \& Luloff, A. E. (1999). Toward an interactional approach to sustainable community development. Journal of Rural Studies, 15(4), 377-387. doi: 10.1016/s0743-0167(98)00076-X 
Brown, J. (1986). The english market town: A social and economic history, 1750-1914. Marlborough: Crowood Press.

Buckingham Town Council. (2008). The Buckingham plan 2008: A vision for a vibrant market town. Buckingham.

Buckingham Town Council. (2010). Planning committee of Buckingham Town Council Retrieved December 5, 2011, from http://www.buckinghamtc.gov.uk/committees/planning.html

Buckingham UK. (2011). Thoroughly modern traditional brand Retrieved Jenuary 17, 2012, from http://www.buckinghamuk.info/special.php?pageno=56

Buckinghamshire County Council. (2011a). Council structure Retrieved December 14, 2011, from http://www.buckscc.gov.uk/bcc/about_your_council/Council_structure.page?

Buckinghamshire County Council. (2011b). The South East plan Retrieved April 2, 2011, from http://www.buckscc.gov.uk/bcc/strategic_planning/south_east_plan.page

Centre for Cities. (2011a). Cities outlook 2011 Enterprise House (pp. 68). London.

Centre for Cities. (2011b). The growth conundrum: The importance of cities to economic growth in the UK Enterprise House (pp. 1-5). London.

Chalklin, C. (2001). The rise of the English town, 1650-1850. Cambridge Cambridge University Press.

Chamberlin, R. (1985). English market towns. London: Weidenfield and Nicolson, Ltd. 
Charmaz, K. (2005). Grounded theory in the 21st century: Applications for advancing social justice. In N. K. Denzin \& Y. S. Lincoln (Eds.), The sage handbook of qualitative research (Third ed.). Thousand Oaks: Sage Publications, Inc.

Clarke, J. (1984). The book of Buckingham. Buckingham: Busiprint, Ltd.

Close, C. (2009). Buckingham through time. Stroud: Amberley Publishing Plc.

Cohen, R. (1997). Small town revitalization planning: Case studies and a critique. Journal of the American Planning Association, 43(1), 3-12.

Communities and Local Government. (2011). Net supply of housing: 2010 -11, England (pp. 18).

Congress for the New Urbanism. (2011). What is CNU? Retrieved February 7, 2010, from http://www.cnu.org/who_we_are

Cross, N. (2007). Designerly ways of knowing. Boston: Birkhauser Verlag AG.

Davies, H. (2008, 20 April). This little town beat market, The Sunday Times p. 8.

Deitrick, S., \& Ellis, C. (2004). New Urbanism in the inner city. [Article]. Journal of the American Planning Association, 70(4), 426.

Denzin, N. K., \& Lincoln, Y. S. (2005). The sage handbook of qualitative research. Thousand Oaks: Sage Publications, Ltd.

Department for Environment Food and Rural Affairs. (2011). Mid-2010 population estimates for lower layer super output areas (pp. 6).

Dixon, T. (2009). Urban land and property ownership patterns in the UK: Trends and forces for change. Land Use Policy, 26, Supplement 1(0), S43-S53. doi: 10.1016/j.landusepol.2009.08.017 
Downs, A. (2001). What does 'smart growth' really mean? The Kentucky Long-Term Researcher, 8(2), 1-12.

Dredge, D., \& Jenkins, J. (2003). Destination place identity and regional tourism policy. [Article]. Tourism Geographies, 5(4), 383-407.

Duany, A., \& Plater-Zyberk, E. (1991). Towns and town-making principles. New York: Rizzoli.

Dyckhoff, T. (2009, August 15). Space: Let's move to Buckingham: it's for when Milton Keynes proves too 20th century, The Guardian, p. 55.

Elliott, D. J. (1975). Buckingham: The loyal and ancient borough. Chichester: Phillimore \& Co.

Ewing, R., Pendall, R., Chen, D., \& America, S. G. (2002). Measuring sprawl and its impact. Smart Growth America. Washington D.C.

Ewing, R., Schmid, T., Killingsworth, R., Zlot, A., \& Raudenbush, S. (2008).

Relationship between urban sprawl and physical activity, obesity, and morbidity: Urban ecology. In J. M. Marzluff, E. Shulenberger, W. Endlicher, M. Alberti, G. Bradley, C. Ryan, U. Simon \& C. ZumBrunnen (Eds.), (pp. 567-582): Springer US.

Fainstein, S. S., \& Campbell, S. (2002). Introduction: Theories of urban development and their implications for policy and planning. In S. S. Fainstein, Campbell, S. (Ed.), Readings in Urban Theory (Second ed.). Oxford: Blackwell.

Fisherman, R. (2003). Urban utopias: Ebenezer Howard, Frank Llyod Wright, and Le Corbusier. In S. Campbell \& S. S. Fainstein (Eds.), Readings in planning theory (pp. 21-60). Oxford: Blackwell Publishers. 
Flood, R. (2010). The relationship of 'systems thinking' to action research. Systemic Practice and Action Research, 23(4), 269-284. doi: 10.1007/s11213-010-9169-1

Government Office for the South East. (2009). The south east plan: Regional spatial strategy for the south east of England London: The Stationary Office.

Grbich. (2007). Qualitative data analysis: An introduction. Thousand Oaks: Sage Publications, Ltd.

Hall, J. (2009, August 2). Market towns fit for the future; Self-help is the key to survival of local business centres, The Sunday Telegraph, p. 7.

Hall, K. B., \& Porterfield, G. A. (2003). Community by design: New Urbanism for suburbs and small communities. Journal of the American Planning Association, 69(3), 323-324.

Howard, E. (1902). Garden cities of to-morrow. London: S. Sonnenschein \& Co., Ltd. Humphrey, A. S. (2005). SWOT analysis for management consulting SRI Alumni Association Newsletter. Menlo Park.

Jacobs, J. (1961). The death and life of great American cities. New York: Vintage Books.

Kemp, R. L. (2007). Managing America's cities: A handbook for local government productivity. Jefferson, NC: McFarland.

Kincheloe, J. L., \& McLaren, P. (2005). Rethinking critical theory and qualitative research (Third ed.). Thousand Oaks: Sage Publications.

Kleiner, A., \& Roth, G. (1996). Field manual for a Learning Historian. In M. Center for Organizational Learning (Ed.).

Kleiner, A., \& Roth, G. (1997). Learning Histories: A new tool for turning organizational experience into action. In S. Wetlaufield (Ed.), (pp. 6). 
Kleiner, A., \& Roth, G. (2000). Oil change: Perspectives and corporate transformation. New York: Oxford University Press, Inc.

Kotkin, J. (2006). Suburbia: Homeland of the American future. In E. L. Birch (Ed.), The urban and regional planning reader. New York: Routledge.

Lincoln, Y. S., \& Guba, E. G. (1985). Naturalistic inquiry. Beverly Hills: Sage Publications.

Local Government Improvement and Development. (2010a). City regions - key links and contacts Retrieved January 13, 2011, from http://www.idea.gov.uk/idk/core/page.do?pageId=4730958

Local Government Improvement and Development. (2010b). What is sustainable development? Retrieved February 9, 2012, from http://www.idea.gov.uk/idk/core/page.do?pageId=9574569

McFall, B. (2012). Design Research.

New Market Towns. (2011). New market town roots. In B. a. Willmore (Ed.).

Parliament of England. (2012). Localism act 2010-2012 Retrieved January 4, 2012, from http://services.parliament.uk/bills/2010-12/localism.html

Press Association. (2011, November 11). House prices soar in market towns, The Guardian.

Roth, G. (1996). Learning Histories: Using documentation to assess and facilitate organizational learning (pp. 31). Cambridge: MIT.

Roth, G., \& Kleiner, A. (1995). Learning about organizational learning: Creating a Learning History Sloan School of Management. 
Roth, G., \& Kleiner, A. (1997). Learning about organizational learning. In M. C. f. O. Learning (Ed.). Cambridge, MA.

Roth, G., \& Kleiner, A. (2000). Car launch: The human side of managing change. New York: Oxford University Press, Inc.

Roth, G. L., \& Senge, P. M. (1995). Research territory, from theory to practice: Processes and structure at the MIT center for organizational learning. Society for Organizational Learning, 14.

Silverman, D. (1998). Qualitative research: Theory, method and practice. Thousand Oaks: Sage Publishing, Ltd.

Soule, D. (2006). Urban sprawl: A comprehensive reference guide. Westport: Greenwood Press.

Sustainability Reporting Program. (2004). Sustainable communities Retrieved February 7, 2012, from http://www.sustreport.org/issues/sust_comm.html

Sustainable Development Commission. (2011). What is sustainable development Retrieved February 9, 2012, from http://www.sd-commission.org.uk/pages/whatis-sustainable-development.html

SWOT Analysis Template. (2011) Retrieved February 15, 2012, from http://swotanalysistemplate.com/

Tedlock, B. (2005). The observation of participation and the emergence of public ethnography. In N. K. Denzin \& Y. S. Lincoln (Eds.), The sage handbook of qualitative research (Third ed.). Thousand Oaks: Sage Publications, Inc.

The Buckingham Design Group. (2001). Buckingham vision and design statement. Buckingham, England. 
The South East England Development Agency. (2011, January 17). The south east plan, from www.seeda.org.uk/about_the_south_east/

Walker, D. (1994). New towns. In Guest (Ed.), Architectural Design (Vol. 111). London: Academy.

Wallace, A. F. C. (1956). Revitalization movements. American Anthropologist, 58(2), 264-281.

Wiewel, W., Gaffikin, F., \& Morrissey, M. (2000). Community-University partnerships for affordable housing. Journal of Policy Developmnet and Research, 5(1), 27-45. World Commission on Environment and Development. (1987). Our common future. Oxford: University Press. 
APPENDICES 
APPENDIX A

IRB Protocol - Approval 


\title{
WWestVirginiaUniversity.
}

Office of Research Compliance

\section{Expedited-IRB Protocol-Approval}

\author{
To: $\quad$ McFall, Barbara \\ From: $\quad$ WVU Office of Research Compliance \\ Date: $\quad$ Monday, January 10, 2011 \\ Subject: Approval Letter \\ Tracking \#: H-22856 \\ Title: $\quad$ A UK Market Town Maintaining Identity Amidst Urbanizing Sprawl, A \\ Learning History
}

The research study referenced above was reviewed by the West Virginia University Instituional Review Board (IRB) via expedited review procedures and was approved in accordance with 46 CFR 46.101(b).

This protocol was reviewed using the following:

Initial Protocol (Expedited/Full Board) Review Checklist

The following documents have been approved and validated for use in this study and are available in the BRAAN system:

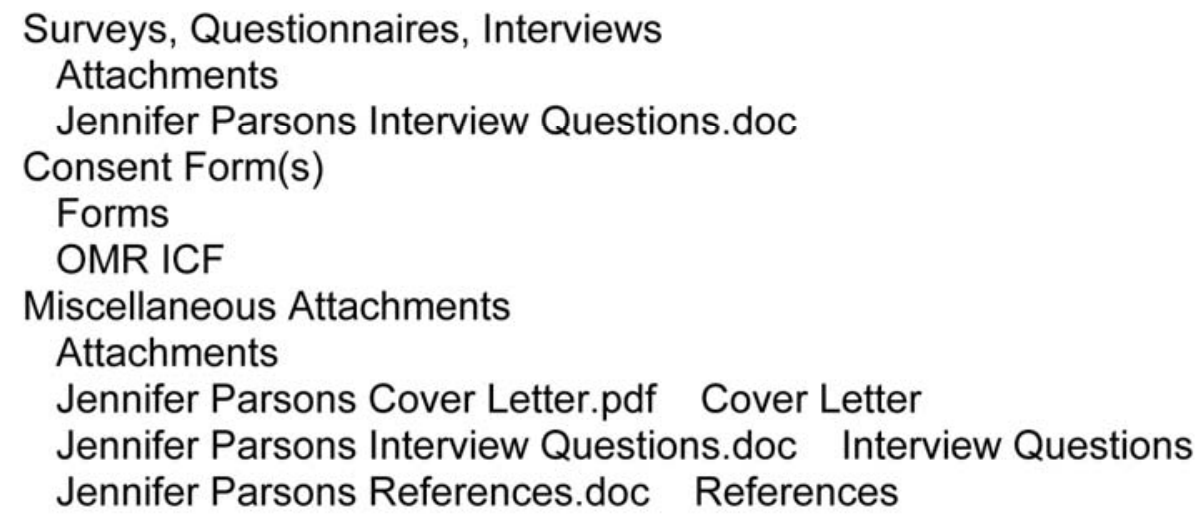


The approval period is from January 10, 2010 through January 9, 2011.

Thank you.

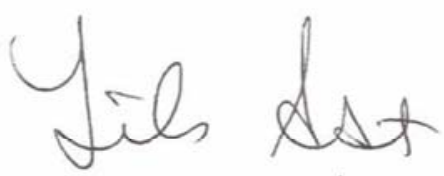

Board Designee: Ast, Lilo

Letter Sent By: Ast, Lilo, 1/10/2011 3:29 PM

Once you begin your human subject research, the following regulations apply:

1. Unanticipated or serious adverse events/side effects encountered in this research study must be reported to the IRB within five (5) days.

2. Any modifications to the study protocol or informed consent form must be reviewed and approved by the IRB prior to implementation.

3. You may not use a modified informed consent form until it has been approved and validated by the IRB. 
APPENDIX B

IRB Protocol - Continuing Review 


\section{W. WestVirginiaUniversity. \\ Office of Research Compliance}

\section{Expedited-Continuing Review-Approval}

To: $\quad$ McFall, Barbara

From: $\quad$ WVU Office of Research Compliance

Date: $\quad$ Monday, February 06, 2012

Subject: Approval Letter

Tracking \#: CR-1907 (H-22856)

Title: $\quad$ A UK Market Town Maintaining Identity Amidst Urbanizing Sprawl, A Learning History

This continuing review was reviewed using the following:

Continuing Review Checklist (210c)

The following Documents have been reviewed and approved:

Surveys, Questionnaires, Interviews Attachments Jennifer Parsons Interview Questions.doc Consent Form(s) Forms OMR ICF Miscellaneous Attachments Attachments Jennifer Parsons Cover Letter.pdf Cover Letter Jennifer Parsons Interview Questions.doc Interview Questions Jennifer Parsons References.doc References The expedited category is 7.The approval period is from February 6, 2012 through February 5, 2013.

Thank you.
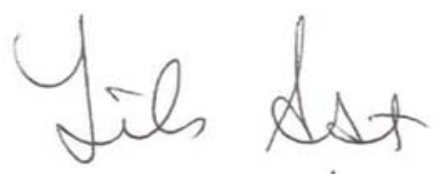

Board Designee: Ast, Lilo

Letter Sent By: Ast, Lilo, 2/6/2012 6:46 PM

Continue following the regulations below:

1. Unanticipated or serious adverse events/side effects encountered in this research study must be reported to the IRB within five (5) days.

2. Any modifications to the study protocol or informed consent form must be reviewed and approved by the IRB prior to implementation.

3. You may not use a modified informed consent form until it has been approved and validated by the IRB. 
APPENDIX C

Cover Letter 


\section{W WestVirginiaUniversity Davis College of Agriculture, Natural Resources and Design}

Dear Participant,

This letter is a request for you to take part in a Learning History project to document the planning for growth of the town of Buckingham, United Kingdom and its connection to the Stowe Estate in an effort to preserve the vibrant, market town. This research study is being conducted in pursuit of a Ph.D., by Jennifer Parsons in the Division of Design and Merchandising at West Virginia University. She will be working under the supervision of Dr. Barbara McFall, as Associate Professor in the Davis College of Agriculture, Natural Resources and Design. Your participation in this project is greatly appreciated and will include an interview that will take approximately one to two hours and will be recorded.

Your involvement in this project will be kept as confidential as legally possible. Your recorded interview will be quoted in the final report/publication; however, you will not be listed be name but rather by title. You must be at least 18 years of age to participate. Your participation is completely voluntary. You may choose to skip any questions you do not wish to answer, or you may discontinue at any time. You are free to discuss any and all aspects of your involvement in the planning process, but are advised to speak carefully because you may be identifiable by your specific story or "voice".

West Virginia University's Institutional Review Board acknowledgement of this project is on file.

I will be contacting you shortly by phone and/or email to schedule an interview. I hope that you will participate in this research project, as it could be beneficial in understanding of future revitalization and planning projects. Thank you very much for your time. Should you have any questions about this letter or the research project, please feel free to contact Jennifer Parsons by phone at (301) 697-9389 or by email at Jennifer.Parsons@mail.wvu.edu. You may also contact Dr. Barbara McFall at (304) 293-3402 or by email at Barbara.McFall@mail.wvu.edu.

Thank you for your time and help with this project.

Sincerely,

Jennifer Parsons

Division of Design \& Merchandising

Phone: 304-293-3402 702 Allen Hall

Fax: 304-293-2750 P.O. Box 6124

www.design.wvu.edu Morgantown, WV 26506 Equal Opportunity/Affirmative Action Institution 
APPENDIX D

Consent Form 


\title{
WestVirginiaUniversity.
}

Office of Research Compliance

\section{CONSENT AND INFORMATION FORM}

\author{
OMR ICF
}

Principle Investigator: McFall, Barbara

Department:

AGRICULTURE \& FORESTRY - Family \& Cons. Science

Tracking Number:

$\mathrm{H}-22856$

\section{Study Title:}

A UK Market Town Maintaining Identity Amidst Urbanizing Sprawl, A Learning

History

Co-Investigator (s):

Parsons, Jennifer

\section{Sponsor:}

Barbara, McFall, Ph.D.

\section{Contact Persons}

In the event you should experience any side effects or injury related to this research, you should contact Dr. Barbara McFall at (304) 293-3402. (After hours contact Dr. Barbara McFall at (304) 594-0717.)

If you have any questions, concerns, or complaints about this research, you can contact Dr. Barbara McFall at (304) 293-3402.

For information regarding you rights as a research subject, you may contact the Office of Research Compliance at (304) 293-7073.

\section{Introduction}

In addition, if you would like to discuss problems, concerns, have suggestions related to research, or would like to offer input about the research, contact the Office of Research Integrity and Compliance at (304) 293-7073.

You, , have been asked to participate in this research study, which has been explained to you by Jennifer Parsons. This study is being conducted by Jennifer Parsons, Bachelor of Architecture, in the Department of Resource Management at West Virginia University sponsored by the Division of Design and Merchandising with funding provided by the Division of Design and Merchandising. This research is being conducted to fulfill the requirements for $a$ 
doctoral dissertation in Human and Community Development in Davis College of Agriculture, Natural Resources and Design at West Virginia University, under the supervision of Dr. Barbara McFall.

\section{Purposes of the Study}

The purpose of this study is to learn more about the planning process and future plans for Buckingham, UK as it plans to remain a self-sustaining market town amidst the urbanizing sprawl surrounding London. WVU expects to enroll approximately 20-25 subjects from the greater Buckingham community and participating individuals that are expected to participate in this study.

\section{Description of Procedures}

This study involves an interview that will take 1-2 hours for you to complete and will be recorded. You will be asked to discuss your involvement in the planning process of Buckingham, UK. You do not have to answer all the questions. You will have the opportunity to see your questionnaire before signing this consent form, and approve your transcript prior to publication later. You will have the opportunity to see the questionnaire before signing this consent form.

\section{Risks and Discomforts}

There are no known or expected risks from participating in this study, except for the mild frustration associated with answering the questions. The only possible risk anticipated is social (if you are identifiable in your story telling), and the mild frustration associated with answering the questions.

\section{Alternatives}

You do not have to participate in this study.

\section{Benefits}

You may not receive and direct benefit from this study. This knowledge gained from this study may eventually benefit others.

\section{Financial Considerations}

There are no special fees or payments for participating in this study.

\section{Confidentiality}

Any information about you that is obtained as a result of your participation in this research will be kept as confidential as legally possible. Your research records and test results, just like hospital records, may be subpoenaed by court order or may be inspected by federal regulatory authorities without your additional consent. 
Audiotapes or videotapes will be kept locked up and will be destroyed as soon as possible after the research is finished.

In any publications that result from this research, neither your name nor any information from which you might be identified will be published without your consent.

Your name will not be released

You can decide to sign or not to sign this authorization section. However, if you choose to not sign this authorization, you will not be able to take part in the research study.

\section{Persons/Organizations providing the information:}

- Interviewees

\section{Persons/Organizations receiving the information:}

- Dr. Barbara McFall, Jennifer Parsons, and the people and companies that they use to oversee, manage, or conduct this research study.

- The members and staff of any Institutional Review Board (IRB) that oversees this research study.

- West Virginia University Office of Research Compliance and Office of Sponsored Programs.

The Information is being disclosed for the following reasons:

- Review of your data for quality assurance purposes

- Publication of study results (without identifying you)

You may cancel this authorization at any time by writing to the Principle Investigator:

Dr. Barbara McFall

702 B Allen Hall

P.O. Box 6124

West Virginia University

Morgantown, WV 26506-6124 U.S.A.

If you cancel this authorization, any information that was collected already for this study cannot be withdrawn. Once information is disclosed, according to this authorization the recipient may re-disclose it and then the information may no longer be protected by federal privacy regulations. This authorization will not expire unless you cancel it. 


\section{SIGNATURE}

I have read this section and all of my questions have been answered. By signing below, I acknowledge that I have read and accept all of the above.

\section{Voluntary participation}

Participation in this study is voluntary. You are free to withdraw your consent to participate in this study at any time. Refusal to participate or withdrawal will not affect your future care, [or your employee status at West Virginia University or your class standing or grades, as appropriate] and will involve no penalty to you. In the event new information becomes available that may affect your willingness to participate in this study, this information will be given to you so that you can make an informed decision about whether or not to continue your participation. You have been given the opportunity to ask questions about the research, and you have received answers concerning areas you did not understand.

Upon signing this form, you will receive a copy.

I willingly consent to participate in this research.

Signature of Subject or

The participant has had the opportunity to have questions addressed. The participant willingly agrees to be in the study. 
APPENDIX E

Defense Presentation 


\section{A UK Market Town Maintaining Identity Amidst Urbanizing Sprawl: A Learning History}

\section{Jennifer Parsons, Ph.D. Candidate}

Barbara McFall, Ph.D., Chair

Kathryn Burton, Ph.D.

Michael Dougherty, Ph.D.

Ron Dulaney, M.Arch.

Jennifer Selin, J.D.

PhD in Human and Community Development Doctoral Defense: March $19^{\text {th }}, 2012$

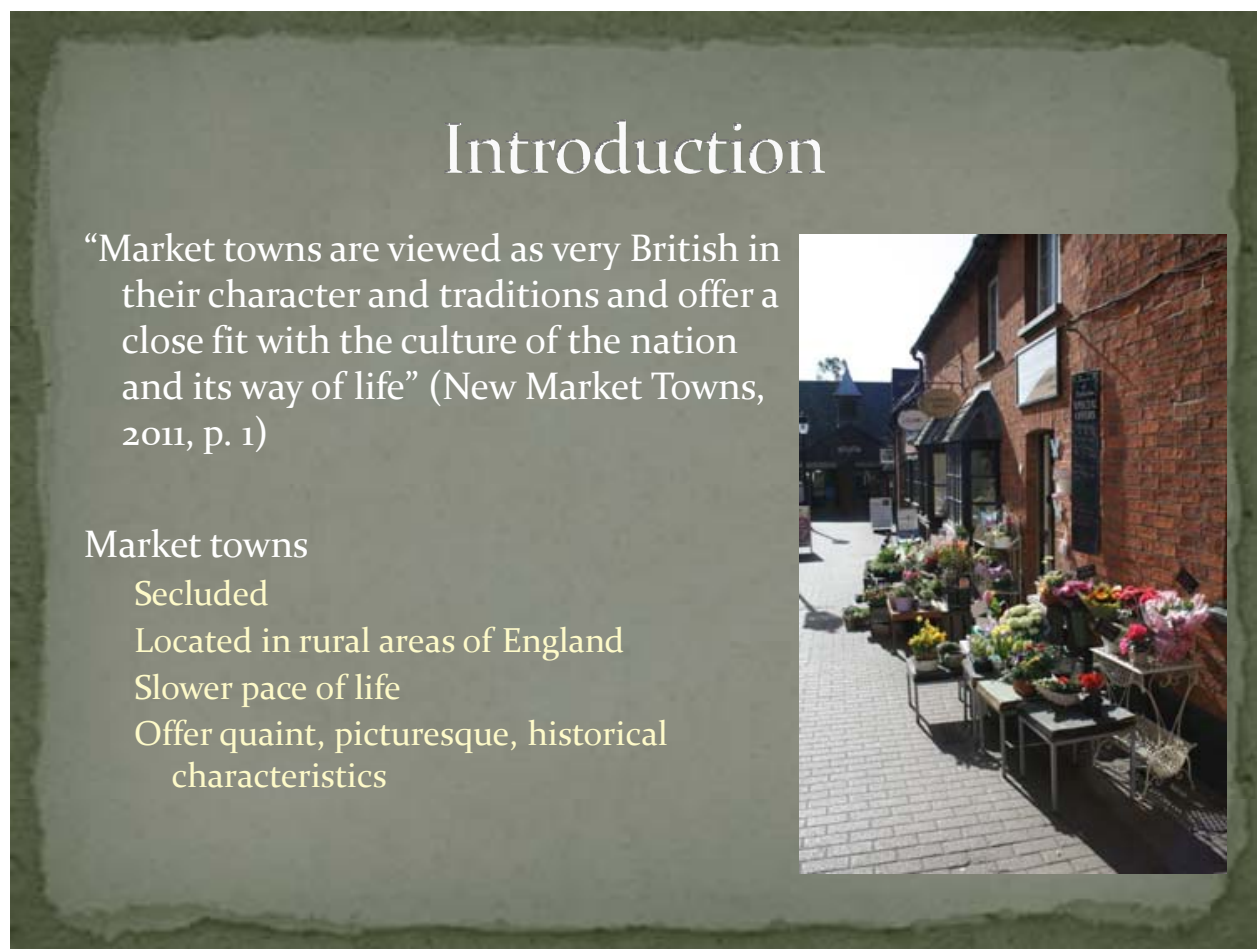




\section{Introduction}

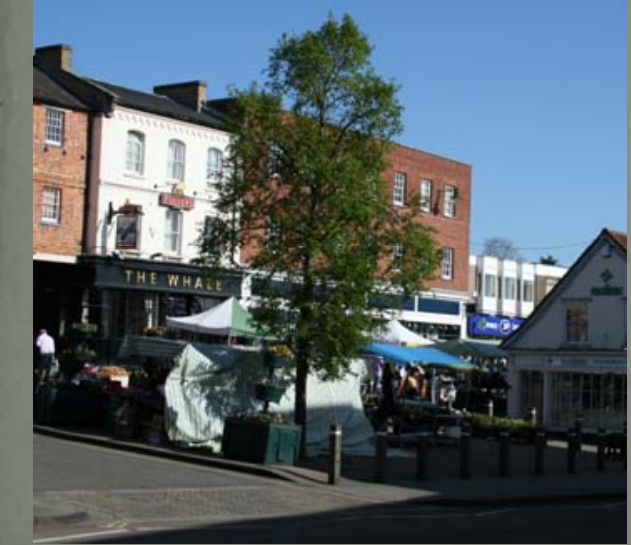

Buckingham's Town Center: Market Day

\section{Market towns}

Trading at a fixed time and place

Way of life for townspeople and other small villages

Produce, livestock, baked goods, and services

Permission to be a market town was granted by the Royal Charter, English Monarchy

Limited number of market towns - about 6 miles apart

\section{Introduction}

Buckingham, England

Granted Royal Charter by the King January 17, 1554

Holds a regular market twice a week

Located just 70 miles NW of London in Buckinghamshire County

Current population: 12,00o

Located on River Ouse

Serves as a hub of activity to other towns and villages in the northwestern part of Buckinghamshire

Area is predominantly rural with agriculture and farming

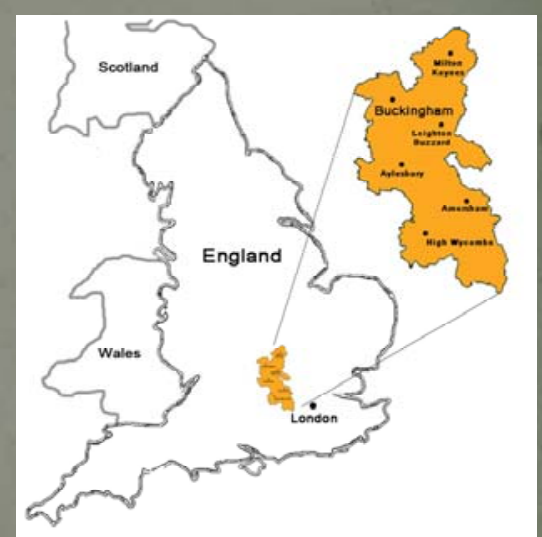



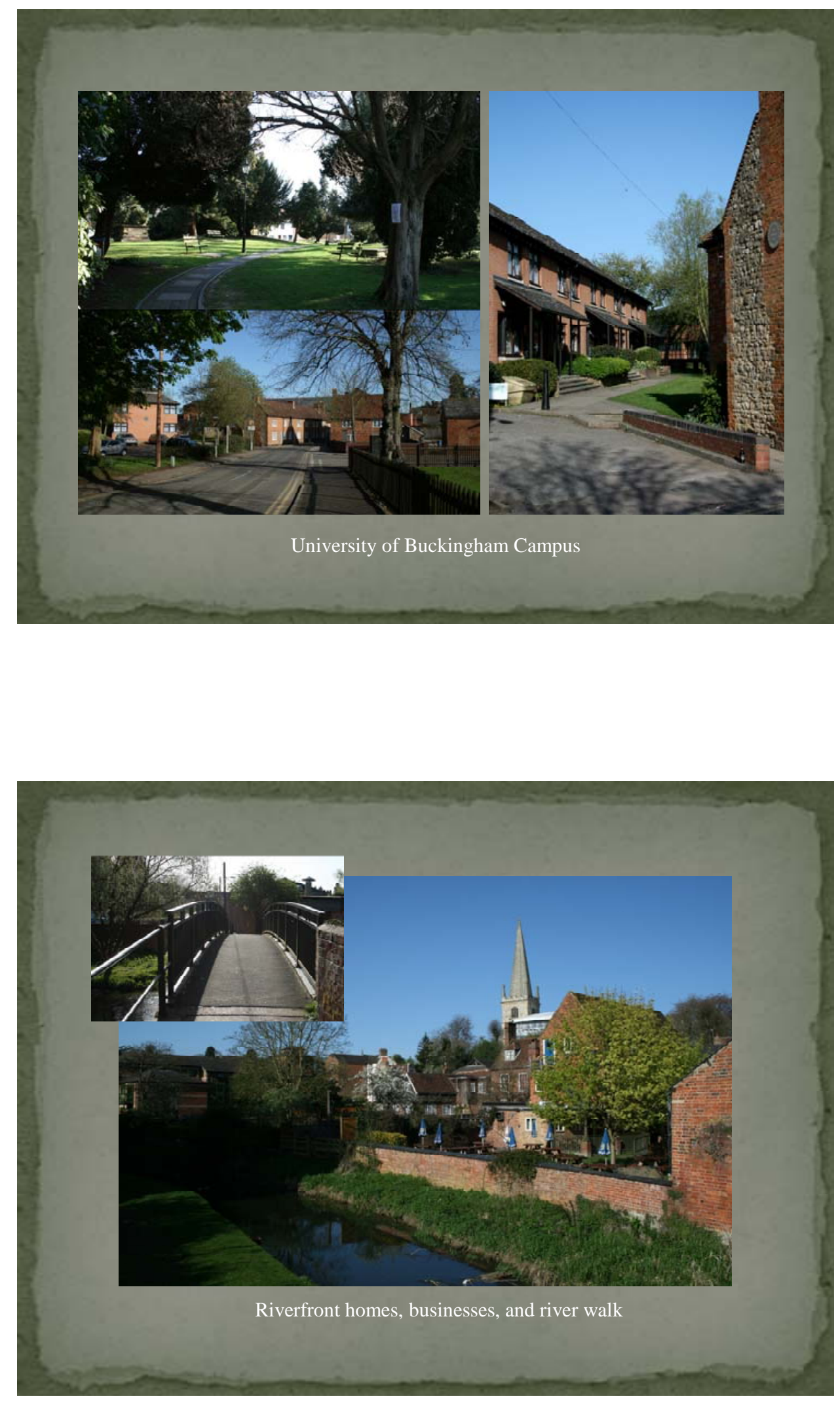


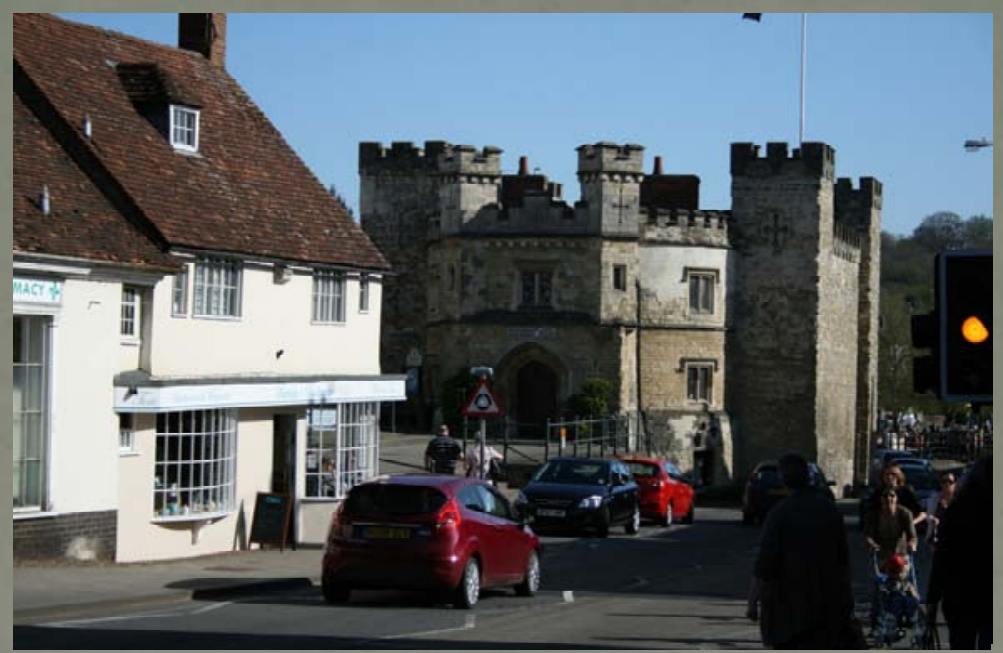

Town Center - Old Gaol

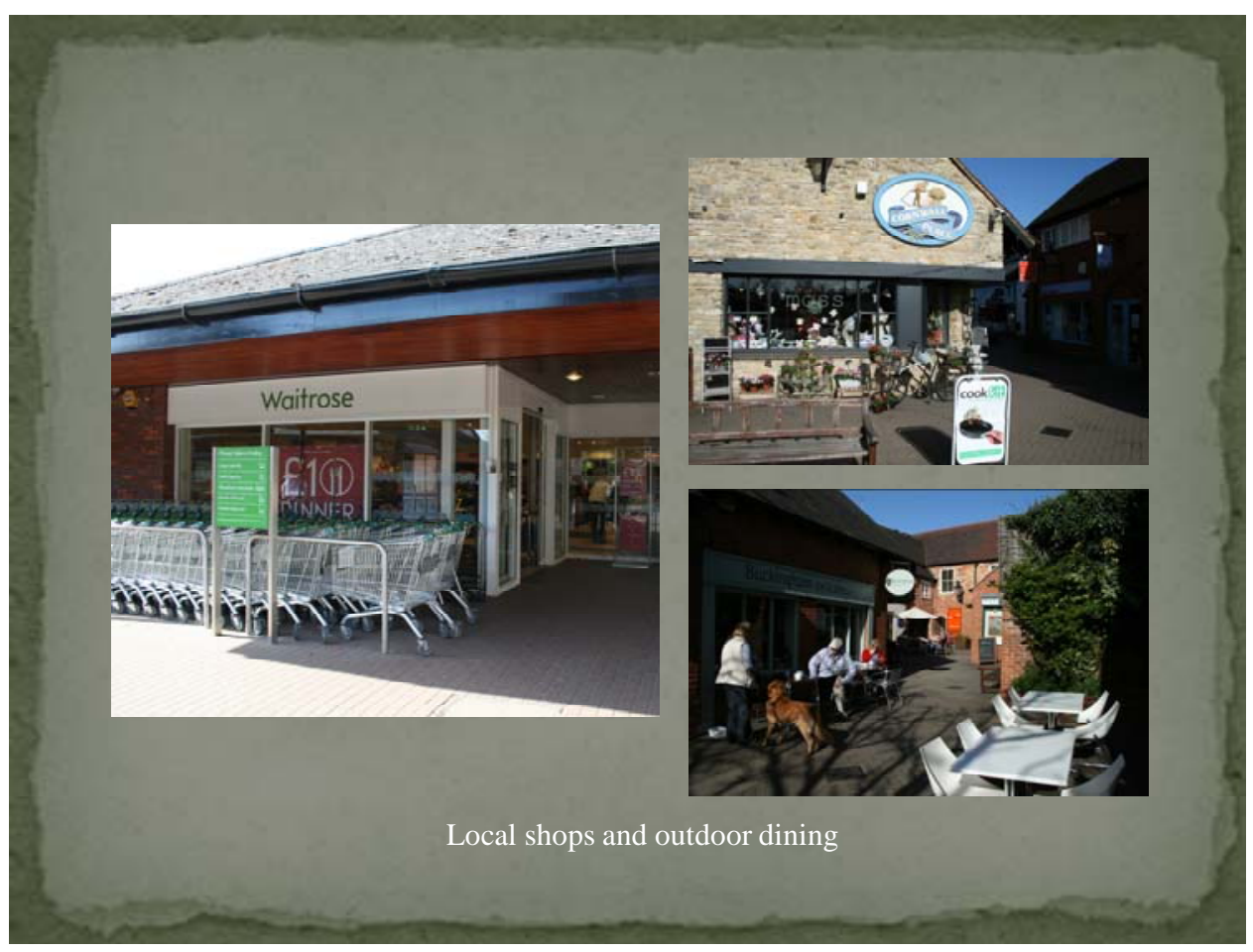



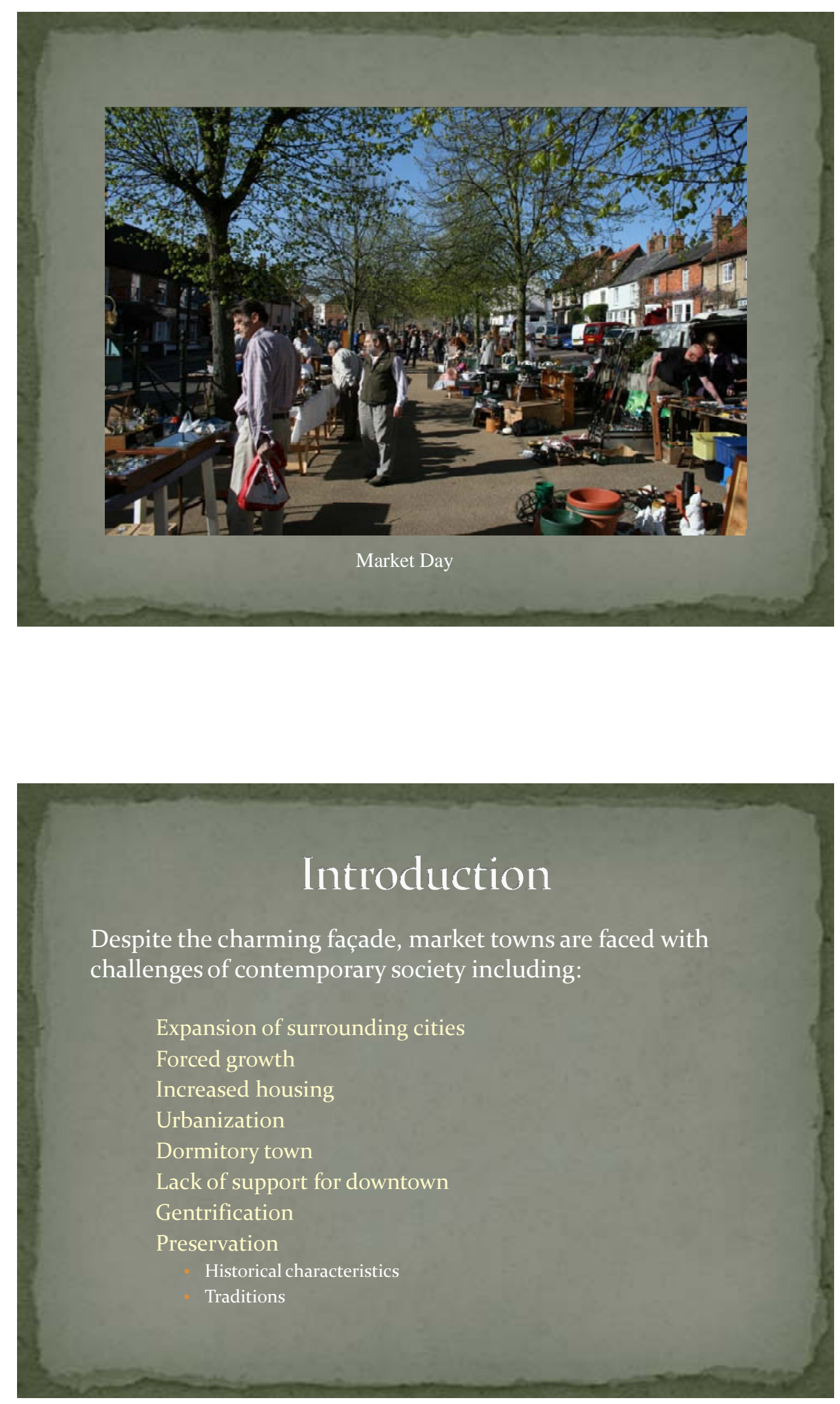


\section{Problem Statement}

How can a town maintain it's identity amongst urbanizing sprawl that occurs around it?

The Learning History methodology, developed at MIT (Kleiner \& Roth, 1997), explores the lived experience of change in the small market town of

Buckingham, England, with specific emphasis on:

Issues of growth

Urban sprawl

Decline of the historic downtown area

Community involvement in planning and change efforts from 1967-2011 will be examined through the narrative of key stakeholders.

The goal of this research is to provide credible and useful information about Buckingham's experience with change and planning processes over time in a format that might inform similar communities seeking to retain or re-envision their identities in the future.

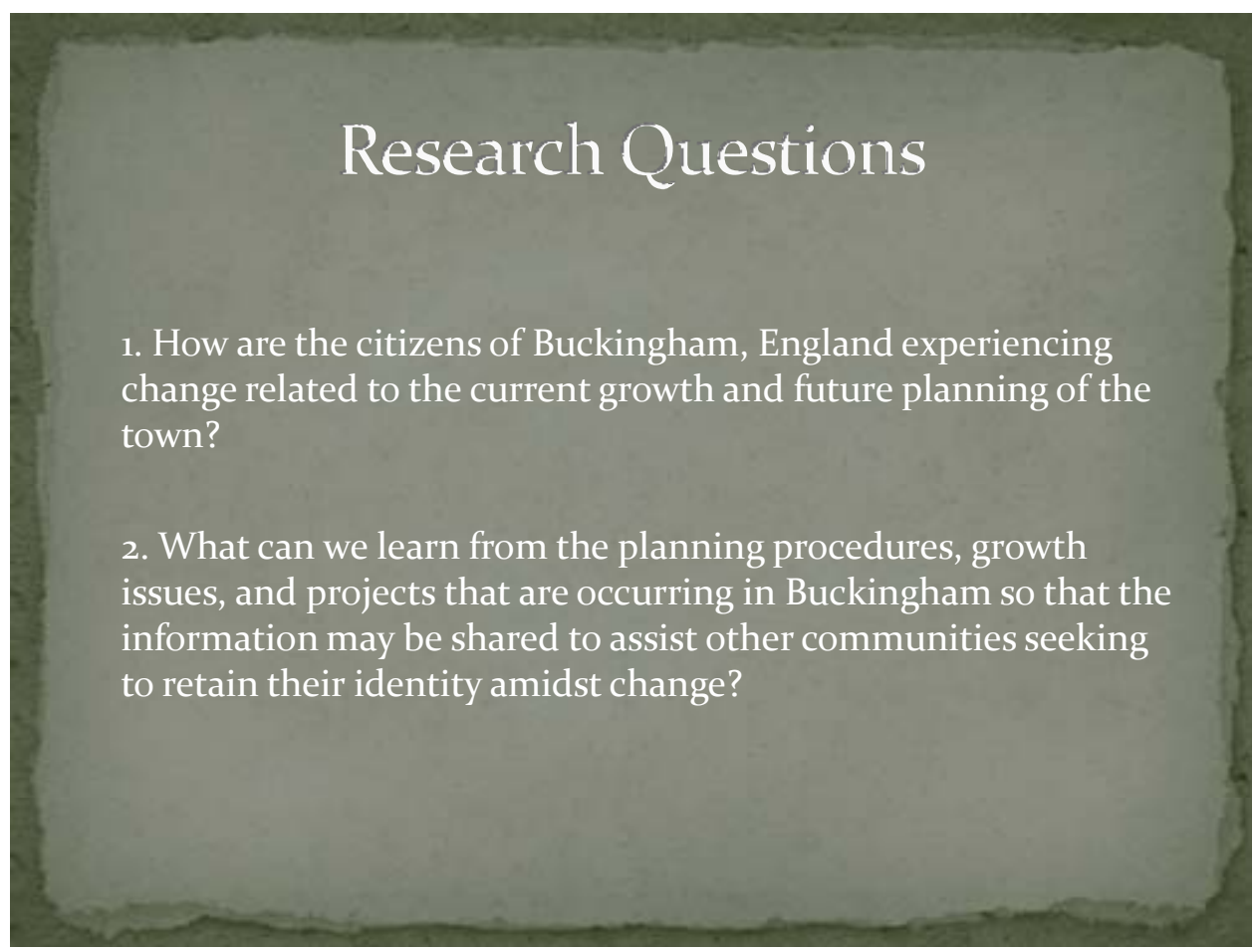




\section{Delimitations and Limitations}

\section{Delimitations:}

This research was delimited to a 44-year period in the market town of Buckingham, England (1967-2011), and a convenience sample of involved stakeholders.

\section{Limitations}

The findings from this study are unique to its participants, local, and time. They may or may not be credible and useful in other situations. These findings will certainly inform design of future projects in Buckingham as they engage with the South East Plan.

The findings may also have applications in similar small towns.

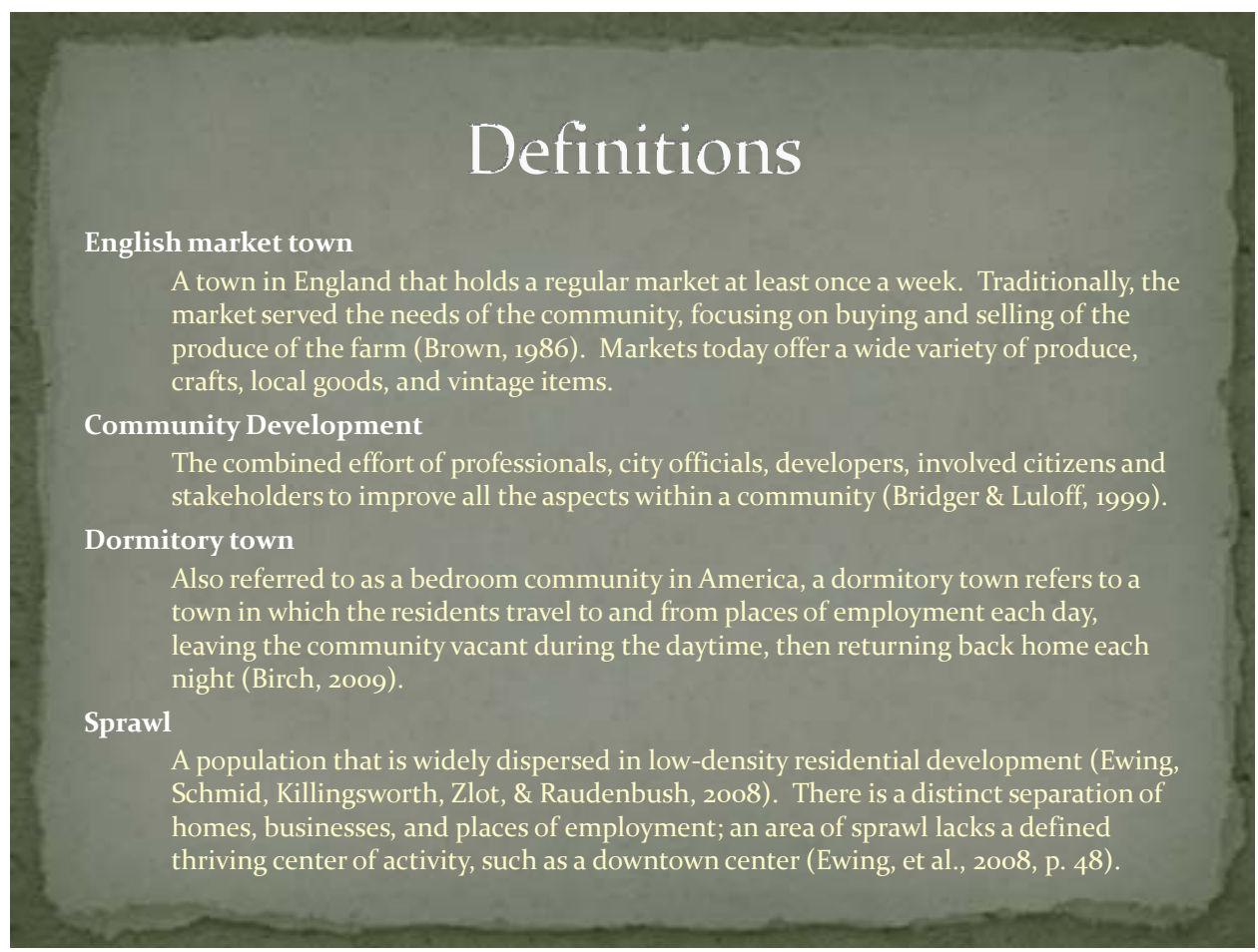




\section{The Growth Challenge}

England has been experiencing continuous growth in recent decades

By 2016 , the UK is projected to increase by 4.4 million to a total population of 71 million

(Dixon, 2009)

Government is forcing policies to increase homebuilding, especially in the South East region

117,700 new homes were constructed in 2010-2011

South East region has the largest proportion of new homes

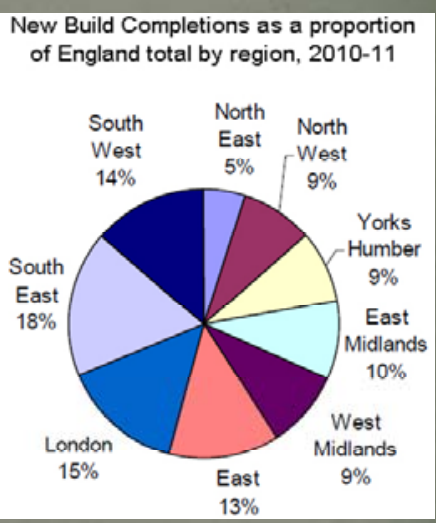

(Communities and Local Government, 2011)

20,980 new homes (18\%)

(Communities and Local Government, 2011)

\section{(Communities and Local Government, 2011)}

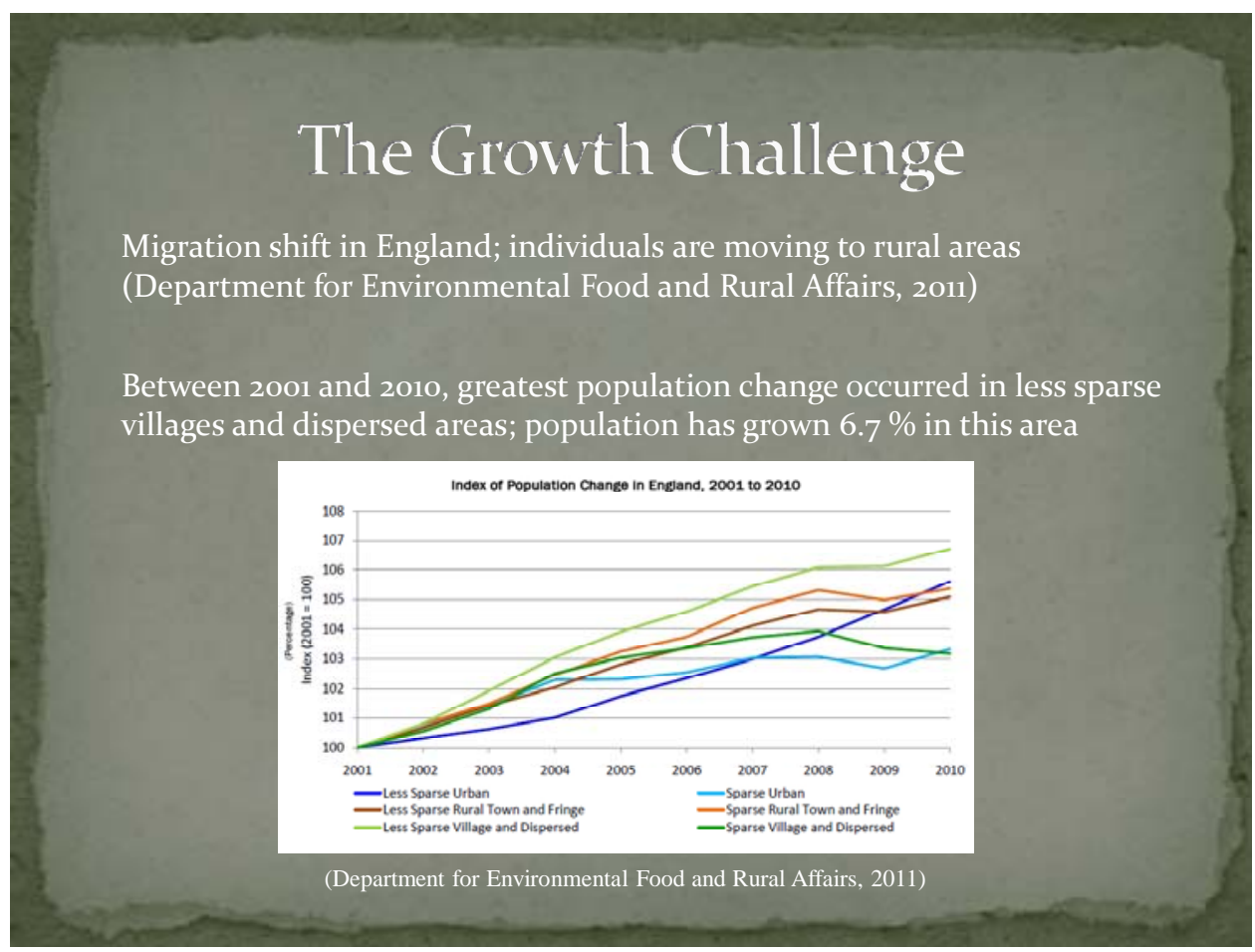




\section{The Growth Challenge}

The South East Plan

Created by Parliament of England

Devoted to long term spatial planning for the south east region of England from 2006-2026 (The South East England Development Agency, 2011)

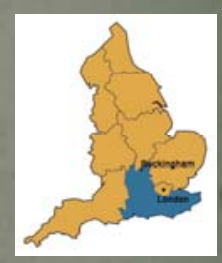

Cope with the growth of greater London

Eight sub-regions identified

for growth and regeneration

Milton Keynes

Aylesbury Vale

Buckingham

Projected 5,000 new households

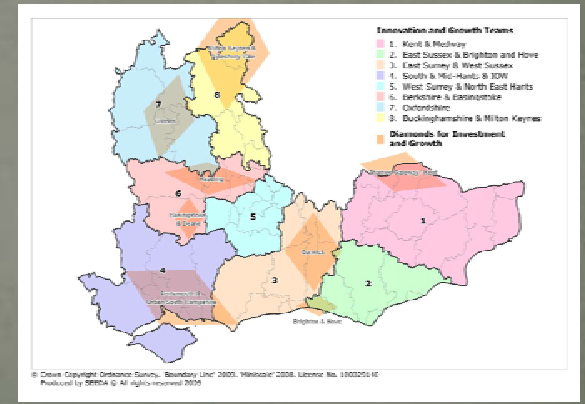

(The South East England Development Agency, 2011)

\section{Exploration of Planning in England}

Explores local planning in England, more specifically the South East region, and the market town of Buckingham

Explores influences that have historically shaped the planning processes

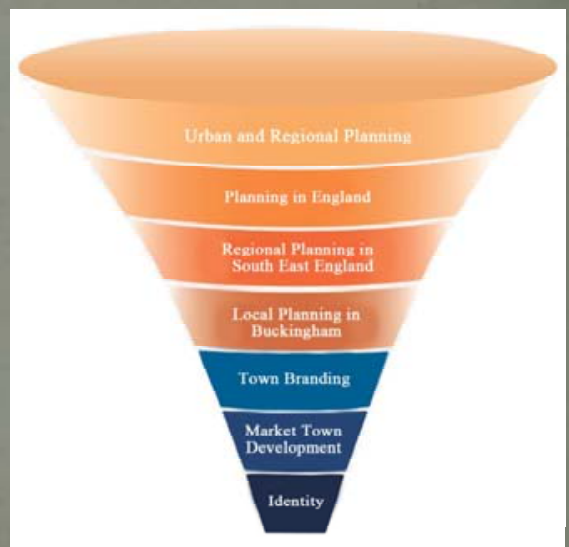




\section{Urban and Regional Planning}

Historically defined as "design and regulation of the uses of space that focus on the physical form, economic functions, and social impacts of the urban environment and on the location of different activities within it" (Howard, 1898)

Multidisciplinary field which includes:

Architecture, landscape architecture, various forms of engineering, policy and law, social and behavioral sciences, and economics

Systems thinking; each system within a community directly affects others (Flood, 2010)

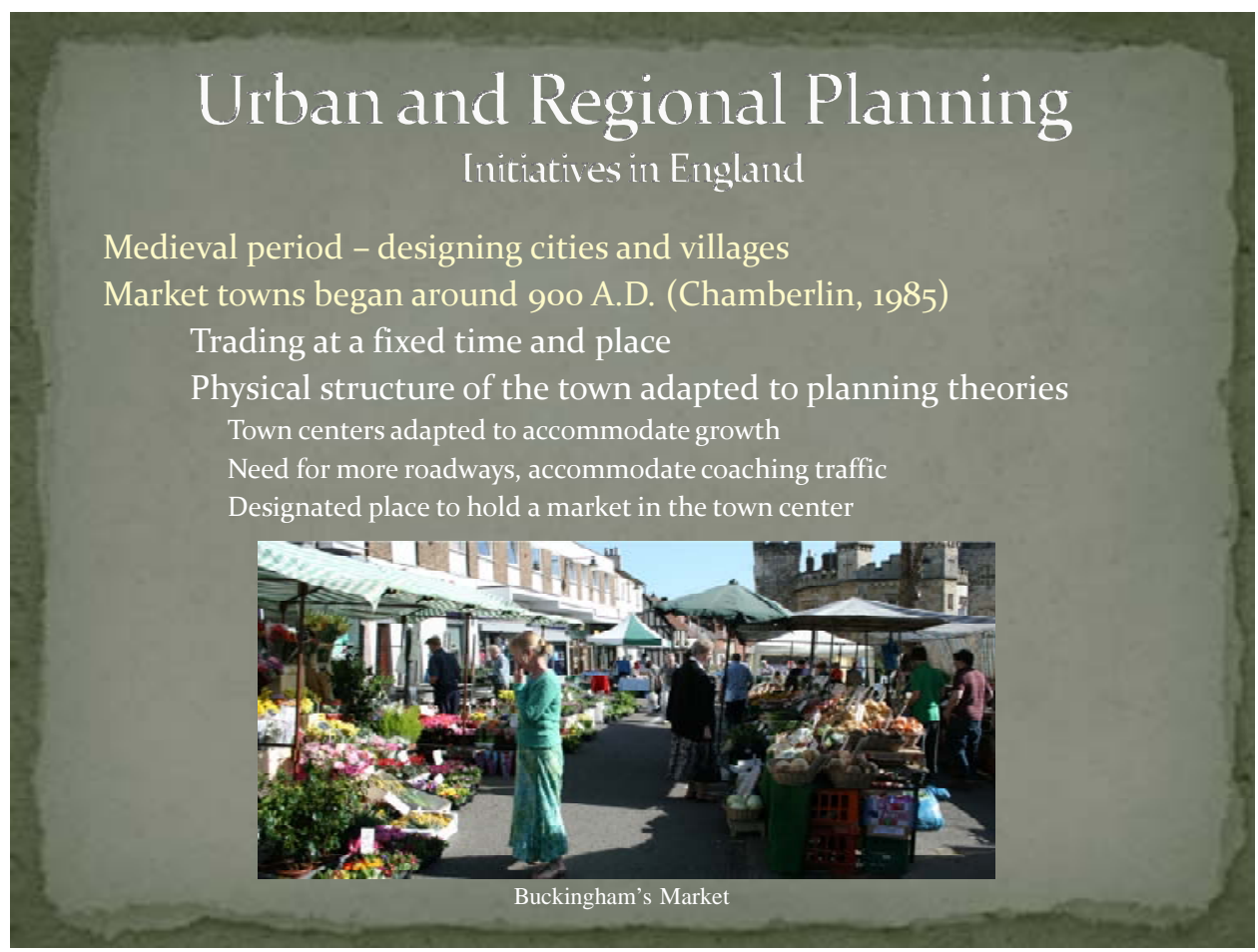




\title{
Urban and Regional Planning
}

\author{
Initiatives in England
}

Garden City Movement (Howard, 1902)

Ebenezer Howard - 1902

Self-controlled, self-contained

communities surrounded by gardens

When a town reaches capacity, another town would be created with a "garden" area in between

Pressure to control the population in London after WWI \& WWII Intent was to create bedroom communities in the countryside around London

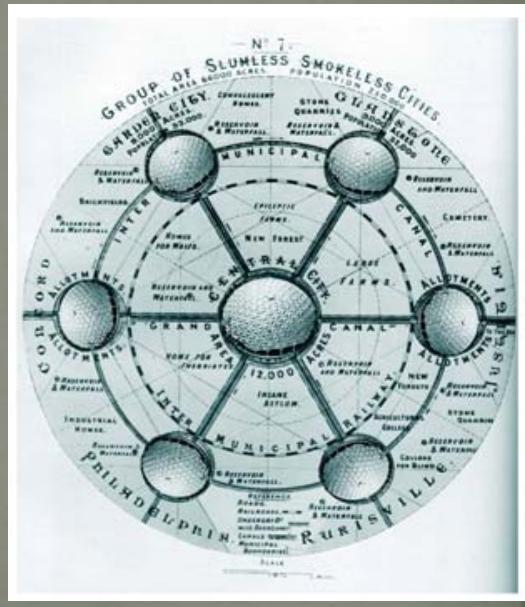

(Howard, 1902)

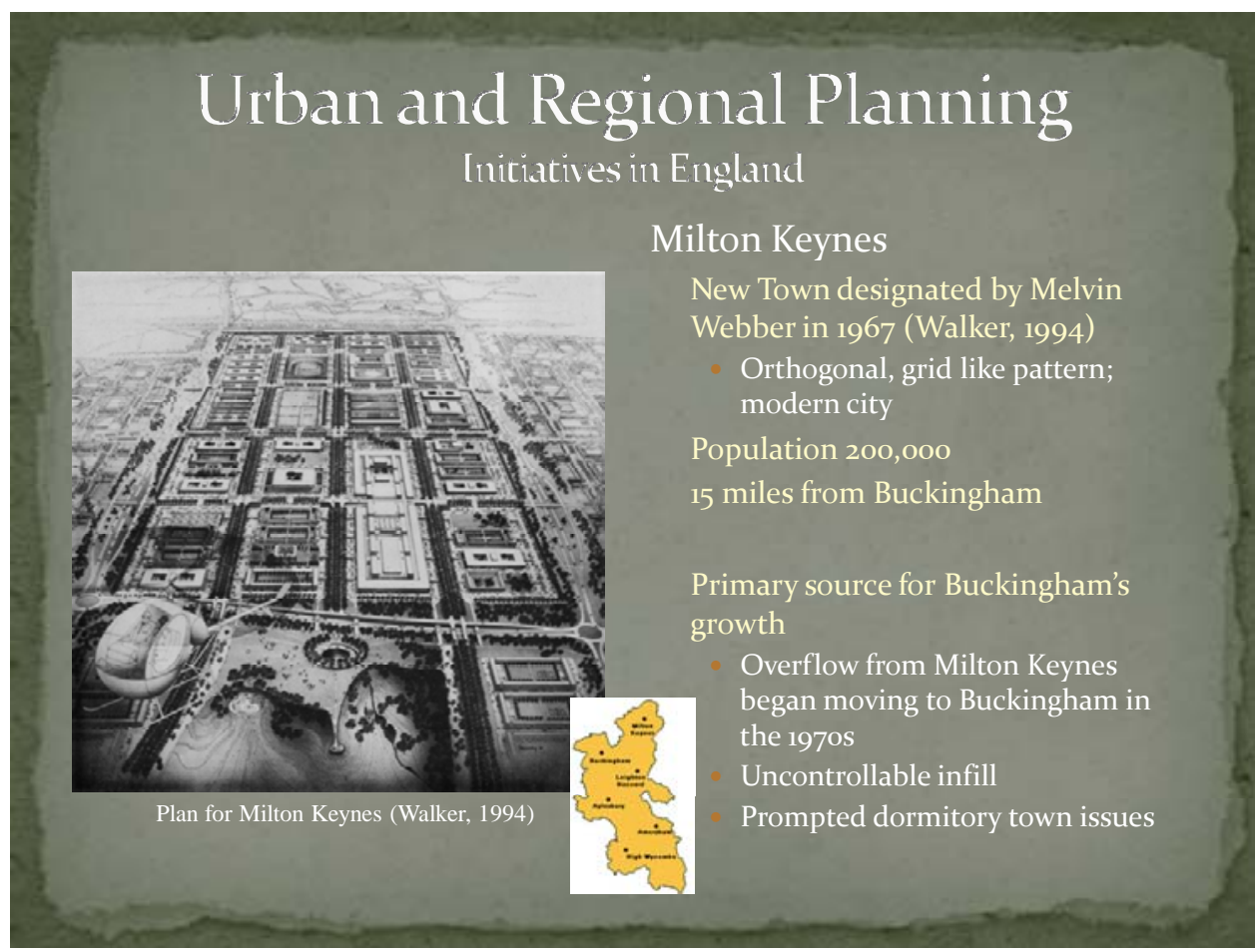




\title{
Urban and Regional Planning
}

\author{
Initiatives in England
}

Guiding principles for Sustainable Development in the UK (Local

Government and Improvement Agency, 2010)

Effectively promote sustainable development:

Living within environmental limits

Ensuring a strong, healthy and just society

Achieving a sustainable economy

Promoting good governance

Using sound science responsibly

New Urbanism Principles (Congress for New Urbanism, 2011)

Promoting a higher quality of life and sense of community:

Livable streets arranged in compact, walkable blocks

A range of housing choices to serve people of diverse ages and income levels

Schools, stores and other nearby destinations reachable by walking, bicycling or transit service

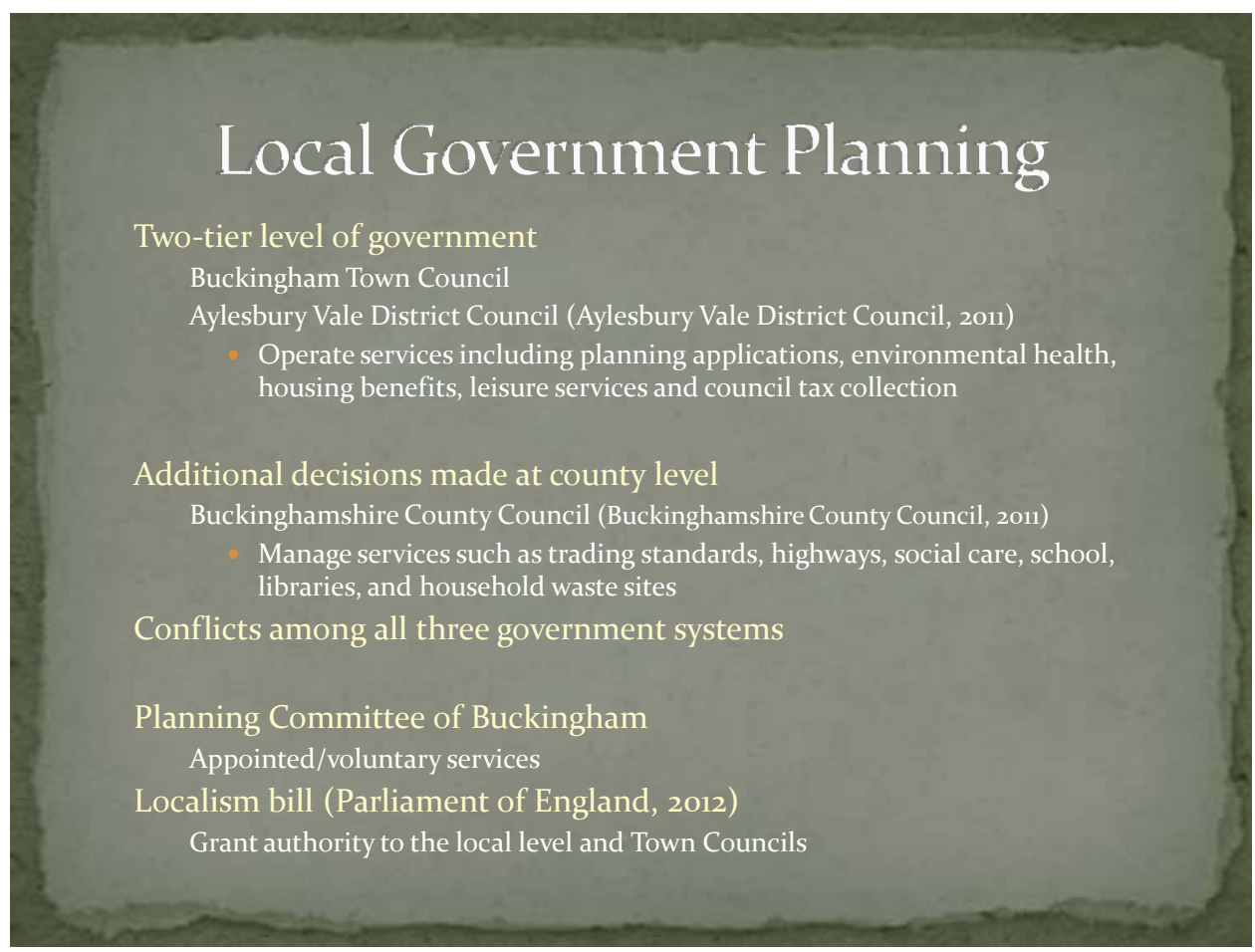




\section{Local Government Planning}

27 Buckingham Buckingnam Plan

The Buckingham Plan 2008

A vision for a vibrant market town
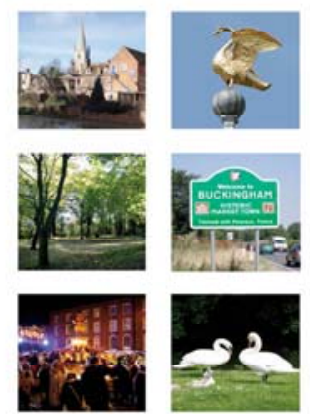
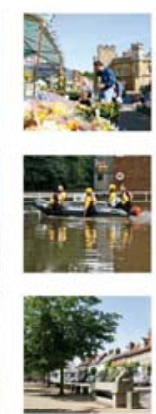

Buckingham Plan (2008)

Planning for the Future of Buckingham

Improving quality of life Coping with growth Infrastructure, development, town center, transportation, housing, education, tourism, conservation

Buckingham: Vision and Design Statement (2001)

Guidebook for future construction

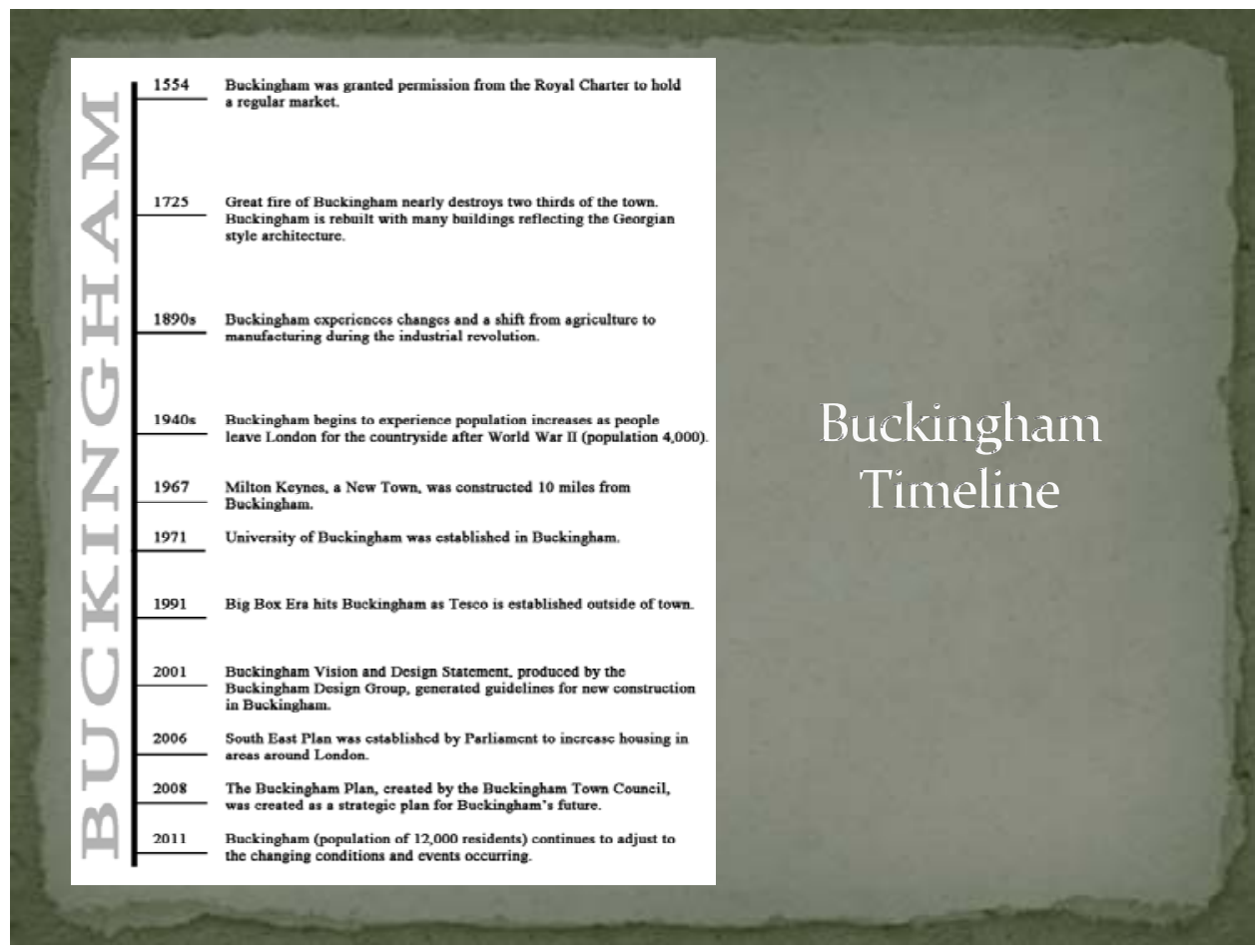




\section{Buckingham, England}

University of Buckingham

Established in 1971; only private university in England

Plans for growth; 1,000 students to 2,000 students in next 5 to 10 years

Town and Gown relationship

Both positive and negative

Buckingham Trader's Association

Proactive in supporting the local shopping \& dining

Branding Logo - Launched in 2011

\section{Thoroughly MODERN

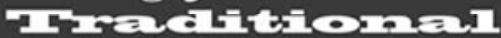 BUCKINGHAM}

(Buckingham UK, 2011)

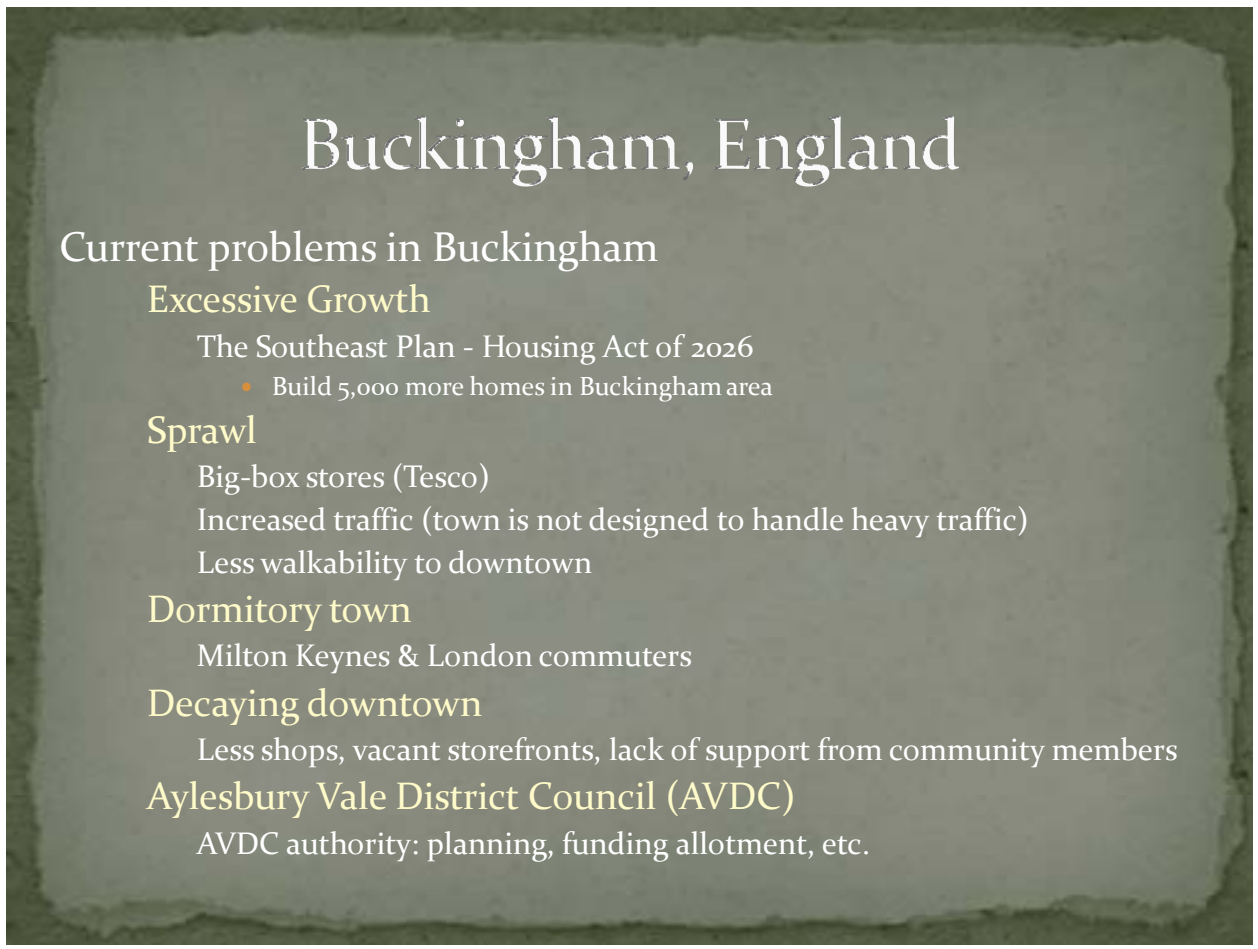




\section{Buckingham, England}
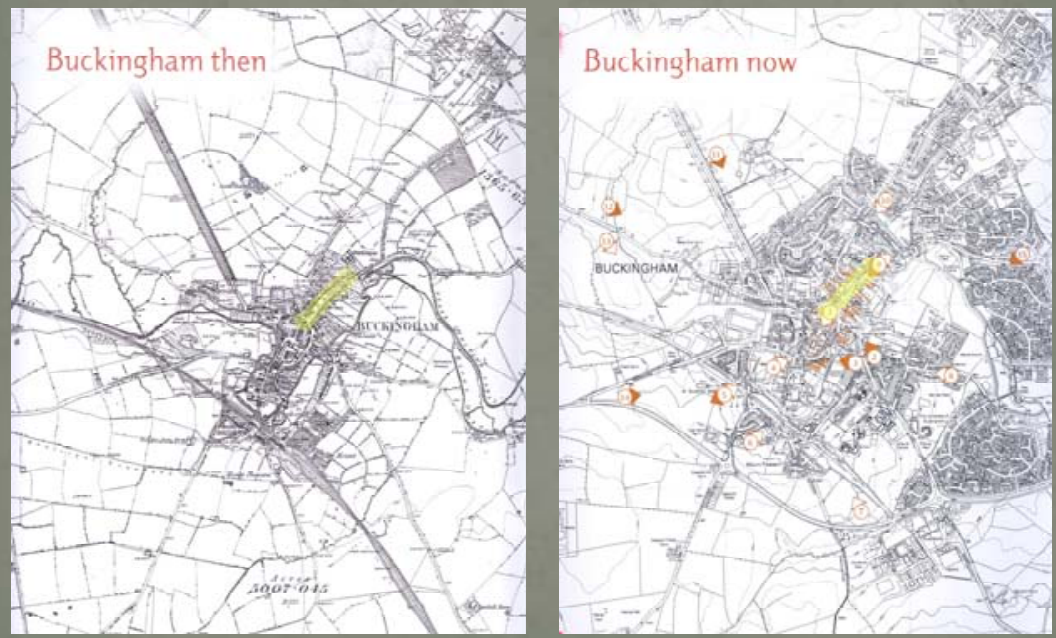

1886

\section{Buckingham, England}

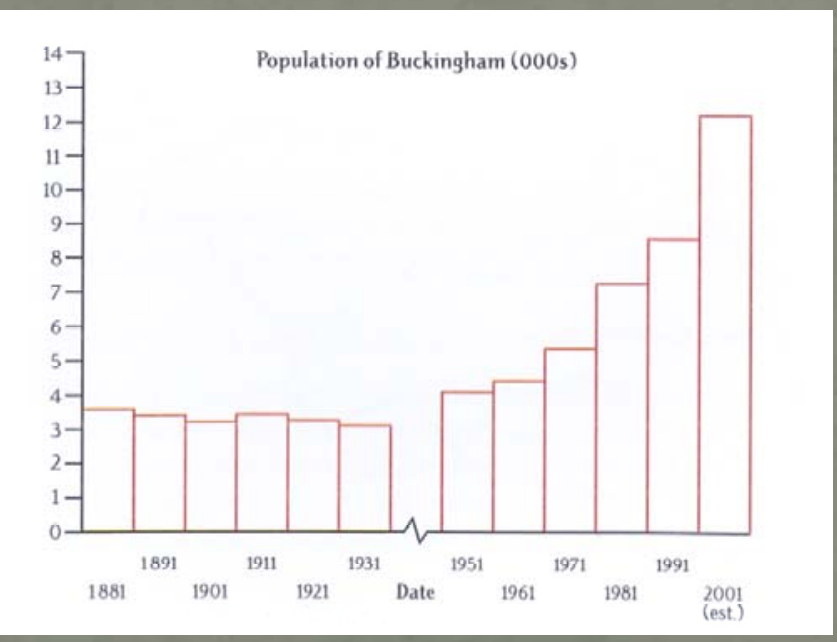

(Buckingham Town Council, 2008) 


\section{Methodology - A Learning History}

Developed by researchers and professors at Massachusetts Institute of Technology

Art Kleiner and George Roth (Roth \& Kleiner, 1997)

What is a Learning History?

Subset of a Case Study

Method of research that documents change through the perspective of the individual's experiences

Very few studies have been documented with a Learning History

Usually documenting change in an organization (administrative)

Oil Change (2000); Car Launch (2000)

Documents change that occurs over an extended period of time

Examining reported accounts of key stakeholders and involved citizens participating in the in change process in Buckingham

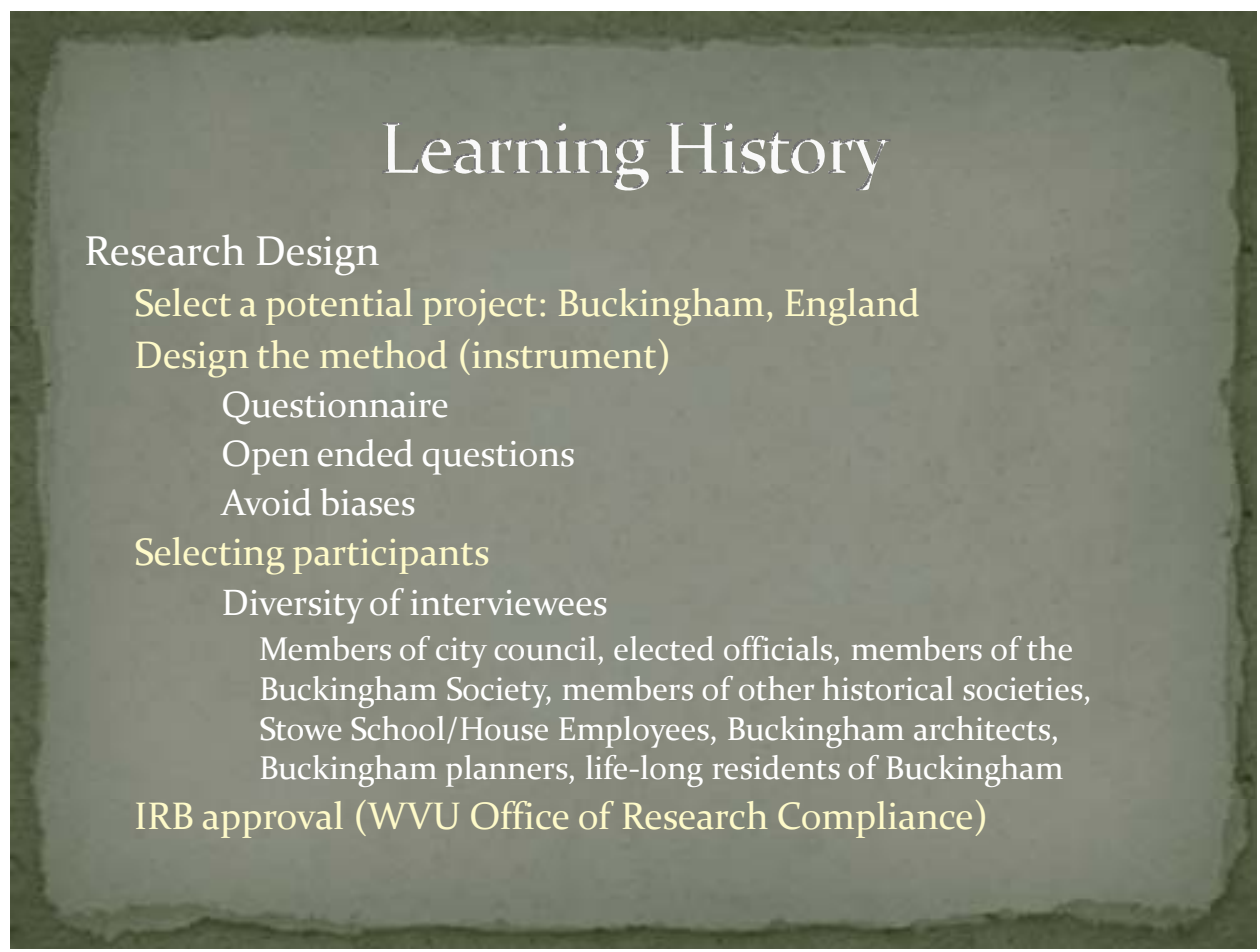




\section{Learning History}

Executing the Research Design

Data Collection (January - April 2011)

Observations

Conversations with stakeholders

Researched planning documents and processes

Attended Town Council/Buckingham Planning Committee meetings

Interview Process

Identified key stakeholders

Sent cover letter (email: consent/decline interview)

Scheduled

Voice recorded

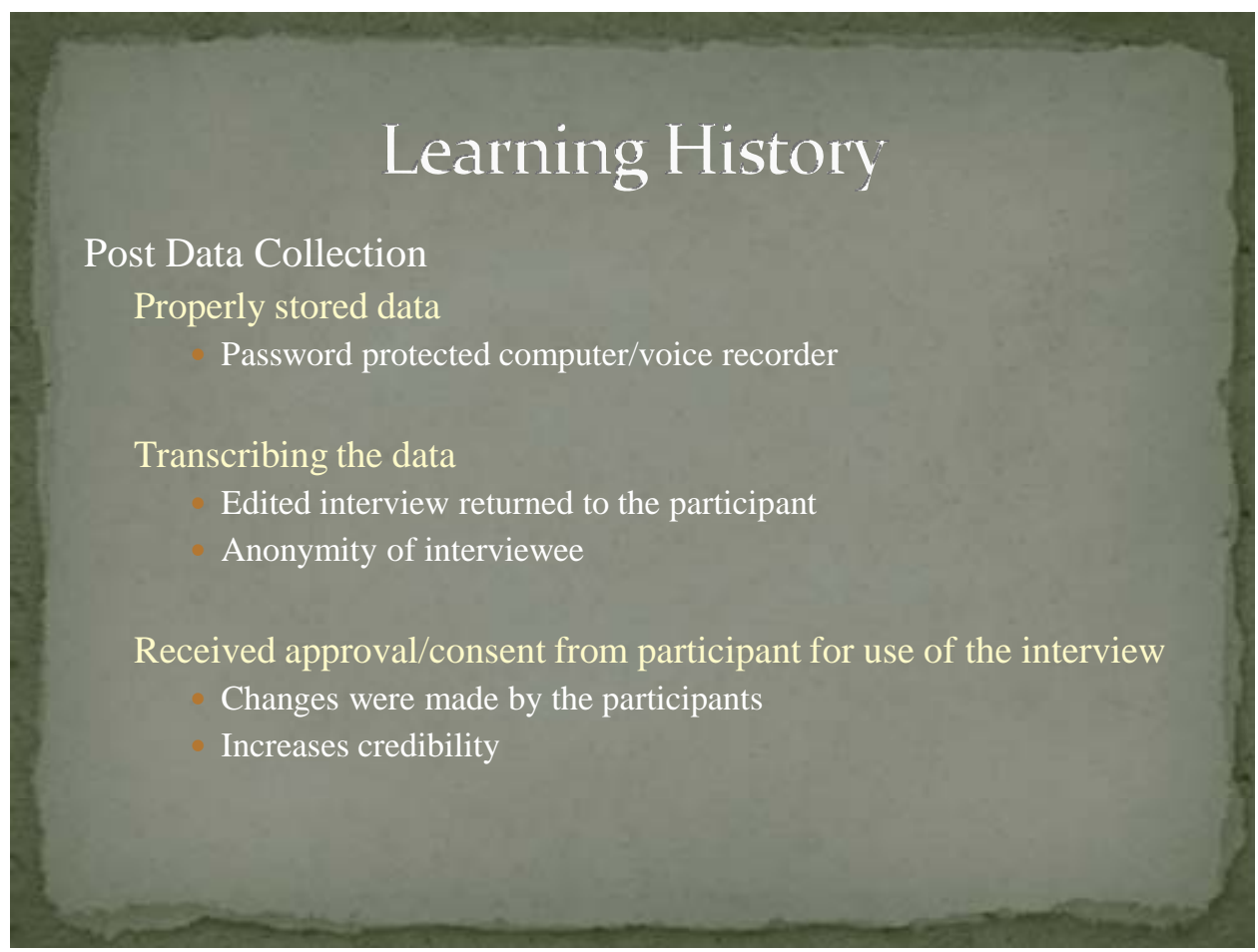




\section{Learning History}

Establishing Creditability (Denzin \& Lincoln, 2005)

- Researcher acknowledges the information provided by the contributor is truthful only from the contributor's unique perspective

- Stakeholders had some level of expertise with their experience in Buckingham

Qualifies them to have a credible opinion

Establishing Utility (Charmaz, 2005, p. 528)

Can the themes (analysis) speak to generic processes?

Can the analysis spark further research in related areas?

How does the work contribute to making a better society?

Findings can be applied to other communities

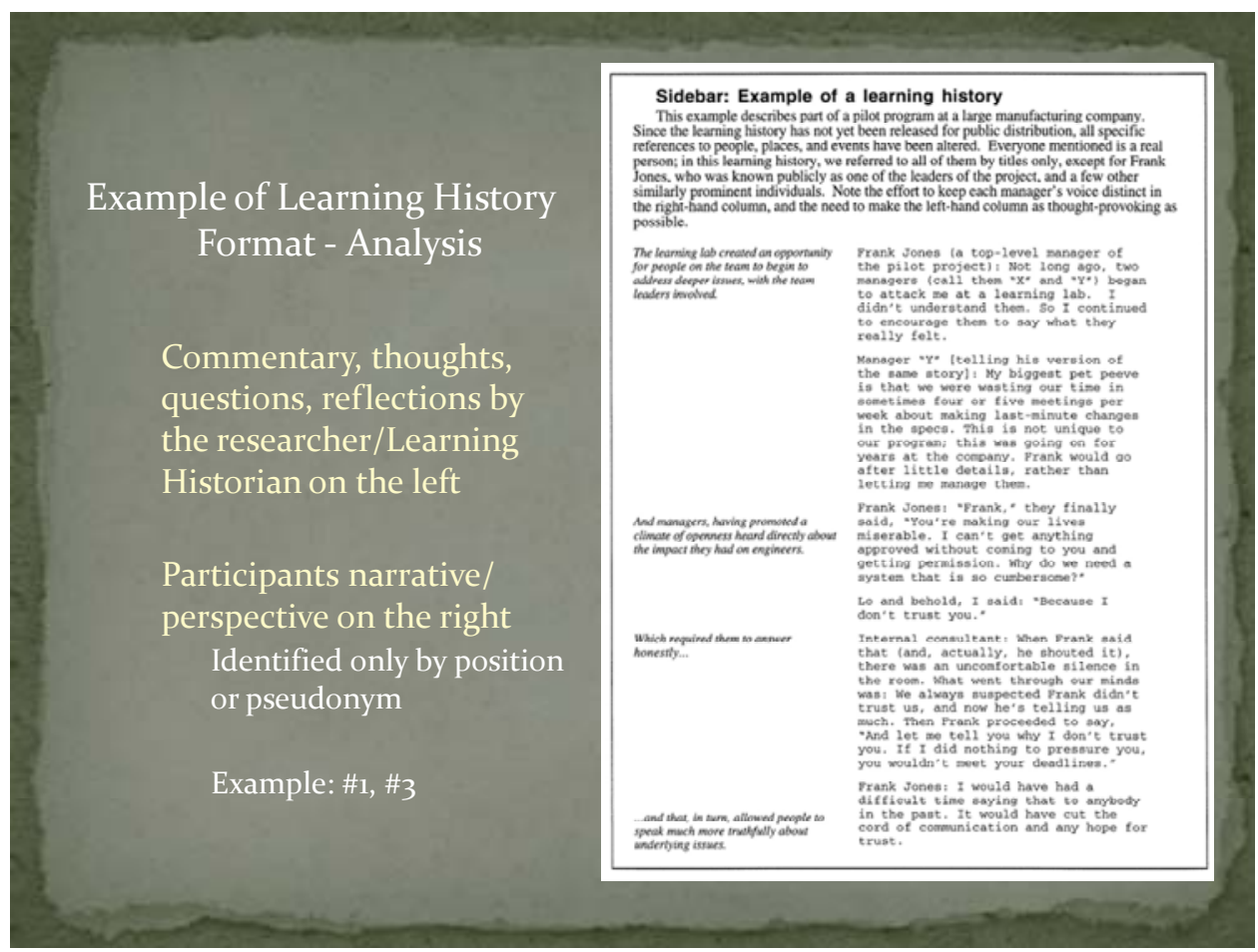




\section{Learning History}

The Learning History Narrative

Organized each participant's interview into thematic sections

Repeating patterns and emerging themes

Overview of the Participants

Searching for the identity of a Market Town

Trading in Buckingham

Changes in Buckingham 1967-2011

Growth in Buckingham

Local, District and County Council

Buckingham Planning Projects

The Future of Buckingham

Participants' Conclusions

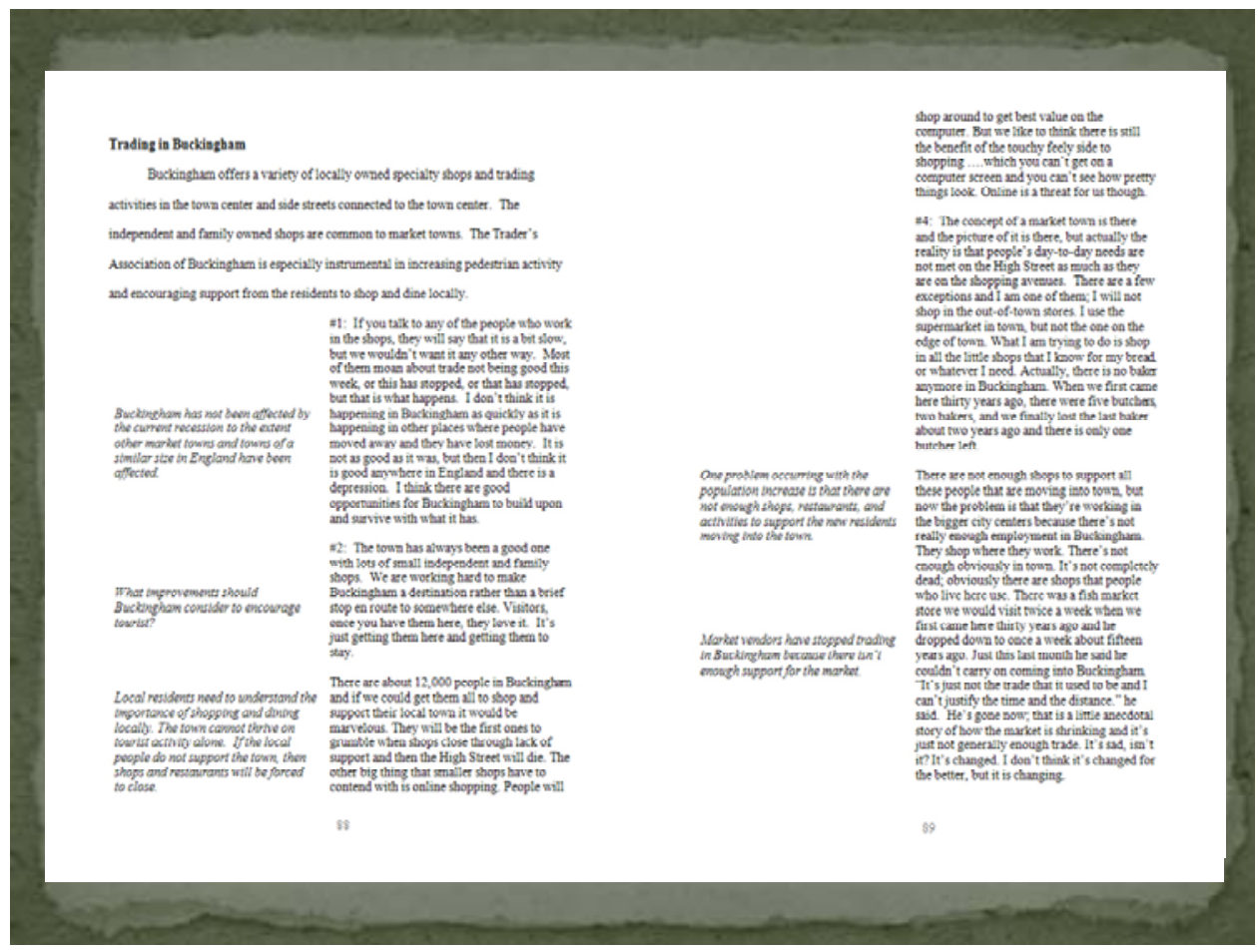



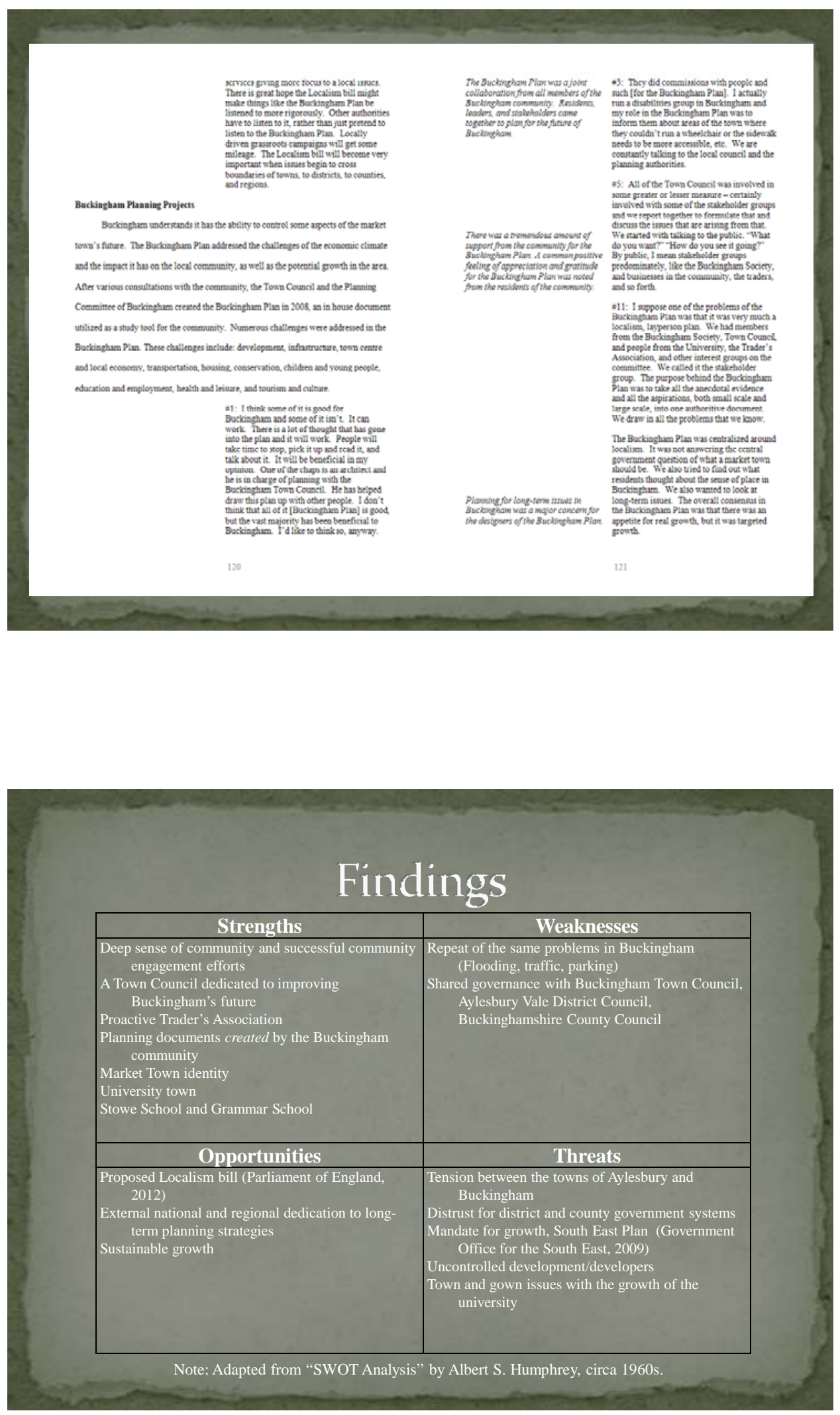


\section{Findings}

\section{Strengths}

SWOT Analysis defines internal strengths as areas that an organization has excelled or illustrated distinctive competencies over others (Humphrey, circa 196os).

Deep sense of community and successful community engagement efforts A Town Council dedicated to improving Buckingham's future Proactive Trader's Association

Planning documents created by the Buckingham community Market Town identity

University town

Stowe School and Grammar School

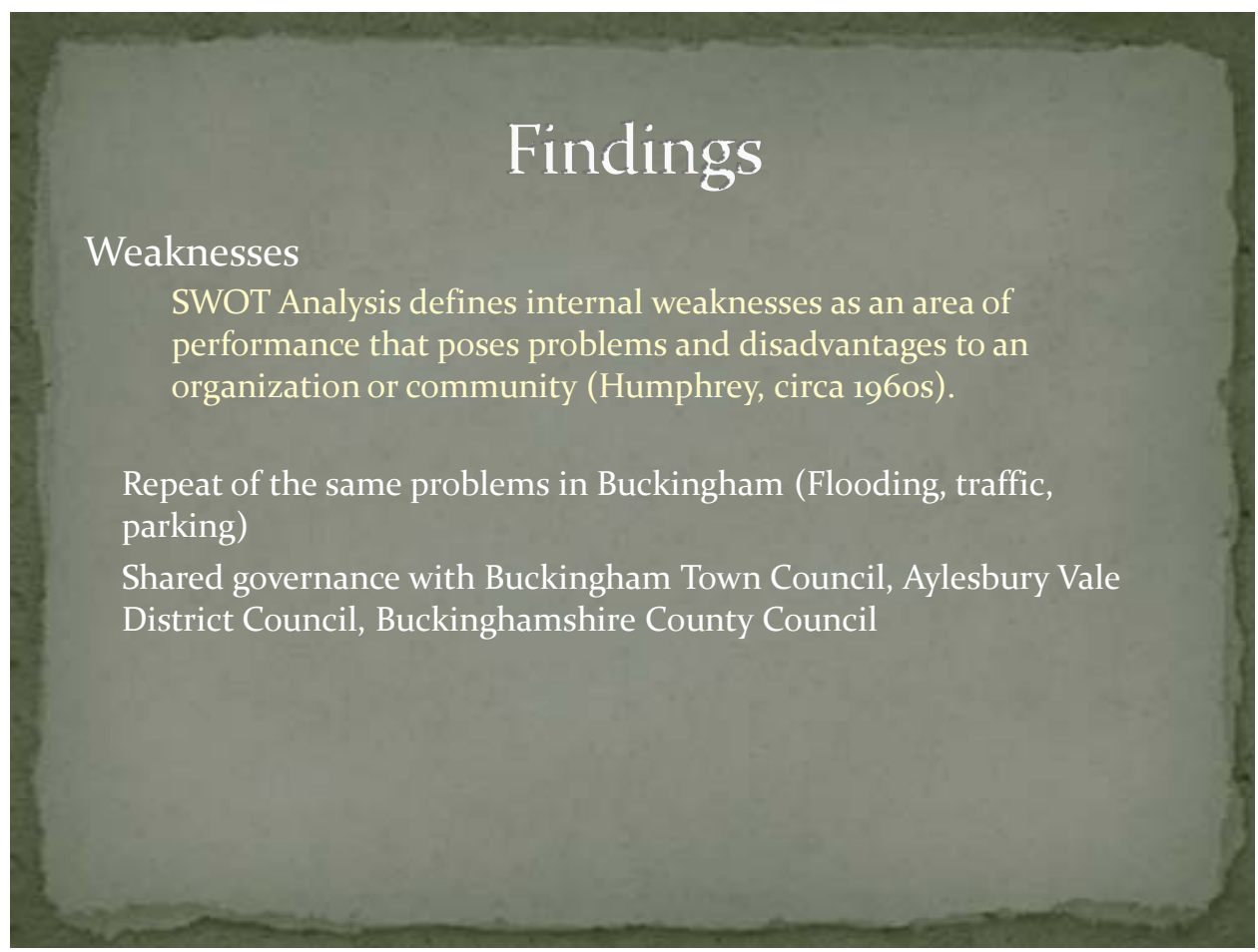




\section{Findings}

\section{Opportunities}

SWOT Analysis defines opportunities as external environmental factors that would allow an organization or community to improve (Humphrey, circa 196os).

Proposed Localism bill (Parliament of England, 2012)

External national and regional dedication to long-term planning strategies

Sustainable growth

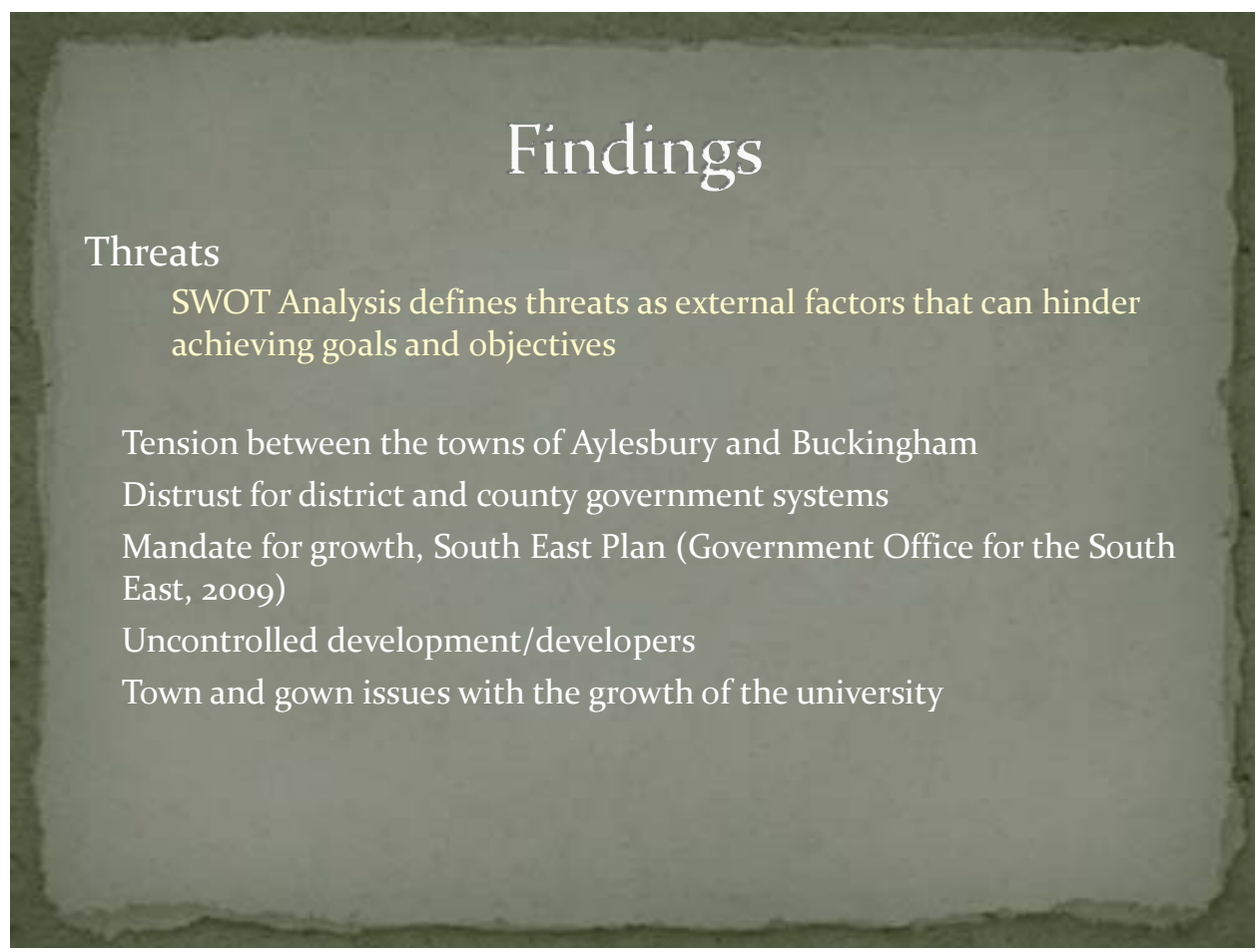




\section{Implications of Research}

Finished document has the potential to inform stakeholders and decision makers about future decisions in communities

Analysis provides positive findings and shortcomings of the Buckingham community

Findings of this study have the potential to assist other communities that may be facing similar challenges such as those that Buckingham experienced

Use of the Learning History methodology contributes to existing knowledge regarding planning processes, strategies for community development and revitalization efforts

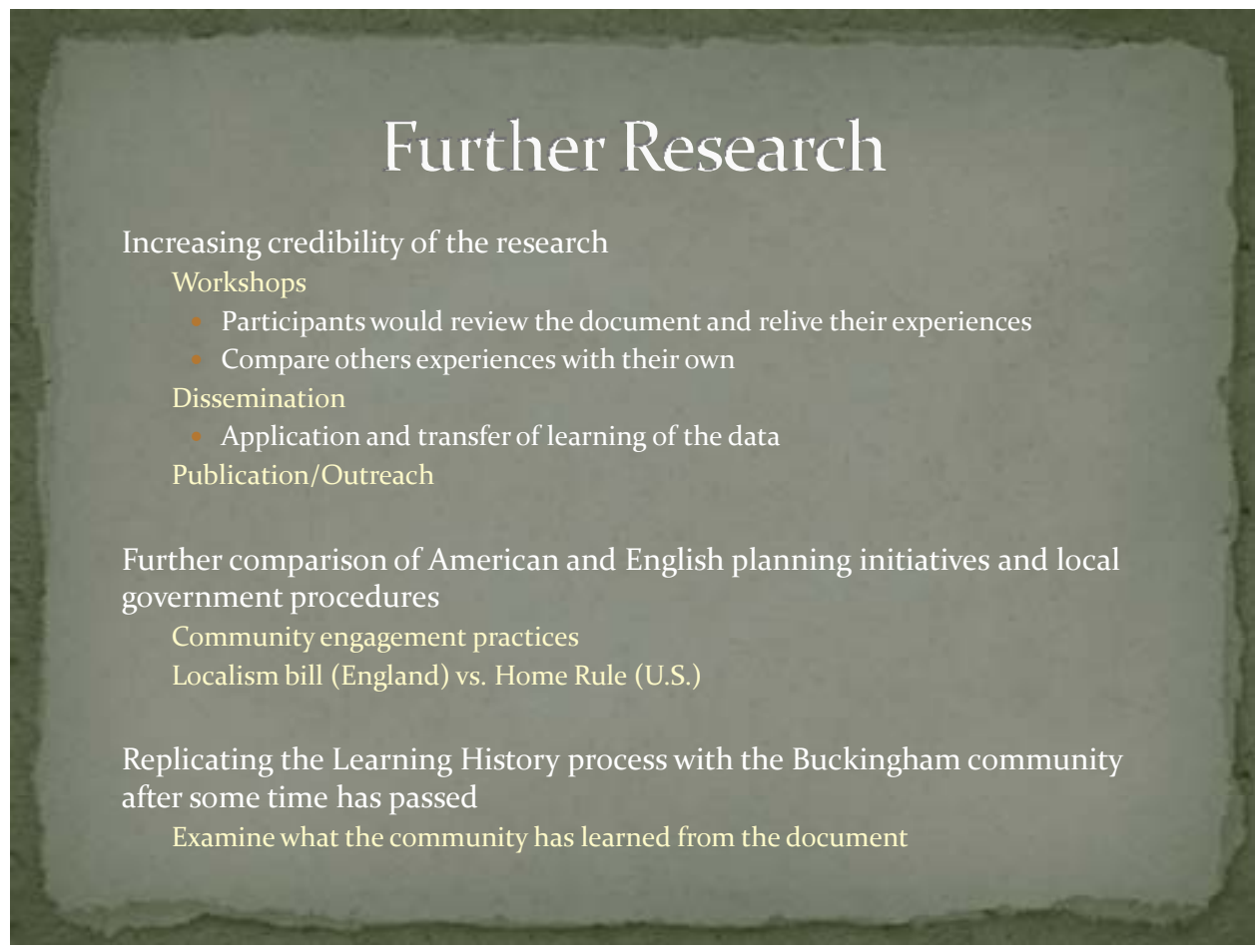




\section{References}

Aylesbury Vale District Council (2011). "Aylesbury Vale local strategic partnership.". Retrieved December 12, 2011, from http://www.aylesburyvaledc.gov.uk/community-living/community-planning-partnerships/local-strategic-partnership/.

Birch, E. L. (Ed.). (2009). The Urban and Regional Planning Reader. New York: Routledge.

Bridger, J. C., \& Luloff, A. E. (1999). Toward an interactional approach to sustainable community development. Journal of Rural Studies, 15(4), 377-387. doi: 10.1016/s0743-0167(98)00076-x

Brown, J. (1986). The english market town: a social and economic history, 1750-1914. Marlborough: Crowood Press.

Buckinghamshire County Council (2011). "Council structure." Retrieved December 14, 2011, from

http://www.buckscc.gov.uk/bcc/about_your_council/Council_structure.page?

Buckingham Town Council. (2008). The Buckingham Plan. Buckingham: BCQ.

Buckingham UK (2011). "Thoroughly modern traditional brand." Retrieved Jenuary 17, 2012, from

http://www.buckinghamuk.info/special.php?pageno=56.

Chamberlin, R. (1985). Engligh Market Towns. London: Weidenfield and Nicolson, Ltd.

Charmaz, K. (2005). Grounded theory in the 21st century: Applications for advancing social justice. The sage handbook of

qualitative research. N. K. Denzin and Y. S. Lincoln. Thousand Oaks, Sage Publications, Inc.

Communities and Local Government (2011). Net supply of housing: 2010 -11, England: 18.

Congress for the New Urbanism (2011). "What is CNU?". Retrieved February 7, 2010, from http://www.cnu.org/who_we_are.

Denzin, N. K. and Y. S. Lincoln (2005). The discipline and practice of qualitative research. The sage handbook of qualitative research. N. K. Denzin and Y. S. Lincoln. Thousand Oaks, Sage Publications, Inc.

Department for Environment Food and Rural Affairs (2011). Mid-2010 population estimates for lower layer super output areas: 6.

Dixon, T. (2009). "Urban land and property ownership patterns in the UK: Trends and forces for change." Land Use Policy 26, Supplement 1(0): S43-S53.

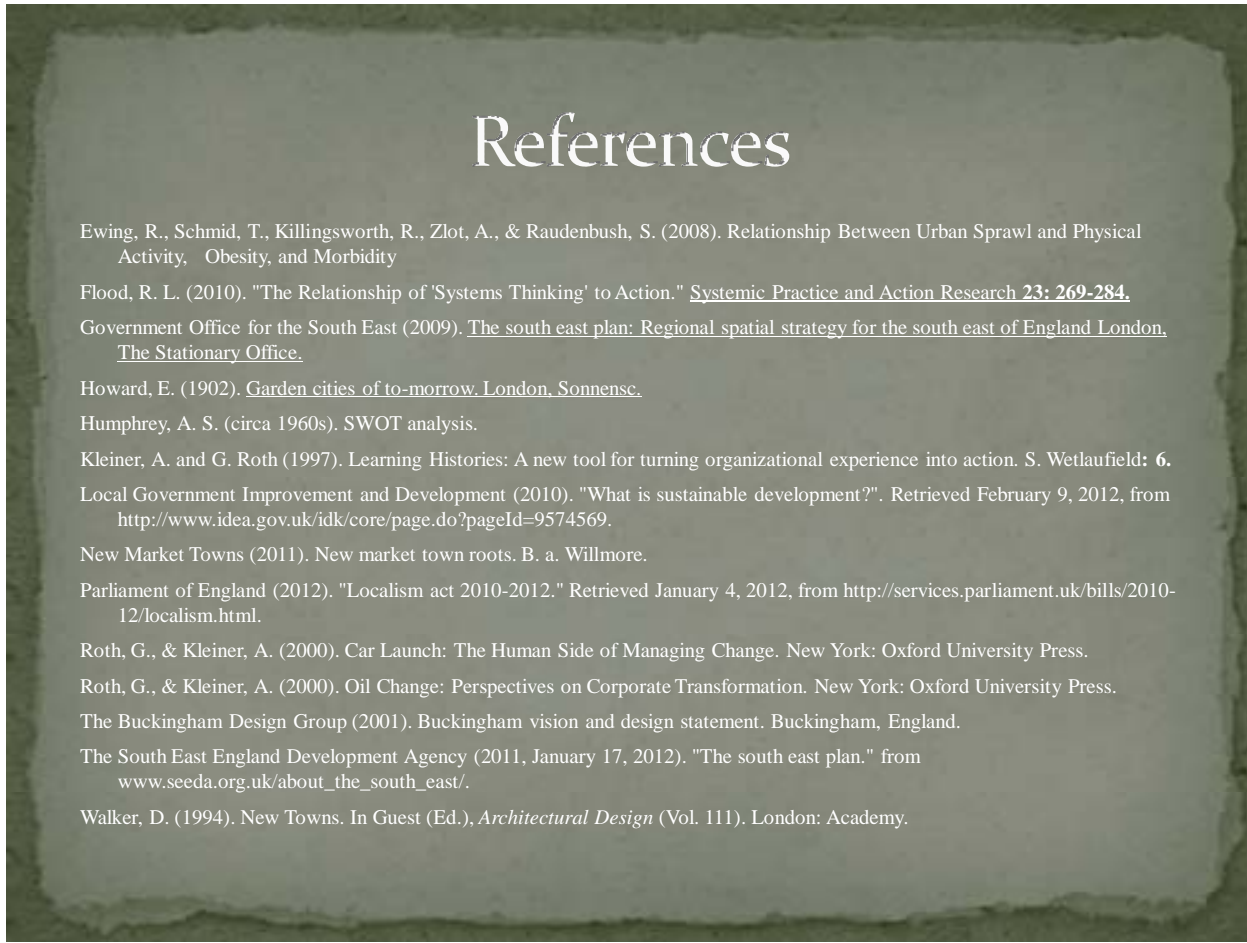




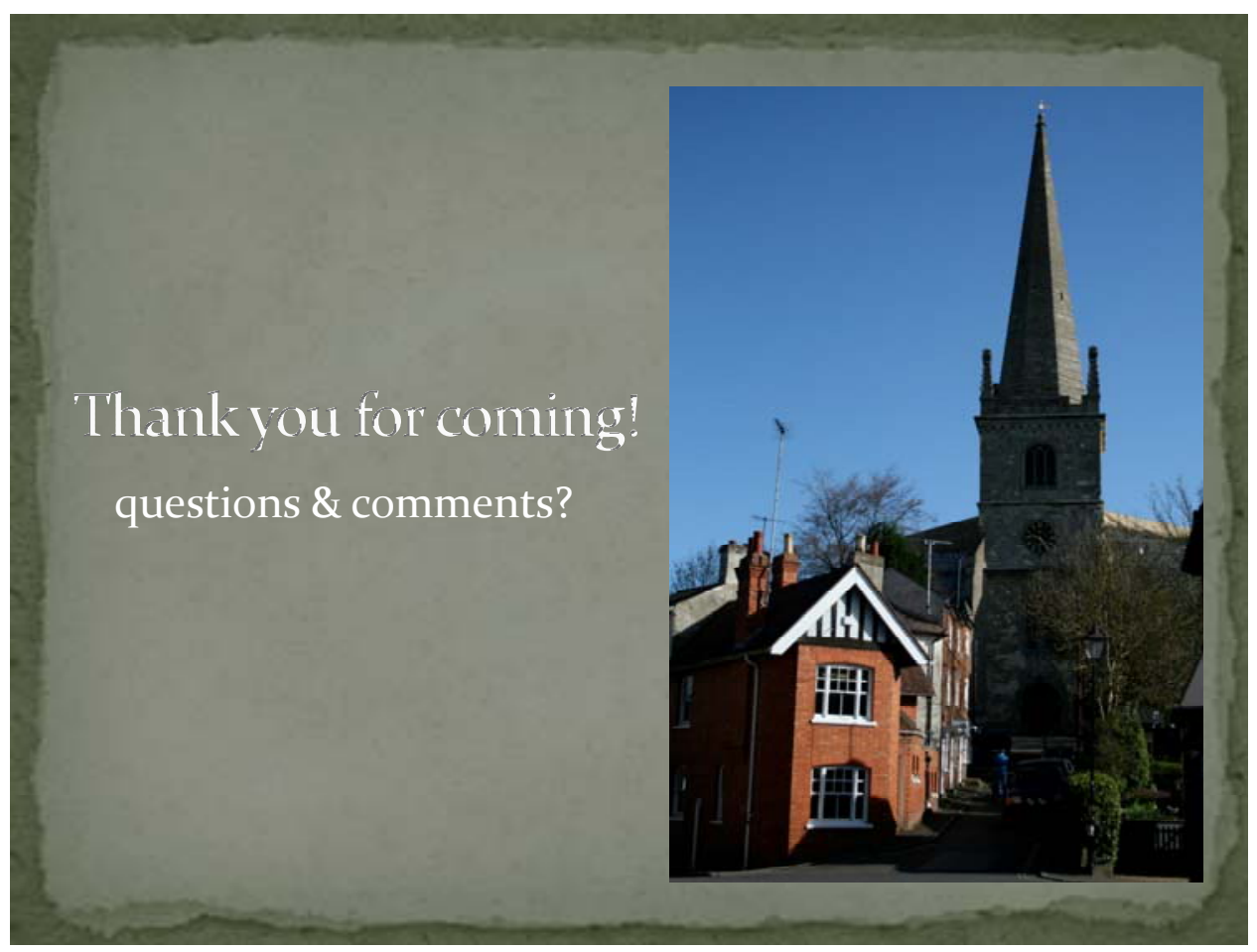




\section{VITA}

Jennifer R. Parsons

West Virginia University

Davis College of Agriculture, Natural Resources, and Design

Doctor of Philosophy

Morgantown, West Virginia

Major: Human and Community Development

2009

Virginia Polytechnic Institute and State University

College of Architecture and Urban Studies

Bachelor of Architecture

Blacksburg, Virginia

Major: Architecture 